Florida International University FIU Digital Commons

FIU Electronic Theses and Dissertations

University Graduate School

2-9-2012

\title{
Essays on City Size Distribution and Real Estate Bubbles
}

John Paul Lucas

Florida International University, jplucas2@yahoo.com

DOI: $10.25148 /$ etd.FI12041104

Follow this and additional works at: https://digitalcommons.fiu.edu/etd

\section{Recommended Citation}

Lucas, John Paul, "Essays on City Size Distribution and Real Estate Bubbles" (2012). FIU Electronic Theses and Dissertations. 552.

https://digitalcommons.fiu.edu/etd/552

This work is brought to you for free and open access by the University Graduate School at FIU Digital Commons. It has been accepted for inclusion in FIU Electronic Theses and Dissertations by an authorized administrator of FIU Digital Commons. For more information, please contact dcc@fiu.edu. 
FLORIDA INTERNATIONAL UNIVERSITY

Miami, Florida

ESSAYS ON CITY SIZE DISTRIBUTION AND

REAL ESTATE BUBBLES

A dissertation submitted in partial fulfillment of the

requirements for the degree of

DOCTOR OF PHILOSOPHY

in

ECONOMICS

by

John Paul Lucas

2012 
To: Dean Kenneth G. Furton

College of Arts and Sciences

This dissertation, written by John Paul Lucas, and entitled Essays on City Size Distribution and Real Estate Bubbles, having been approved in respect to style and intellectual content, is referred to you for judgment.

We have read this dissertation and recommend that it be approved.

Sheng Guo

Mihaela Pintea

Zhonghua $\mathrm{Wu}$

Cem Karayalcin, Major Professor

Date of Defense: February 9, 2012

The dissertation of John Paul Lucas is approved.

Dean Kenneth G. Furton

College of Arts and Sciences

Dean Lakshmi N. Reddi

University Graduate School

Florida International University, 2012 


\section{DEDICATION}

To my classmate, to my friend, to my girlfriend, to my companion, to my wife, to my rock, to the mother of Emily, Sabrina and who is to come, to the source of so many wonderful memories, to the love of my life: Emeris. 


\section{ACKNOWLEDGMENTS}

Many inspiring and wonderful people helped me on the long and winding road that has been the development and completion of this dissertation. In chronological order, I would like to thank Dr. Peter Thompson for sharing his time and knowledge during many long and fruitful sessions that evolved into Chapter II. For his contributions to Chapter III and guidance, I thank Dr. Jungmin Lee. For sharing his datasets and enthusiastically responding to all my questions in the development of Chapter III, I thank Dr. Bertrand Roehner. For his comments and contributions towards Chapter III and IV, I thank Committee member Dr. Sheng Guo. For patiently listening and helping me improve the whole dissertation I thank Dr. Zhonghua Wu and Dr. Mihaela Pintea, both of whom agreed to serve on the Dissertation Committee. For his comments, support and understanding, I thank my boss Manuel Armada. For always being there and gladly complying with my many requests, I thank Mariela Delgado. For their helpful tips and comments, for their editorial assistance, for a lifetime of unconditional support, and most of all, for setting a great example, I tip my hat to, and thank my mother and father: Dr. Teresa Lucas and Dr. Gerardo Lucas.

Finally, and I am not saying this lightly, the completion of this dissertation would have not been possible if not for the guidance, support and encouragement provided by Dr. Sheng Guo and Dr. Cem Karayalcin. To them I am forever grateful. 


\section{ABSTRACT OF THE DISSERTATION \\ ESSAYS ON CITY SIZE DISTRIBUTION AND \\ REAL ESTATE BUBBLES}

by

John Paul Lucas

Florida International University, 2012

Miami, Florida

\section{Professor Cem Karayalcin, Major Professor}

This is a dissertation about urban systems; within this broad subject I tackle three issues, one that focuses on an observed inter-city relationship and two that focus on an intra-city phenomenon.

In Chapter II I adapt a model of random emergence of economic opportunities from the firm growth literature to the urban dynamics situation and present several predictions for urban system dynamics. One of these predictions is that the older the city the larger and more diversified it is going to be on average, which I proceed to verify empirically using two distinct datasets.

In Chapter III I analyze the Residential Real Estate Bubble that took place in Miami-Dade County from 1999 to 2006. I adopt a Spatial- Economic model developed for the Paris Bubble episode of 1984-1993 and formulate an innovative test of the results in terms of speculative intensity on the basis of proxies of investor activity available in my dataset. My results support the idea that the best or more expensive areas are also where the greatest speculative activity takes place and where the rapid increase in prices begins. The most significant departure from previous studies that emerges in my results is 
the absence of a wider gap between high priced areas and low priced areas in the peak year. I develop a measure of dispersion in value among areas and contrast the MiamiDade and Paris episodes.

In Chapter IV I analyze the impact on tax equity of a Florida tax-limiting legislation known as Save Our Homes (SOH). I first compare homesteaded and nonhomesteaded properties, and second, look within the subset of homesteaded properties. I find that non- homesteaded properties increase their share of taxes paid relative to homesteaded properties during an up market, but that this is reversed during a down market. For the subset of homesteaded properties I find that the impact on tax equity of SOH will depend on differential growth rates among higher and lower valued homes, but during times of rapid home price appreciation, in a scenario of no differential growth rates in property values, $\mathrm{SOH}$ increases progressivity relative to the prior system. 


\section{TABLE OF CONTENTS}

CHAPTER

PAGE

CHAPTER I: INTRODUCTION

CHAPTER II: DOES CITY AGE MATTER? POISSON MIXING

DISTRIBUTIONS, ECONOMIC OPPORTUNITIES AND THE RELATION

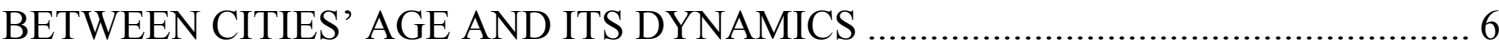

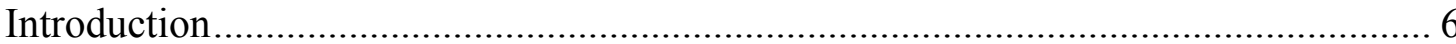

Model: Justification and Basic Framework ................................................................ 13

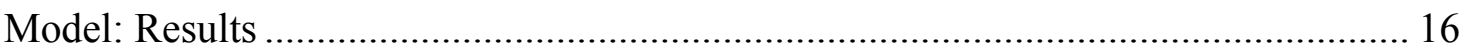

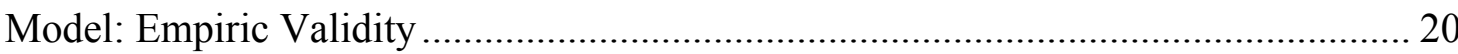

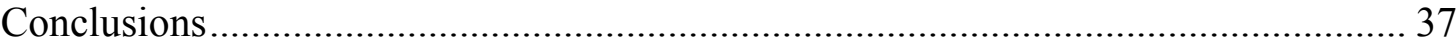

CHAPTER III: IN SEARCH OF A SPATIAL PATTERN FOR A REAL ESTATE BUBBLE: THE MIAMI-DADE 1999-2006 CASE ………............................................. 39

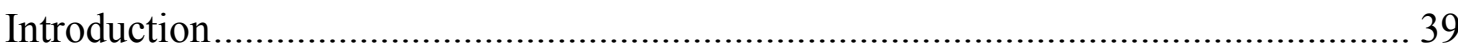

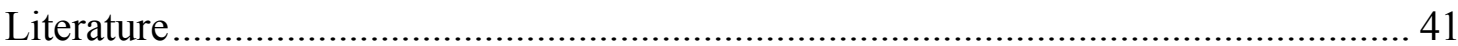

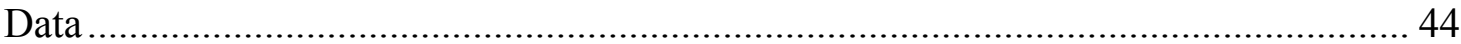

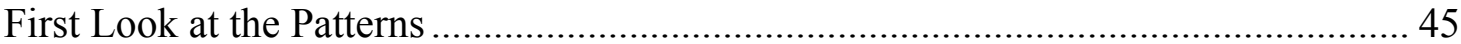

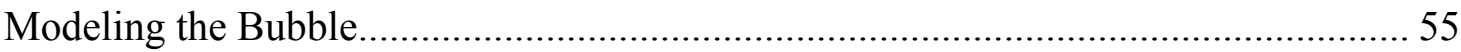

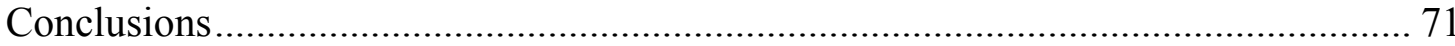

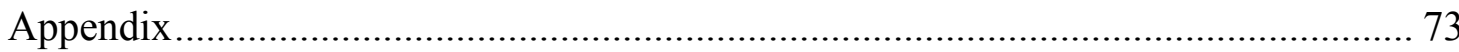

CHAPTER IV: PROPERTY TAX EQUITY IMPLICATIONS OF SAVE OUR

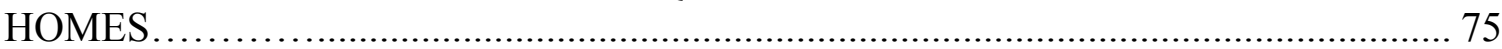

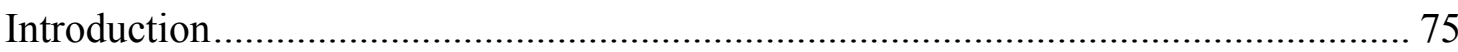

Background on Florida's Property Tax and Homestead Exemption .............................. 77

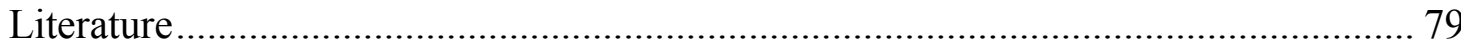

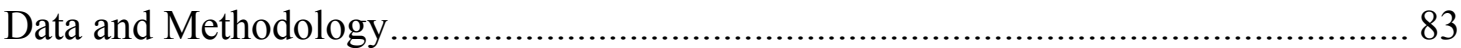

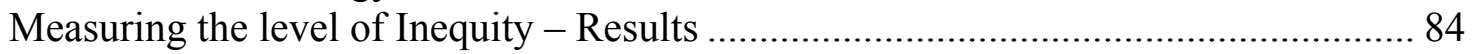

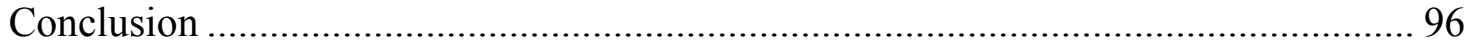

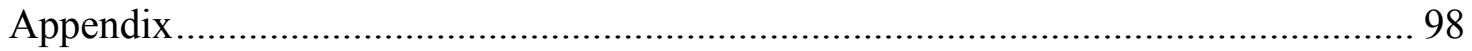

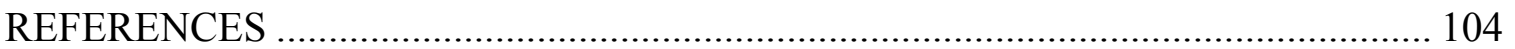

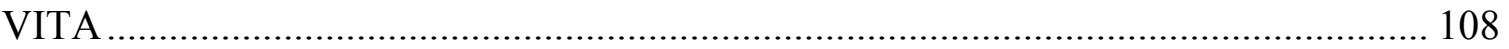




\section{LIST OF TABLES}

TABLE

PAGE

Table II-1 - Size, Variance and Skewness of Cities by Age ........................................ 24

Table II-2 - OLS Results of Regressing Growth Rates on Size and Age....................... 28

Table II-3 - OLS Results of Regressing Variance of Growth Rates on Size and Age..... 37

Table III-1 - Regression Results and Relevant Characteristics of Each Zip Code ......... 73

Table IV-1 - Tax Equity by Tax Structure and Market Evolution ............................... 92

Table IV-2 - Share of Value Sheltered by the Save Our Homes Amendment Homesteaded Properties from 1998 to 2010 -Miami-Dade County, FL ......................... 98

Table IV-3 - Regression Results: Progressivity by Year and Scenario.......................... 99 


\section{LIST OF FIGURES}

\section{FIGURE}

Figure II-1 - City Size Distribution for all 'cities' in 2000 US A- Top 100 Cities........... 22

Figure II-2 - Average Population of Groups of Cities by Year of Entry ........................ 25

Figure II-3 - Average Growth Rate of Cities that entered the system in each decade...... 26

Figure II-4 - Average Growth rate against size for 'Old' Cities .................................... 29

Figure II-5 - Average Growth rate against size for 'Young' Cities ............................... 30

Figure II-6 - Variance of Growth rate against size for 'Old' Cities ............................... 32

Figure II-7 - 1970-2000 Variance of Growth rate against size for 'Young' Cities............ 33

Figure II-8 - Variance of Growth rate by Year of Entry Cities Larger than 300,000 A-

Top 100 Cities (Population in 1950 period 1950-1990) ............................................. 34

Figure II-9 - Variance of Growth rate by Year of Entry Cities Smaller than 300,000 Top

100 Cities (Population in 1950 period 1950-1990).....

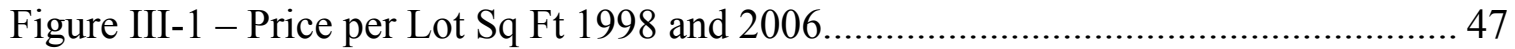

Figure III-2 - Absolute and Percent Change 1998 - 2006 ....................................... 48

Figure III-3 - Annual Percent Change 1999 - 2006 .................................................... 50

Figure III-4 - Year Percent Change Reaches $20 \%$.................................................. 51

Figure III-5 - Distance from CBD Against Year Percent Change Reaches 20\%........... 52

Figure III-6 - Price per Lot Sq Ft by Zip Code 1998 - 2007 ...................................... 53

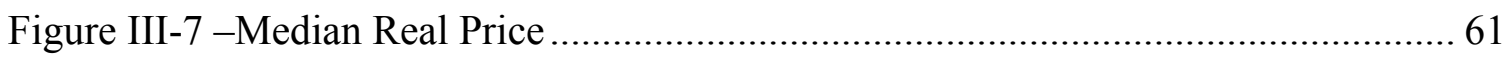

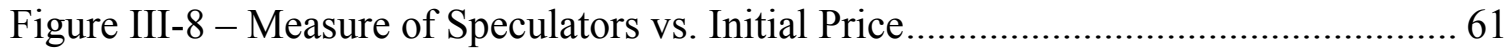

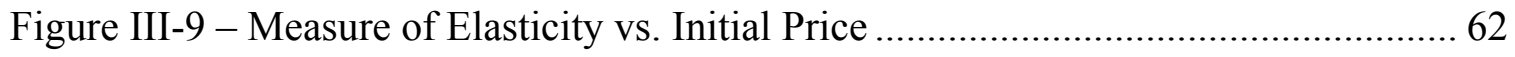

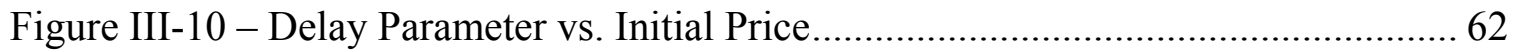

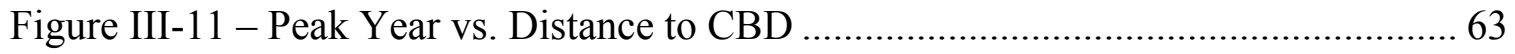


Figure III-12 - Peak Price vs. Distance to CBD ................................................................. 63

Figure III-13 - Speculation Intensity vs. Inelasticity of Supply ...................................... 64

Figure III-14 - Relation between Proxies of Speculative Intensity ................................. 66

Figure III-15 - Speculative Intensity: Estimates vs. Proxies .......................................... 67

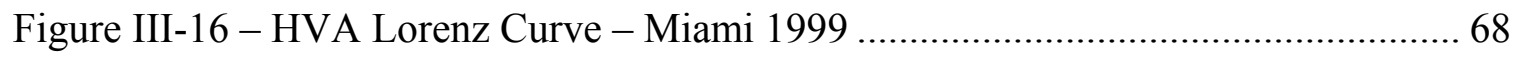

Figure III-17 - HVA Lorenz Curve - Paris 1984-1991 and Miami 1999-2006 ............... 69

Figure III-18 - HVA Gini Coefficient - Paris 1984-1991 and Miami 1998-2006 ........... 70

Figure IV-1 - Percent of Homesteaded Home's Market Value Sheltered from Taxation by

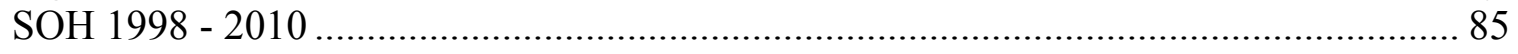

Figure IV-2-Percent of Homesteaded Home's Market Value Sheltered from Taxation by SOH and Homestead Exemption 1998 - 2010 ................................................................ 85

Figure IV-3 - Level of Progressivity under Different Scenarios 1998 -2010 ….............. 88 


\section{CHAPTER I: INTRODUCTION}

This is a dissertation about urban systems; within this broad subject I tackle three issues, one that focuses on an observed inter-city relationship and two that focus on an intra-city phenomenon.

In Chapter II I examine the arrangement of cities in terms of size within a country, and the multivariate relationship between the size, age and economic diversity of cities.

No matter the time period nor the region considered, the bulk of cities or settlements consists of small populations coexisting alongside a relatively small number of large cities with widely varying populations. The pattern is known broadly as a skewed distribution, and more specifically Power Law distribution.

The patterns seen in the city data mimic many other distributions that occur in the physical, natural and social worlds (Simon, 1955). Data for firm size, individual incomes, word frequency in the English language, the popularity of internet websites, clicks to links on a particular website, earthquakes, sizes of craters on the moon etc. reveal similar rank - size/frequency distributions.

Since similarities in the observations of firm and city size distribution are particularly numerous, literature on these topics cross paths quite often. A widely argued belief is that the observed size distribution of cities and firms is a result of growth being proportional to size, a phenomenon known as Gibrat's Law. This belief has recently gathered more traction when talking about cities (Gabaix, 1999, Córdoba, 2003) while it has lost steam when talking about firms (Sutton, 1998, Klepper and Thompson, 2006). 
On this point I offer a further intersection of both literatures by translating a recent model of firm growth and market structure by Klepper and Thompson (2006) into a model of city growth and city size distribution within urban systems. I test the predictions of the model empirically on the basis of county level U.S. Decennial Census Data from 1790 to 2000 . The data allow me to analyze the actual relationship between city age, size and growth rate by means of descriptive statistics and regressions. This model of city dynamics deviates from Gibrat's Law, yet results in the observed city size distribution. The new model suggests possible connections between the age of a city and/or system and its economic diversity and size, as well as the role of the economic diversity of a city in its growth process. These factors have been overlooked in previous city size distribution literature.

In Chapter III I study the real estate bubble that took place in Miami-Dade County between 1999 and 2006 from a spatial-economic perspective.

A widely studied area related to urban systems is the real estate market. An important aspect of the real estate market is its spatial dimension and the economic incentives and interactions facing participating agents. Previous studies about speculative behavior and price bubbles rarely consider both dimensions together. One exception is Rohener (1999) who divided a city by areas and classified them by inelasticity of supply, speculative intensity and timing in terms of the initiation of the bubble. To test and expand on Rohener's findings, I investigate a more recent real estate bubble that took place in Miami, Florida in the 2000's, thus expanding this line of research in two ways: first, I use a more complete dataset than has been used in the past to test the validity of the speculative intensity results; and second, I show that the price differential between 
high and low priced areas does not always widen during a bubble (Rohener, 1999, Shimizu and Watanabe, 2010).

The data for the empirical analysis are mined from the Miami-Dade County Property Appraiser's file, also referred to as the PTX file. The PTX file includes every property in the county identified by folio number and consists of more than 117 fields describing many aspects of the properties, including spatial location. I process this file with ArcGIS, a Geographic Information System software, to generate the input for the econometric model that produces the results on the three characteristics mentioned above. The results on speculative intensity are compared against other proxies of speculative activity.

For the second objective I develop an innovative housing price differential index, using as guidance literature on income inequality.

In Chapter IV I investigate the equity implications of a property tax amendment implemented in 1995 in the state of Florida within the context of a period that encompasses both rising and subsequently falling home values.

In 1992 Florida voters passed Amendment 10, known as the "Save Our Homes" (SOH) constitutional amendment that went into effect in 1995. The main feature of the measure was a cap in the yearly increase of assessed value for homesteaded properties of the lesser of three percent and the national rate of inflation, regardless of what happens to market values (Thomas (2006)). This structure has implications on the fairness or equity of the tax. Several studies have looked at these implications in the past, and concluded that the $\mathrm{SOH}$ provision increases considerably the inequities in the tax system (Allen (2009), Shone (2009) and Moore (2008)). The conclusions of these studies are most 
likely exaggerated because they only look at periods of rising home values. Shone (2009) and Moore (2008) look at the inequities between homesteaded and non-homesteaded properties, in which case $\mathrm{SOH}$ can only make the system less equitable, but the degree of this effect goes up in raising markets and goes down in down markets. However, and of more interest to me here, is Shone (2009) who is the only one who has studied the equity implications of SOH within the subset of homesteaded properties. In the case of this last study, the argument of $\mathrm{SOH}$ making the system less progressive is also most likely exaggerated since it only looks at a period of price appreciation and does not consider a baseline scenario to which compare the $\mathrm{SOH}$ outcome. Shone (2009) argues that $\mathrm{SOH}$ makes the system less progressive thanks to a combination of home ownership transfer pattern and differential price appreciations during his study period. Here I present an alternative approach that teases out the actual effects of the $\mathrm{SOH}$ amendment by computing the level of progressivity with and without $\mathrm{SOH}$ and with and without differential growth rates. In doing so I find that the home value appreciation and differentials in appreciation rates make the system less progressive independently of the implementation of $\mathrm{SOH}$. And more importantly, that $\mathrm{SOH}$ may reduce the degree in which the system becomes less progressive.

I will address briefly what happens to the tax equity in terms of homesteaded vs. non-homesteaded properties in a period of both rapid price appreciation and rapid price depreciation followed by an analysis of the inequities within the sub group of homesteaded properties. 
The first analysis will rely on the observed empirical data, while the second will consist of two approaches; an empirical analysis of the observed data coupled with the application of different scenarios followed by a theoretical discussion. 


\section{CHAPTER II: DOES CITY AGE MATTER? POISSON MIXING DISTRIBUTIONS, ECONOMIC OPPORTUNITIES AND THE RELATION BETWEEN CITIES' AGE AND ITS DYNAMICS}

\section{Introduction}

Similarities in the observations of firm size distribution and city size distribution are numerous. This has lead to literature on both topics to cross paths quite often. A widely argued belief in both literatures is that the observed size distribution is a result of growth being proportional to size, phenomenon known as Gibrat's Law. This belief has recently gathered more traction when talking about cities (Gabaix (1999), Córdoba (2003)) while it has lost steam when talking about firms (Sutton (1998), Klepper and Thompson (2006)).

On this point I offer a further intersection of both literatures by translating a recent model of firm growth and market structure by Klepper and Thompson (2006) into a model of city growth and urban systems. By taking this step I not only propose a model for city dynamics that accounts for the observed city size distribution while deviating from Gibrat's Law but I am able to suggest possible connections between the age of a city and/or system and its dynamics, as well as the role of the economic diversity of a city in its growth process, which have been previously overlooked by the city size distribution literature. Before I introduce the model, I will take a look at the accumulated knowledge of city formation and city size distribution. 


\section{What Has Been The Course Of The City Size Distribution Literature?}

I classify the literature into three groups: First there is a literature that deals with the formation and growth of settlements without taking into account the observed patterns of city size distribution. The second group consists of literature both theoretical and empirical on cross sectional observations of city size distribution; and, finally, there is the third group of literature that seeks to identify growth processes that would generate city size distributions as suggested by the theoretical literature without providing much in terms of the history of the system.

With respect to the first literature group, a very rich and useful literature on city growth starting with Henderson (1974), has formed around the idea of urban systems existing as a delicate balance between local external economies of scale and diseconomies of urban crowding. This literature is useful in terms of helping understand the function of cities and their existence but fails to provide an answer as to the plausible growth process of cities given that it does not, in general, take into consideration, nor deliver, the observed patterns in city size distribution as exposed next.

On city size distribution, the second literature mentioned above shows that no matter the period of time nor the region considered the bulk of cities or settlements will consist of small populations while a relatively small number of large cities will present considerable differences in their population sizes.

The statement above is not contested by any researcher in the area, nonetheless; regularities in city size distribution can and are narrowed considerably with the risk of losing support from other researchers in the field. Attempts to do so date back as far as 1913 when Auerbach proposed that city size (in terms of population) distribution could 
be closely approximated by a Pareto Distribution, implying that if cities are ranked (r) from highest population $(\mathrm{P})$ to lowest the resulting relationship would be: $\log r=\log \mathrm{A}-$ $\alpha \log \mathrm{P}$ where $\alpha$ is a constant.

It has been noted by scientists in different fields that the patterns observed in the city data are similar to many other distributions that occur in the physical, natural and social worlds. Similar distributions can be found in the data for firm size, individuals' incomes, frequency of different words in the English language, the popularity of internet websites, clicks to links on a particular website, etc.

In general when a pattern of this sort belongs to the domain of what is called in general skewed distributions, and, in particular, Power Law distributions, where a power law relationship between two scalar quantities $\boldsymbol{x}$ and $\boldsymbol{y}$ is any such that the relationship can be written as $\boldsymbol{y}=\boldsymbol{a} \boldsymbol{x}^{\boldsymbol{k}}$ where $\boldsymbol{a}$ and $\boldsymbol{k}$ are constants.

To represent these types of distributions, researchers have come up with different statistical distributions such as the Pareto Distribution, originally fit to represent the distribution of wealth among individuals; Zipf's Law (or Zeta distribution) and YuleSimon Distribution for the frequency of words in the English language and the Weibull distribution often used to model the time until a given technical device fails.

Given the similarities between the frequency of words in the English language and the distribution of people among cities it is only natural that people studying the latter make use of the tools developed while working on the former. This is the case of the emergence of the Zipf's Law for Cities. Originally, Zipf's stated that, in a system of cities, the population of any city is roughly inversely proportional to its rank in the population table, $\alpha$ is equal to one. 
Setting aside for the moment how valid it is to assign more specific distributions to city size, and given that there is general agreement on that distribution being skewed, the question becomes: Why is this? Of course, the observation on city size distribution is a snapshot of a situation that has its explanation in the history up to that moment. In other words, there must be both a growth process that leads to the observed distribution and a series of factors that promote such growth process.

Here the third group of literature mentioned above seeks to obtain Power and Zipf's Law from growth processes:

A pioneer in the quest for obtaining Power Laws from a growth process is Simon (1955); who referred to a wide range of phenomena including the distribution of cities by population. Simon assumes that urban population grows over time by discrete increments and that these "lumps" of population go to form a new city with certain probability, or else is added to an existing city with a probability that is proportional to the current size of the city. In the limit this process yields a Power Law distribution and Zipf's law (exponent $(\alpha)=1$ ) as a special case. Simon's approach continues to be referred to because of its simplicity and appeal, although its critics Gabaix (1999b) and Krugman (1996) point out that it does not converge well, and requires that the number of cities grow indefinitely and as fast as the urban population.

Steindl (1965) presents a model in which existing cities grow at a rate g while new ones are born at a rate v. Given these assumptions the related system will present a Power Law distribution with an exponent $\mathrm{k}=\mathrm{v} / \mathrm{g}$. 
Gabaix (1999) picks up on the basic logic provided by Simon, mainly, that if a city's population growth is proportional to size the system will end up zipf's distributed. Gabaix argues that "satisfying Zipf's Law should be a prerequisite for taking a model of local growth seriously" and goes on to propose that "Zipf's Law derives from Gibrat's Law, where Gibrat's Law means that the growth process is independent from size" to end up concluding that "thus, the task of economic analysis is reduced from explaining the quite surprising Zipf's Law to the investigation of the more mundane Gibrat's Law".

An interesting feature of Gabaix's work according to Duranton (2002), was to be the first to propose a model that generates Zipf's Law by means of an economic argument. The channel proposed by Gabaix is that cities grow and decline following exogenous idiosyncratic shocks to their amenities.

Córdoba (2003) seeks to push Gabaix's argument for taking the relation between Zipf's Law and Gibrat's Law as certain and focus on modeling Gibrat's Law for cities to explain their distribution by combining Simone's and Gabaix's finding of Gibrat's generating Zipf with his own argument that "under general conditions, Zipf's Law can only result from Gibrat's Law: growth must be independent" to assert that "Zipf's Law is equivalent to Gibrat's Law".

Both the arguments of cities being Zipf's distributed and this distribution arising from a Gibrat's growth process are less then settled. As mentioned above, no one argues against the skewness of city size distribution, but when the argument is pushed further to proclaim that cities are Zipf's distributed a considerable amount of opposition arises. From an empirical standpoint I find at least as many studies rejecting Zipf's Law for cities as I do supporting it. To illustrate this I can mention Volker Nitsch (2005) who in 
his work titled Zipf Zipped looks at 515 estimates from 29 studies that test $\alpha$ for the relation $\log$ Rank $=\log \mathrm{A}-\alpha \log$ Pop, and using the method of meta-analysis finds that combined estimates of the Zipf's coefficient is significantly larger than 1.0 suggesting that cities are on average more evenly distributed than suggested by a strict interpretation of Zipf's Law.

There is also Eeckhout (2004) that not only challenges the validity of a coefficient equal to 1 but also asserts that if the totality of cities ${ }^{1}$ is considered, instead of just the upper tail, city size distribution is lognormal instead of Pareto.

The argument of Zipf's law being uniquely achieved by Gibrat's law is also debatable, given that this assertion rests on the assumption that the number of cities in a system be held constant. Not having this restriction may change the conclusion, as I can cite Boswell and Patil (1970) who demonstrate that there exist at least thirteen different processes that generate a negative binomial distribution, a distribution that is closely related to Zipf's Law.

Finally the idea that Gibrat's Law holds for cities is also inconsistent with several empirical studies such as Dobkins and Ioannides (2001) who find that larger cities tend to grow at a slower pace when looking at United States (US) data starting in 1900, and Black and Henderson (1998) who using a different data set on US cities, find that own lagged city size has a negative effect on city growth.

Rather than building a model that does not take into account the empirical evidence of city size distribution or formulating a model that conforms to a strict

\footnotetext{
${ }^{1}$ Eeckhout uses the totality of Census Designated Places (CDP) for the 2000 Census. That is 25,359 places with no minimum threshold of population, the criteria of inclusion is that it must be a concentration of population, housing, and commercial structures identifiable by name. Covers 208 million individuals or $74 \%$ of US population.
} 
interpretation of Zipf's Law or tying down to a requirement of obeying Gibrat's Law, I seek to suggest a model that is able to replicate existing size distributions and is able to say something about the evolution and history of such a process on the basis of a broad and plausible economic argument.

The history of the process of city growth has received little attention in the city size distribution literature. Although there are many studies viewing the relation between city size and growth, there is virtually none relating the time since settlement and the pattern of growth. An exception is Denise and Francois (1997) who found empirical evidence of a significant difference between old and new urban systems, suggesting that the growth process of cities might indeed be influenced by its "age".

My main purpose in this work is to propose a process that accounts for expansion and contraction of cities on the basis of the appearance and disappearance of economic opportunities that yields a city size distribution consistent with that observed in the data. A process that delivers new suggestions on relationships between city variables which can be further investigated.

A few interesting suggestions from the results reported below are that the older a city, the larger it will be on average; on average larger cities are more diversified than smaller cities; and that for an older group of cities or an older urban system less skewness with respect to cities size will be observed, although with a higher mean and variance compared to a younger group of cities or of urban system.

The chapter continues as follows, in section two I outline the basic argument for the adoption of Klepper and Thompson's (2006) model and lay out its foundations; in 
section three I lay out the main results that can be obtained from the model; and in section four I present empirical findings on the plausibility of the suggested results.

\section{Model: Justification and Basic Framework}

Miami is set to grow in the coming years because of baby boomers retiring and the signing of free trade agreements with several Latin American countries. The Las Vegas' economy and population exploded in the nineteen eighties after gaming became a legitimate business and some gambling establishments became publicly traded companies. Discovery of oil deposits near Houston in the early nineteen hundreds and the explosion in the use of this mineral resource brought about rapid population increase in the area. In 1825 the Erie Canal was completed and Buffalo became the western end of the 524-mile waterway starting in New York City and the population of the city boomed. In 1848 gold was discovered in the foothills of the Sierra Nevada Mountains prompting gold diggers to flock to the area causing San Francisco's population to expand briskly.

Pittsburgh since 1985 has been shrinking thanks to the decline of the U.S. steel industry. Detroit has had a slow decade and has lost $5.5 \%$ of its population since 2000 . Thanks to the decline in U.S. automobile supremacy, it now has the lowest number of people since 1920. Other U.S. manufacturing cities have been caught in a slump as production has moved elsewhere. Nineteen seventy was the worst decade population-

wise for most US manufacturing cities caught in a national process of 'creative destruction'. More acutely, thousands of small towns have turned into ghost towns all over the United States after the resources that had created an employment boom in their 
area ran out before other economic opportunities were available to the settlers. Just to mention one, Central City Colorado, which reached a population peak of 4,000 in 1860 , had a mere 515 inhabitants in 2000. Chicago has avoided a continuing downturn thanks to being able to replace its declining industries with the adoption of new ones by positioning itself as an advance hub for air transportation, Internet traffic and commodities trading.

All of these occurrences have in common the presence of what I will call economic opportunities.

The idea of setting changes in economic opportunities as an important factor behind changes in city size measured by its level of income, employment and ultimately population is attractive, more so when changes in city size are prompted primarily by migration. Many studies of city growth and size distribution use economic opportunities as their defining motor; Gabaix (1999) uses amenities shocks, Duranton (2002) appearance of new innovations etc.

Here I keep the concept broad so as to incorporate all different kinds of opportunities as promoters of growth and decline of cities.

To model this formally, consider an urban system as being a system with a beginning that is spawned by the appearance and adoption by some location of an initial economic opportunity. After the appearance of the first economic opportunity, new economic opportunities emerge randomly according to a homogeneous Poisson point process with mean intensity $\lambda$, which gives a probability $\lambda \mathrm{dt}$ of the new economic opportunity emerging in an interval dt. 
Each potential site such as the San Fernando Valley and/or established city such as New York has a given probability of benefiting from these new economic opportunities, where this probability is the same for all cities/sites and economic opportunities.

Once the economic opportunity emerges it has a random life drawn from a distribution of finite mean.

The size of the economic opportunity a city enjoys once it captures it is drawn from a distribution which is continuous and strictly increasing. This size remains constant for the life of the economic opportunity and then goes to zero as soon as the life of the economic opportunity ends. This last assumption might not be very realistic but it is adequate here since most of my analysis of the model takes place in the steady state.

In this random interplay of economic opportunities the size of a city at any point in time is the random sum of $\mathrm{n}$ draws from the distribution of possible economic opportunity sizes, where $\mathrm{n}$ is the number of current existing economic opportunities that the city was able to take advantage of. The random $n$ of a city can be thought of as the economic diversity of the city.

Although this framework is reasonable when thinking about the evolution of an urban system it does leave many important points out. Probably the most obvious is that it does not take into account explicitly natural population growth, but rather assumes a pool of potential entrants that enter the system as new economic opportunities arise, which is not an unreasonable assumption when there is migration from outside the urban system proper. Another point is that it does not include a mechanism to account for the 
lock-up effect a given area enjoys once its population reaches a certain threshold, as can be seen to be the case in reality.

\section{Model: Results}

Several results can be obtained from the framework outlined above that if verified empirically would give support to the idea that such an interaction actually takes place in urban systems.

Here I present results, derived from Klepper and Thompson's (2006) propositions, who state formal proofs in their appendix. First with regards to the urban system as a whole and second with regards to individual cities.

\section{Urban systems}

Result one: the distribution of city sizes in an urban system is skewed to the right with the same long tail as the Poisson distribution.

This is a result that is consistent with all the empirical evidence available, where a few large cities coexist beside a large number of smaller size urban concentrations. In the city size distribution literature this relationship is usually expressed as a straight line between the log of the rank and the log of the size of the cities in the system.

Result two: an older group of cities or an older urban system will display less skewness with respect to city size although with a higher mean and variance compared to a younger group of cities or urban system.

To my knowledge this has not been tested empirically for different groups of cities within an urban system, but there is one study by Denise and Francois (1997) who find in 
a statistically significant range the skewness of a recent urban system (America and Australia) to be greater than that of an older urban system (European and Asian). Although opposite to my result, they find the mean of the younger system to be higher than that of the older system. On the other hand Dobkins and Ioannides (2001) find that the older the city the larger they are on average for the case of the United States during the first part of the twentieth century.

On the theoretical side Reed (2002) points out the possible importance of the age profile of the system on its size distribution.

Result three: given some mild conditions the number of cities belonging to a system increases with the system's age but the rate of city formation decreases.

Denise and Francois (1997) study also finds supporting evidence for this result. Pointing out that although the urban population is only $40 \%$ smaller than the European one, North America has only one third the number of cities as Europe.

\section{City Specific}

From the model, several city specific implications emerge regarding their size, growth, age and diversity.

On the issue of age I find little work done, but on the issue of diversity there is a nice compilation by Duranton and Puga (2000) whose 'stylized facts' I will mention as they relate to the following results.

Result Four: The older the city, the more diverse it is on average. 
As mentioned above, little empirical evidence is found on the relation of city age to any other aspect, diversity being one of them. Of course in the context of this result diversity relates to the number of economic opportunities a city is currently active in. To pinpoint this idea in an empirically sensible way may be trickier then it might seem. One way is to consider a measurement on the basis of each sector's share of local employment as is the case discussed in Duranton and Puga (2000). Although in following this approach one must be aware that when looking at revenue, employment or any other measure by itself, any linkages between industries that might suggest more or less diversity are left out.

Result Five: The older the city, the larger it is going to be on average.

Result Six: On average larger cities are more diversified then smaller cities.

Result six is consistent with one of the five stylized facts put forward by Duranton and Puga and backed empirically for the United States in Black and Henderson (1998).

Result Seven: The more diversified, the higher the probability that the city is a leader in one or more Economic Opportunities (Industries).

Result Eight: The larger the city, the higher the probability that it is a leader in one or more Economic Opportunities (Industries).

I find no direct observations of these results in the empirical literature.

Result Nine: At some point city size is mean reverting, condition that doesn't have to hold at every time horizon. 
Thinking, in this instance, of city size as in relation to total income, employment or population, result nine arises because of a stable city size distribution combined with changes in relative city sizes brought about by changes in economic opportunities.

Empirical literature (Black and Henderson 1998) points out that the relative position of any individual city is pretty stable over time, which might suggest that the lifespan of the median economic opportunity is relatively long.

Result Ten: Among all the cities in a system, mean city growth is strictly decreasing in city size once it is conditioned on city age.

Although to my knowledge no empirical testing has been done on city growth controlling for age, Dobkins and Ioannides (2001) find that larger cities tend to grow at slower pace when looking at US data starting in 1900. Also Black and Henderson (1998), using a different data set on US cities, find that lagged city size has a negative effect on city growth.

Result Eleven: The variance of city growth is decreasing with respect to city size when conditioned on age, and decreasing in city age when conditioned on city size.

Leaving the support given by Dobkins and Ioannides (2001) and Black and Henderson (1998) aside, results ten and eleven might be considered the most controversial here given that they predict an outcome different from Gibrat's Law, which has been tested with mixed results, although it is worth it to test these results given that to my knowledge no one has tested the growth rate patterns of cities conditional on city age, approach that could provide new insight into the dynamics of urban systems. 
As the results presented in this section come from an adaptation of a model proposed in the context of firm size distribution I find it pertinent to point out that similar discussions have taken place in the literatures for firm size and income distribution with respect to the validity of Gibrat's Law as source of the observed size distribution.

There is a strong point in looking at different alternatives to Gibrat in the city size distribution, as has been the case in related literature with Sutton (1998) and Klepper and Thompson (2006).

\section{Model: Empiric Validity}

In the previous section I mentioned several empirical studies whose findings match the predictions made by the model and presented as results. However, for some of the results I did not find any study that could give them either support or critique, mainly because not much empirical research has been conducted on the behavior of cities controlling for age.

In this section I present findings regarding city size distribution, growth and age obtained from two separate datasets of United States cities. The first dataset, Dataset A, comprises the largest 100 cities in 1990, while the second dataset, Dataset B, is composed of all counties that contained a positive number of urban residents at some point in time. Given the nature of the data I do not present findings on economic diversity, which I will leave for future research.

The first dataset (A) was compiled by the United States Census Bureau in 1998; the data is decennial starting in 1790 . Cities are added to the system in the decade in which they enter the top list of 24,33, 46, 61 and 90 for 1790, 1800, 1810, 1820 and 
1830 respectively, and from 1840 on as they enter the top 100 list. In this sense the oldest cities are New York, Boston and Richmond who enter the system in 1790 with populations of 33,131; 18,320 and 3,761. Followed by Washington added in 1800 and Baltimore and New Orleans in 1810.

The second dataset (B) was constructed from county level populations, using all counties within the 48 contiguous continental United States with urban population at some point between the 1790 and 2000 census. In this sense an urban agglomeration is considered to enter the system when it reaches a population of 2,500. Two types of urban agglomerations are included in this dataset. Larger agglomerations are those defined as "Standard Metropolitan Statistical Areas" (SMSA) in 1990 and may include one or more counties; while smaller agglomerations are composed of the urban population contained in a single county. The count of distinct urban agglomerations adds up to 1,959 of which 288 are SMSAs on the basis of 700 counties and 1671 are individual counties. For the state of Virginia individual counties are not counted because they consider county equivalents and "towns"/ "cities" separately, situation that is incompatible with the rest of the states.

For the remainder of the chapter I will refer to Dataset A as the "first dataset", the "top 100 cities dataset" or "small sample dataset" interchangeably, similarly I will refer to Dataset B as the "second dataset", the "all cities dataset" or "large sample dataset". Figures will be identified "A- Top 100 Cities" and "B- All Cities" for Dataset A and B respectively.

In order to compare 'older' cities or groups of cities with 'younger' cities, I take two approaches. For one I simply divide the sample in two, between cities that entered 
the system prior to 1900 and cities that entered the system in 1900 or later. The second approach is to consider the cities that enter each decade as a single group. I present results from both methods.

To compare growth rates I take the average of the growth rates for each city or for the group between 1950 and 1990 for dataset A and between 1970 and 2000 for dataset B in order to have a consistent period among 'new' and 'old' cities.

For the whole system in 2000 it can be observed in Figure II- 1 that there are a few very large cities with marked difference in their sizes accompanied by a large number of smaller population cities; that is, a skewed distribution in city sizes, as reported in Result 1 above.

Figure II-1 - City Size Distribution for all 'cities' in 2000 US

\section{A- Top 100 Cities}

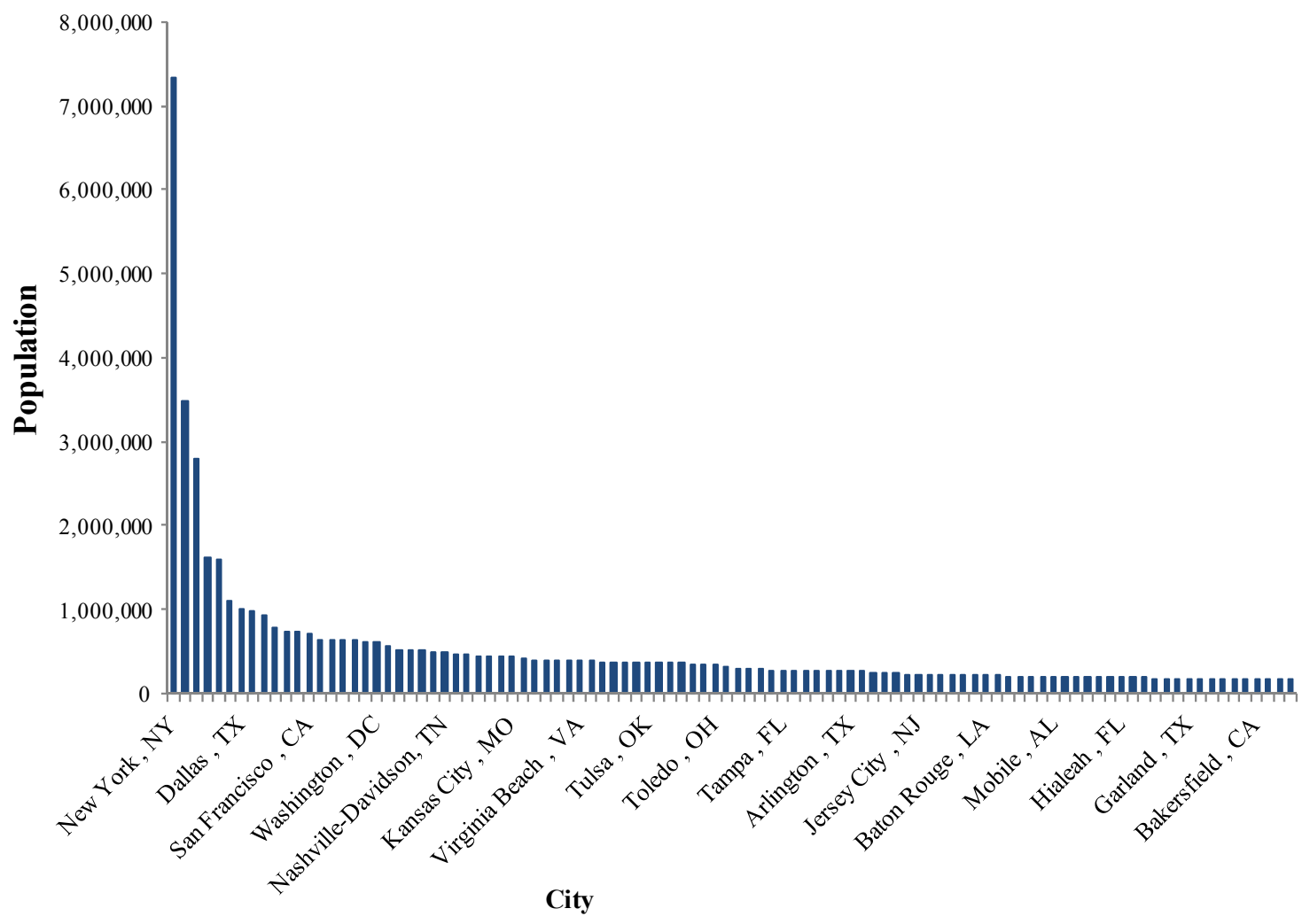




\section{B- All Cities}

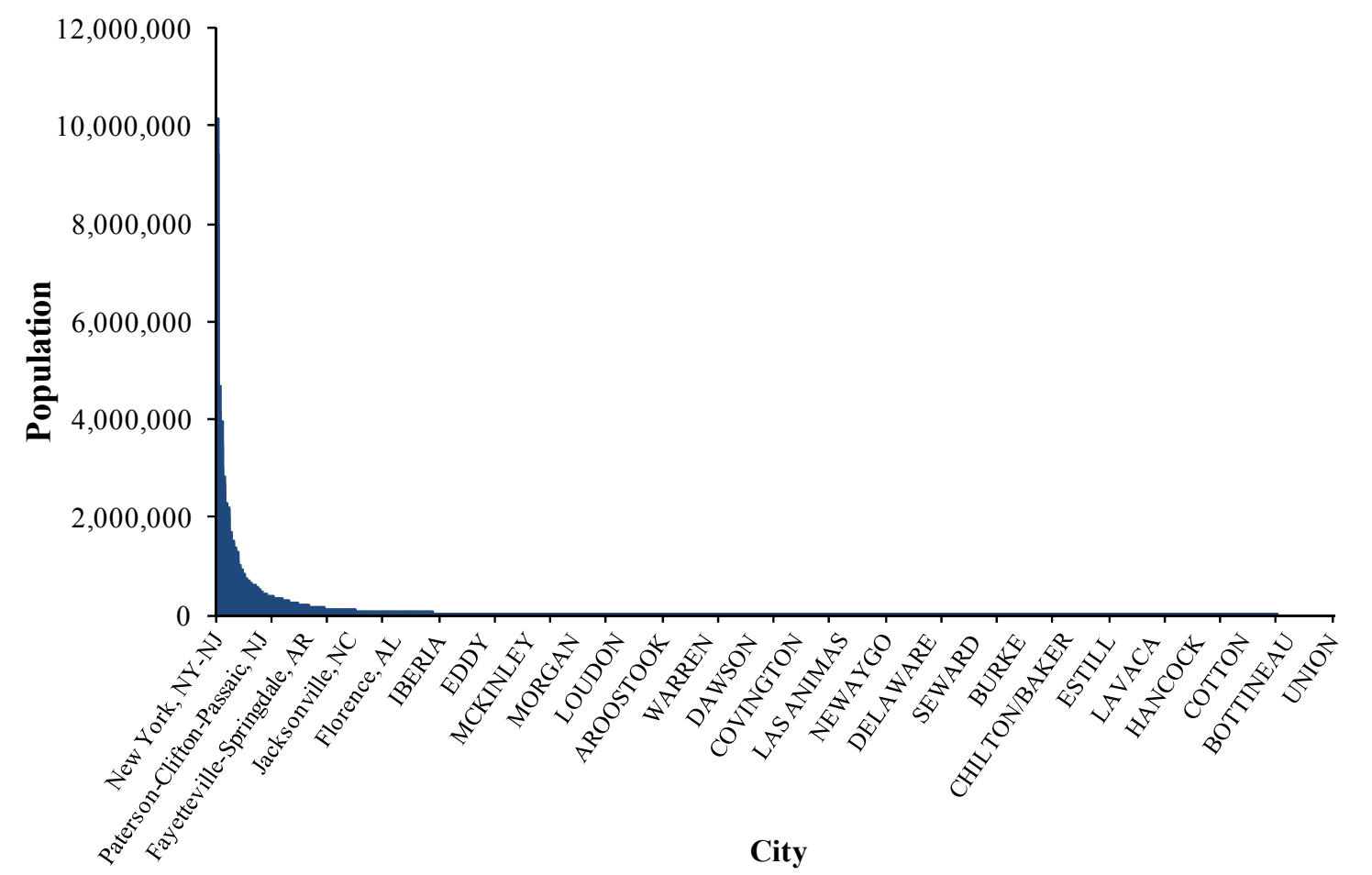

With regards to Result 2 I find support for all the predictions when looking at the dataset for all cities (B), the older group of cities will have a higher mean and variance and will be less skewed then a 'younger' group of cities. As can be seen in Table II-1 both the mean size of the older cities and the variance of these sizes are considerably larger than for the newer group of cities. This continues to be the case even if New York City is considered an outlier and taken out of the picture. When looking at the upper tail, at the top 100 cities the expected results show up in terms of average size and variance of the subsystem but not for the Skewness. 
Table II-1 - Size, Variance and Skewness of Cities by Age

A- Top 100 Cities

\begin{tabular}{|l|r|}
\hline Avg Current Population of Cities that entered prior to 1900 & 711,105 \\
\hline Avg Current Population of Cities that entered after 1900 & 365,934 \\
\hline & \\
\hline Variance of Current Population of Cities that entered prior to 1900 & $1,516,664,805,272$ \\
\hline Variance of Current Population of Cities that entered after 1900 & $68,003,118,516$ \\
\hline & \\
\hline $\begin{array}{l}\text { Coefficient of Skewness for Current Population of Cities that entered prior to } \\
1900\end{array}$ & 4.35 \\
\hline $\begin{array}{l}\text { Coefficient of Skewness for Current Population of Cities that entered after } \\
1900\end{array}$ & 2.83 \\
\hline
\end{tabular}

\section{B- All Cities}

\begin{tabular}{|l|r|}
\hline Average Current Population of Cities that entered prior to 1900 & 228,856 \\
\hline Average Current Population of Cities that entered after 1900 & 30,405 \\
\hline & \\
\hline Variance of Current Population of Cities that entered prior to 1900 & $710,247,354,730$ \\
\hline Variance of Current Population of Cities that entered after 1900 & 7.79 \\
\hline & $13,537,034,897$ \\
\hline $\begin{array}{l}\text { Coefficient of Skewness for Current Population of Cities that entered } \\
\text { prior to 1900 }\end{array}$ & \\
\hline $\begin{array}{l}\text { Coefficient of Skewness for Current Population of Cities that entered } \\
\text { after 1900 }\end{array}$ & \\
\hline
\end{tabular}

As for Result 3, I am not able to present any validation of the model given the nature of the data I am analyzing, the same as for all the results regarding diversity. For this reason I jump to Result 5 which says that the older the city the larger it is going to be on average. This can be seen in the first section of Table II-1, for the case in which I divide the total group of cities in two. Also in Figure II-2 below it is displayed how older groups of cities tend to have a higher mean, once again taking out New York City does not alter the qualitative result. 
Figure II-2 - Average Population of Groups of Cities by Year of Entry A- Top 100 Cities

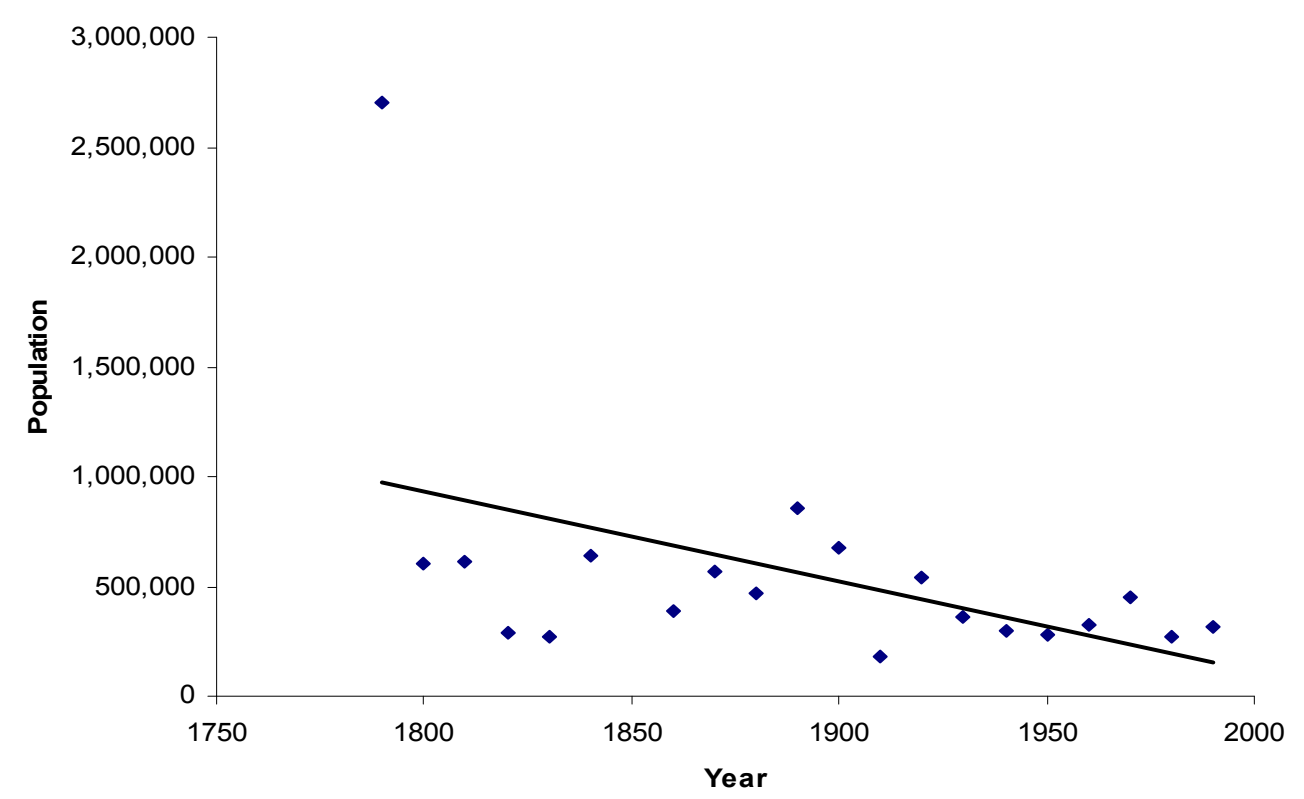

B- All Cities

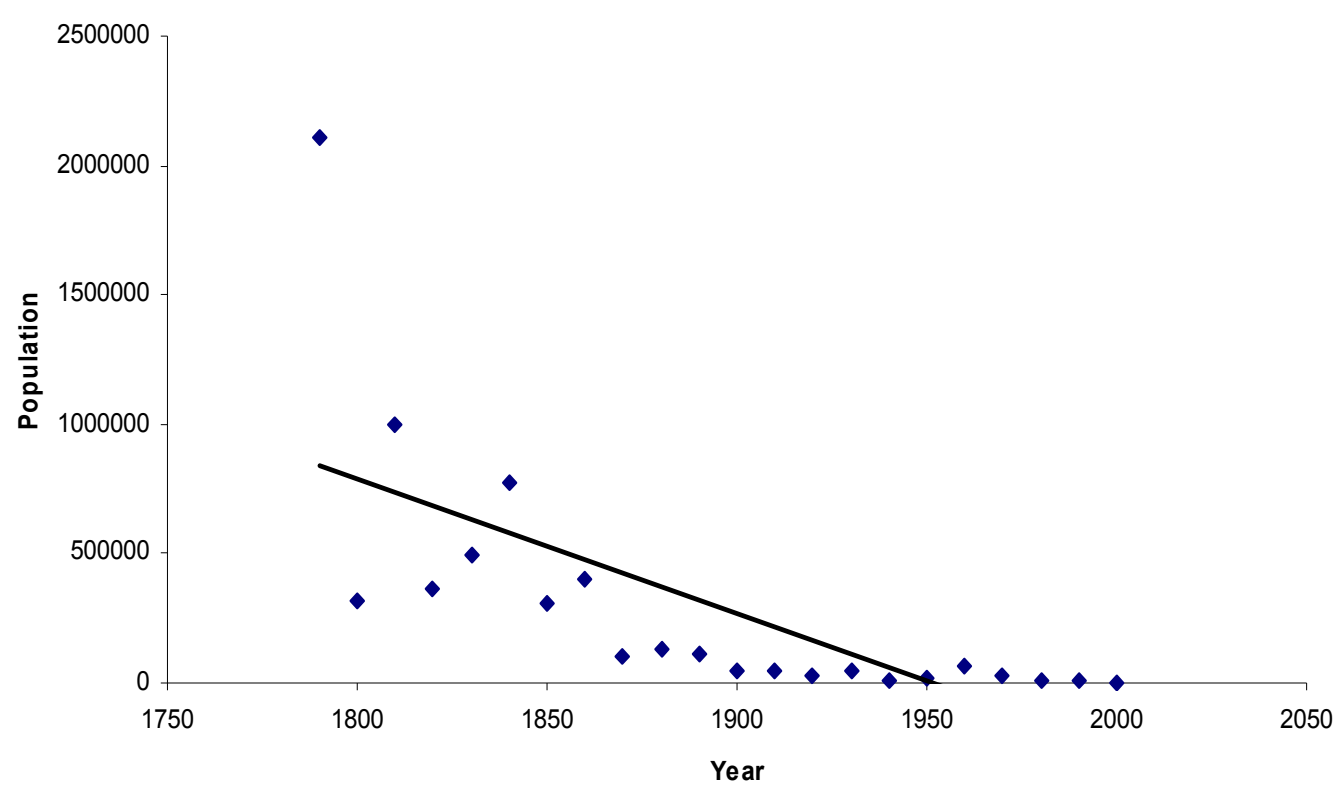

Next I present results pertaining to city growth. The first relation I find is that older cities tended to grow at a slower pace in the 1950-1990 periods for the Top 100 Cities dataset and in the 1970-2000 period in the All Cities dataset then did younger 
cities. This can be appreciated in Figure II-3 where, as in Figure II-2, the black line is a linear trend line.

For my first dataset Figure II-3-A reflects in a disaggregated way the fact that the 'old' group of cities growth rate average was $0.1 \%$ with a variance of 0.014 while the comparable figures for the 'young' group were $15.4 \%$ and 0.071 .

For the second dataset, Figure II-3-B reflects in a disaggregated way the fact that the 'old' group of cities growth rate average was $56 \%$ with a variance of 4.34 while the comparable figures for the 'young' group were $73 \%$ and 3.35 .

Figure II-3 - Average Growth Rate of Cities that entered the system in each decade A- 1950-1990 Top 100 Cities

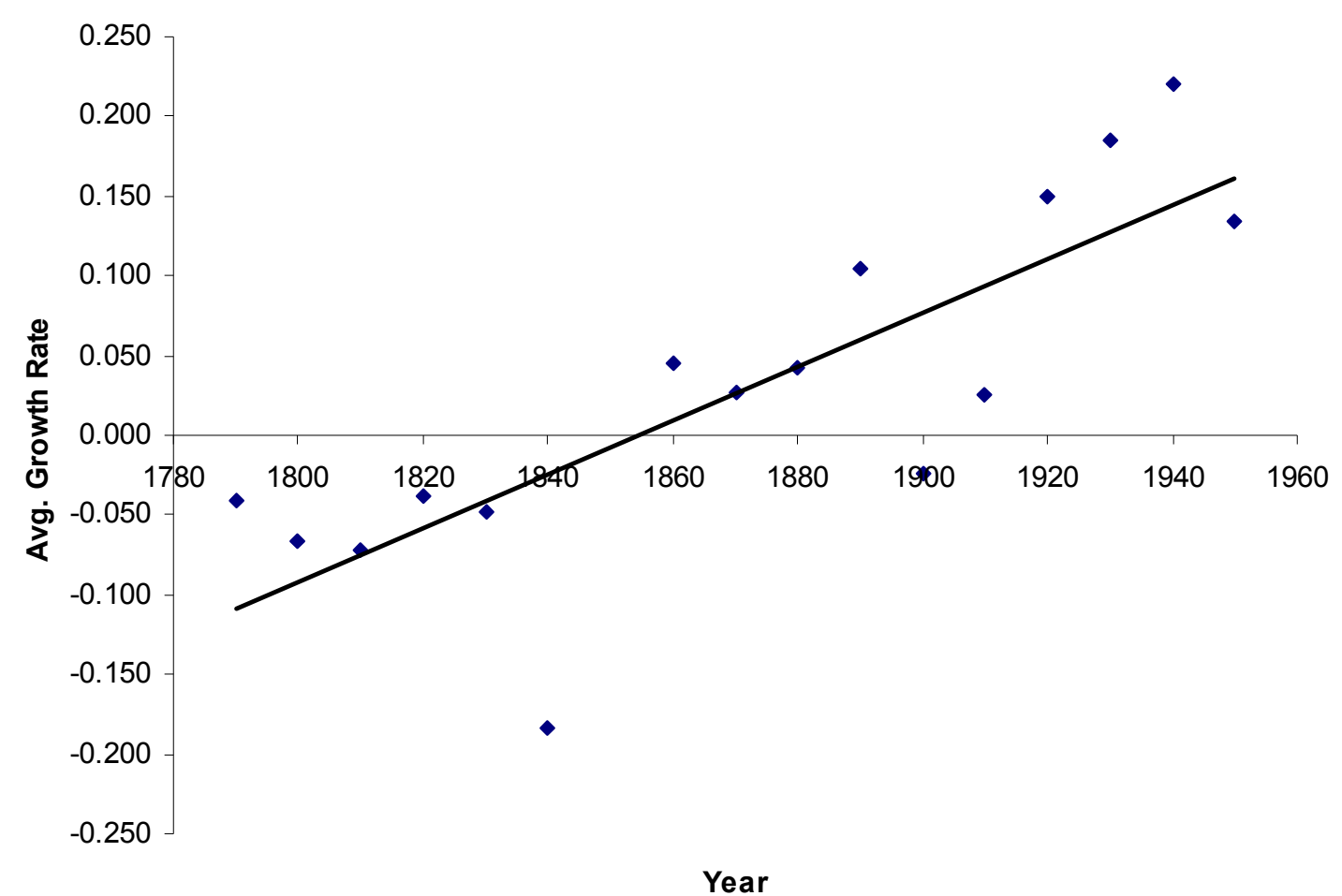




\section{B- 1970-2000 All Cities}

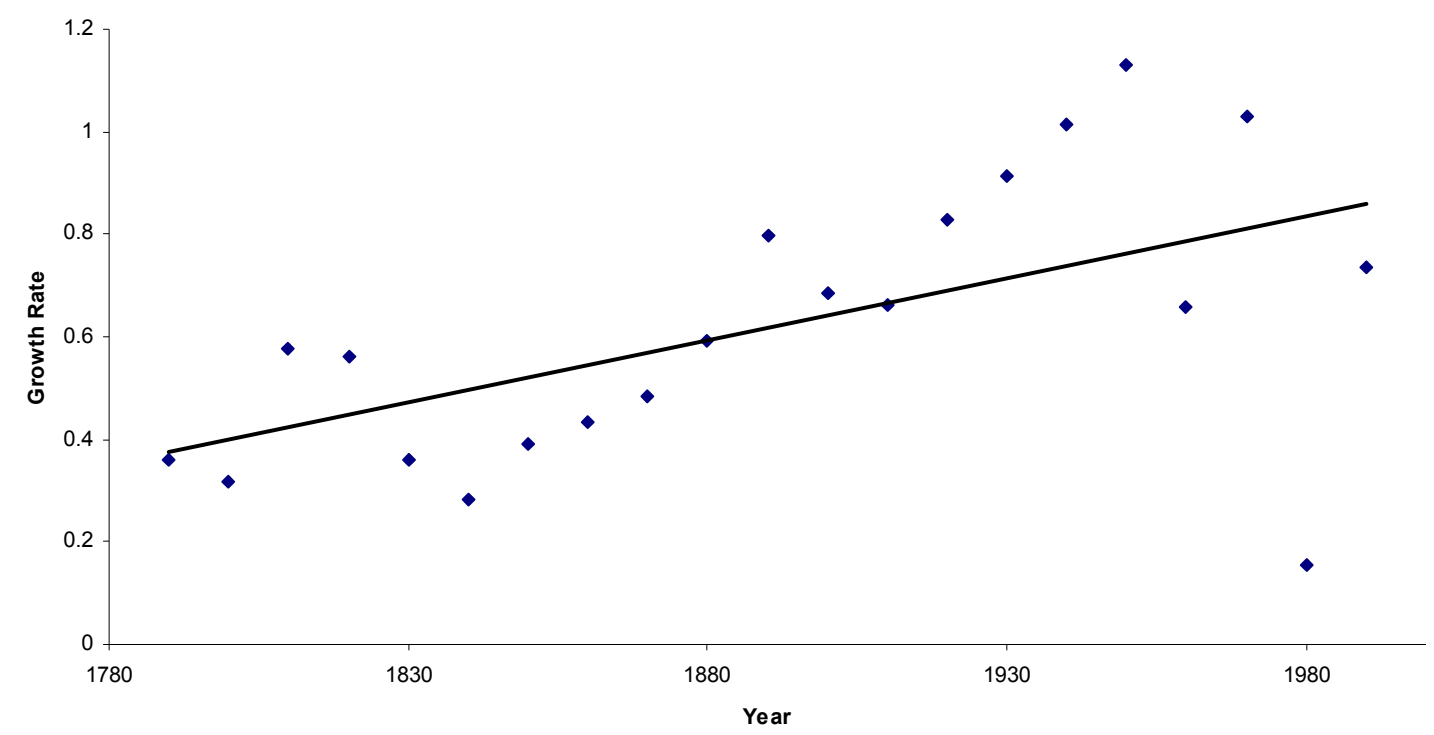

Using a different approach, regressing growth rates between 1970 and 2000 for the large dataset against age and size in 1970, and estimating coefficients by Ordinary Least Squares (OLS) the resulting coefficient for the age variable is negative (the older the city the lower the growth rate) and statistically significant at the $99.99 \%$ level. Although Size and Age can only explain 8\% of variation in Growth rates, when controlled for size, age is inversely related to growth. 
Table II-2 - OLS Results of Regressing Growth Rates on Size and Age

AvgGrowth 70-00 $=$ A $0+A 1 *$ Size1970 + A2*Age1970 +e

SUMMARY OUTPUT

\begin{tabular}{|c|c|c|c|c|c|c|}
\hline \multicolumn{2}{|c|}{ Regression Statistics } & & & & & \\
\hline Multiple R & 0.287517 & & & & & \\
\hline R Square & 0.082666 & & & & & \\
\hline Adjusted R Square & 0.081527 & & & & & \\
\hline Standard Error & 0.674702 & & & & & \\
\hline Observations & 1614 & & & & & \\
\hline \multicolumn{7}{|l|}{ ANOVA } \\
\hline & $d f$ & SS & $M S$ & $F$ & Significance $F$ & \\
\hline Regression & 2 & 66.08757782 & 33.04378891 & 72.588261 & $6.54 \mathrm{E}-31$ & \\
\hline Residual & 1611 & 733.3629876 & 0.455222215 & & & \\
\hline \multirow[t]{2}{*}{ Total } & 1613 & 799.4505654 & & & & \\
\hline & Coefficients & Standard Error & $t$ Stat & $P$-value & Lower 95\% & Upper 95\% \\
\hline Intercept & 1.119903 & 0.040929 & 27.362304 & 0.000000 & 1.039624 & 1.200182 \\
\hline Size1970 & $-8.89 \mathrm{E}-08$ & 4.16E-08 & -2.13697067 & 0.03275061 & $-1.70 \mathrm{E}-07$ & $-7.30 \mathrm{E}-09$ \\
\hline Age 1970 & -0.005893 & 0.000543 & -10.851458 & 0.000000 & -0.006958 & -0.0048278 \\
\hline
\end{tabular}

According to the results presented in Table II-2, for every decade that passes since the foundation of a city, its decennial percentage growth rate declines by 5.89 .

The story with the relation between city size and city growth in these groups of cities is also as predicted by the model. I took the size of cities in 1950 for Dataset A and in 1970 for Dataset B and plotted it against the growth rate they experienced between 1950 and 1990 for $\mathrm{A}$ and 1970 and 2000 for B and found a negative relation in the unconditional plot. I then divided the cities into age groups and found a negative relationship in both the 'old' and 'new' groups presented here in Figures II-3 and II-4. When I look at each age group by decade separately I find that the relation is negative for only 8 of 13 in the small sample but a more robust 18 of 19 for the larger sample, where the exception is the group from 1970. 
All of this is consistent with Result 10 which states that among all cities in a system, mean city growth is strictly decreasing in city size when conditioned on city age. Regressing growth rates between 1970 and 2000 for my large dataset against age and size I have that the resulting coefficient for the size variable, is negative and statistically significant at the $95 \%$ confidence level; for every 100,000 increase in the population of an urban agglomeration, the decennial percentage growth rate declines by 0.089 . This last result is shown in Table II-2 and is consistent with Result 10.

Figure II-4 - Average Growth rate against size for 'Old' Cities

A- 1950-1990 Top 100

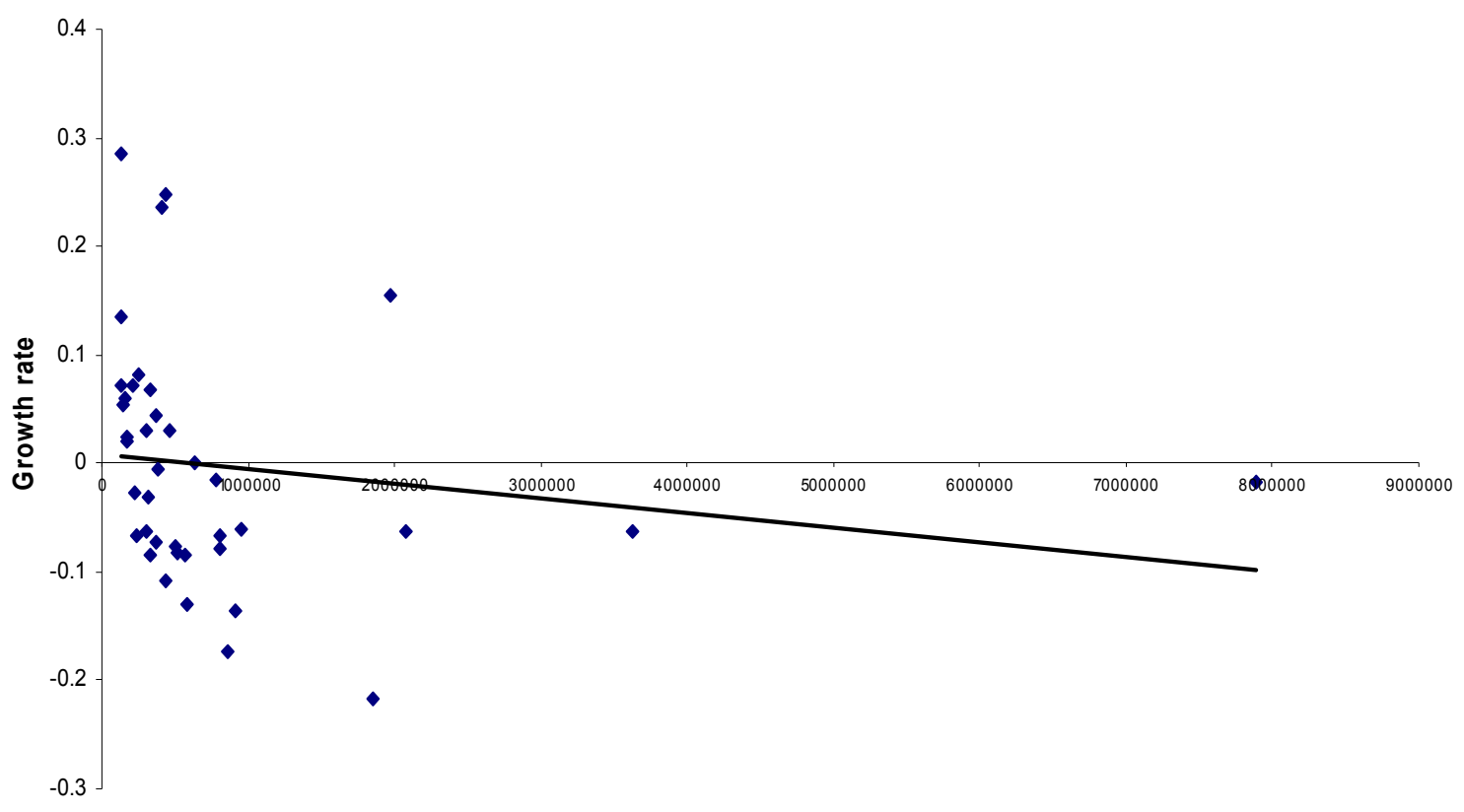




\section{B- 1970-2000 All Cities}

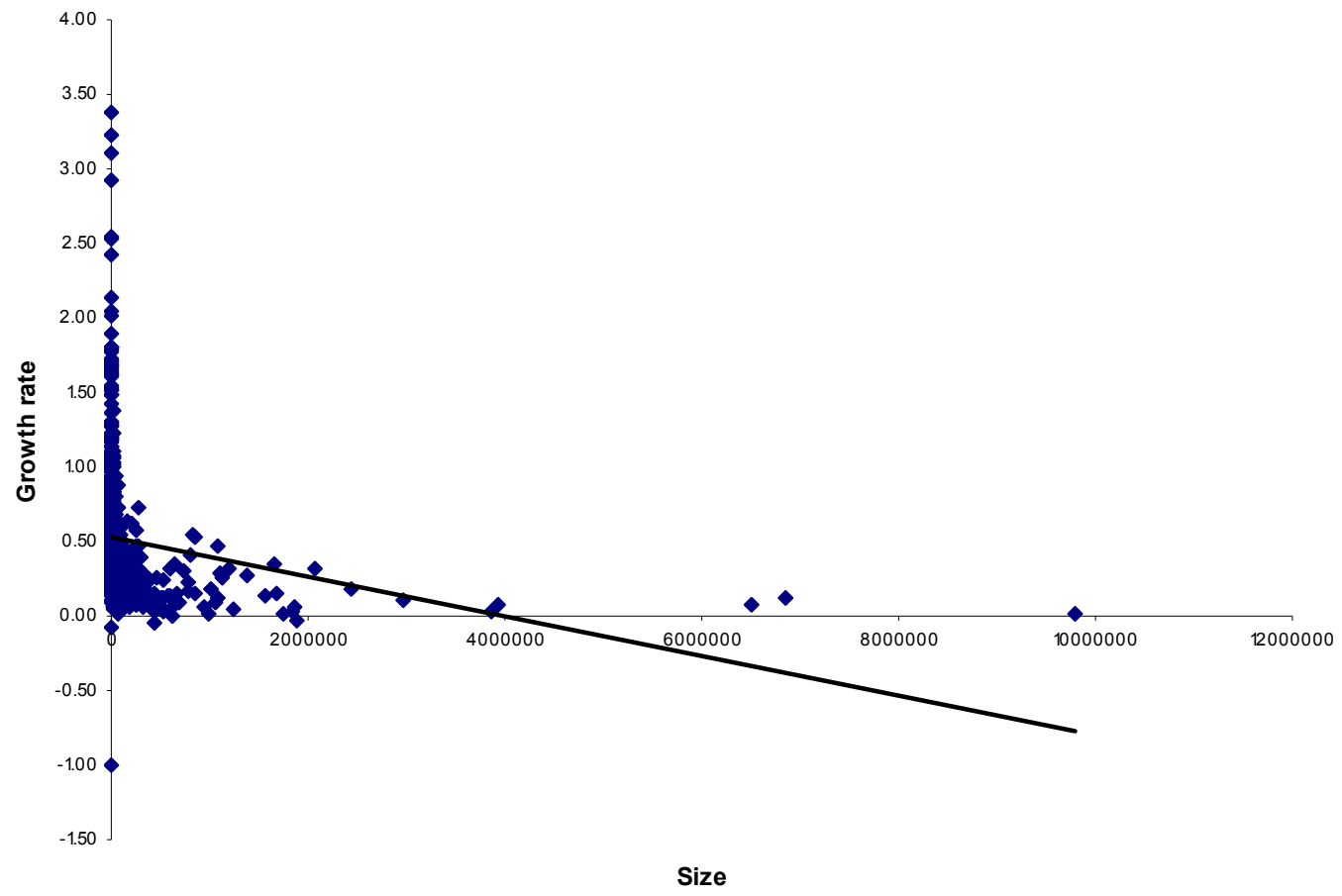

Figure II-5 - Average Growth rate against size for 'Young' Cities

A- 1950-1990 Top 100

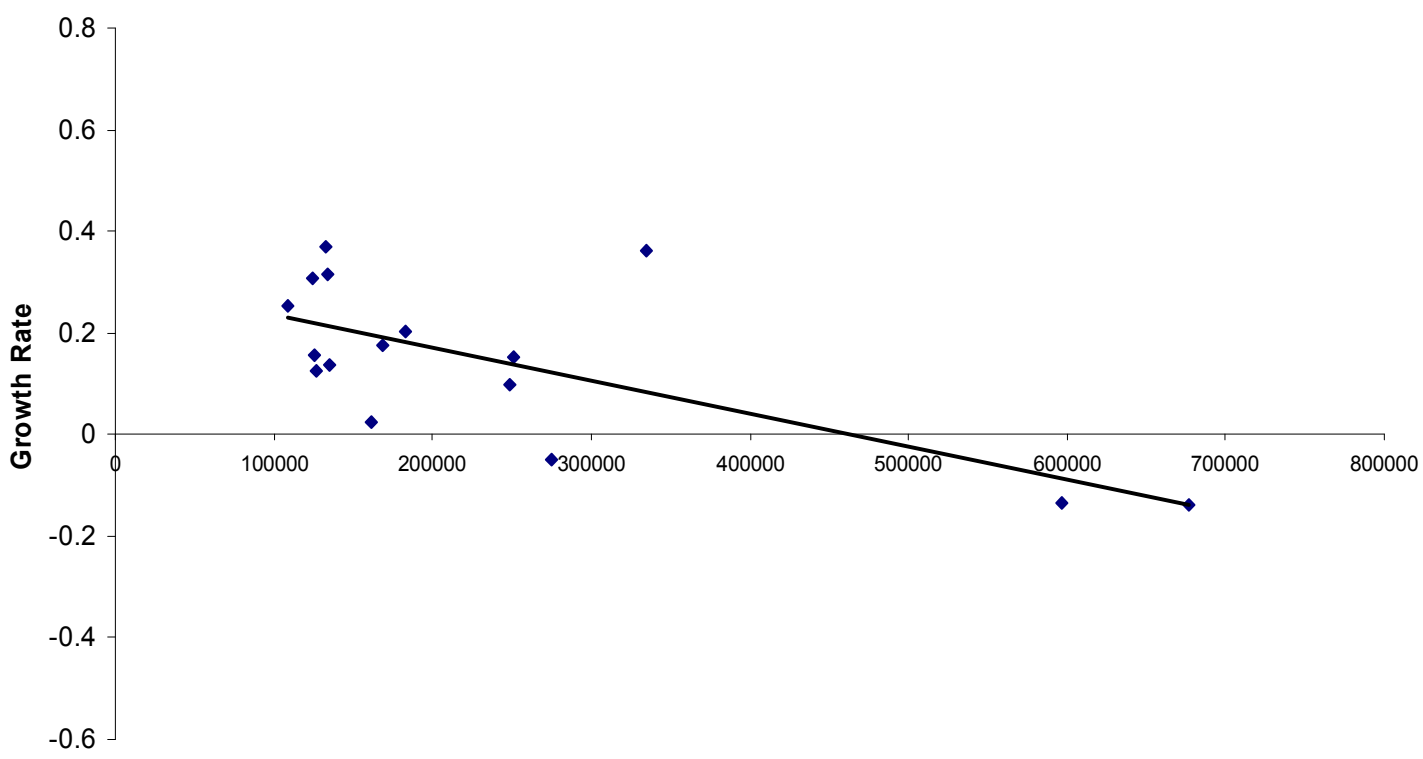

Size 


\section{B- 1970-2000 All Cities}

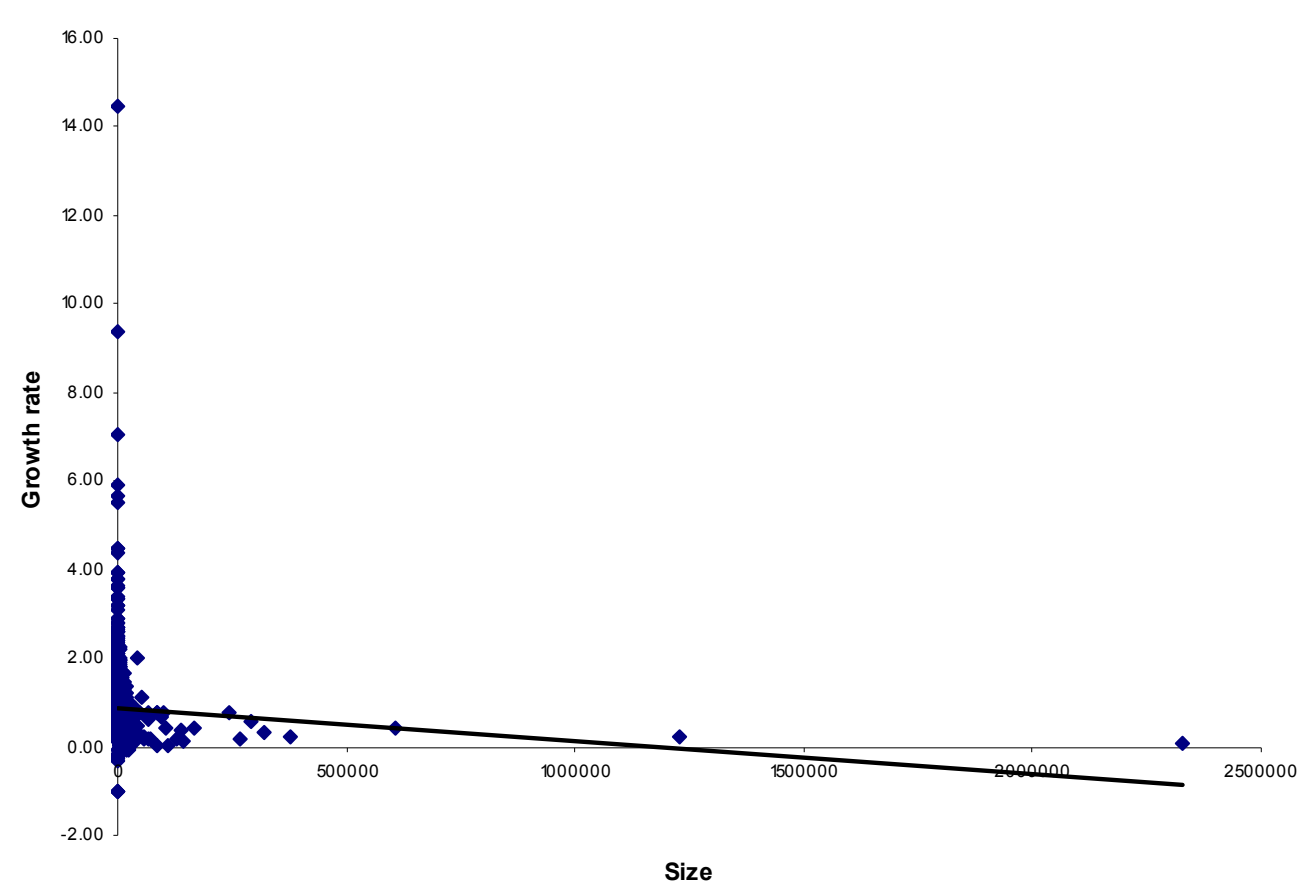

The results I get with respect to city size and variance of growth rate are also consistent with the predictions of the model, specifically, with the first part of Result Eleven which states that the variance of city growth is decreasing with respect to city size when conditioned on age. Taking the same procedures as in the growth rate analysis I find an inverse relationship between city size and the variance of its growth rate for my two main groups (old and young) as well as in 11 of the 13 groups in my small sample and in all 19 of my disaggregated age groups in the larger sample. I present next the figures for the two broad groups where I show the relation between the average size of each group and its average variance of growth rate. 
Figure II-6 - Variance of Growth rate against size for 'Old' Cities A-1950-1990 Top 100 Cities

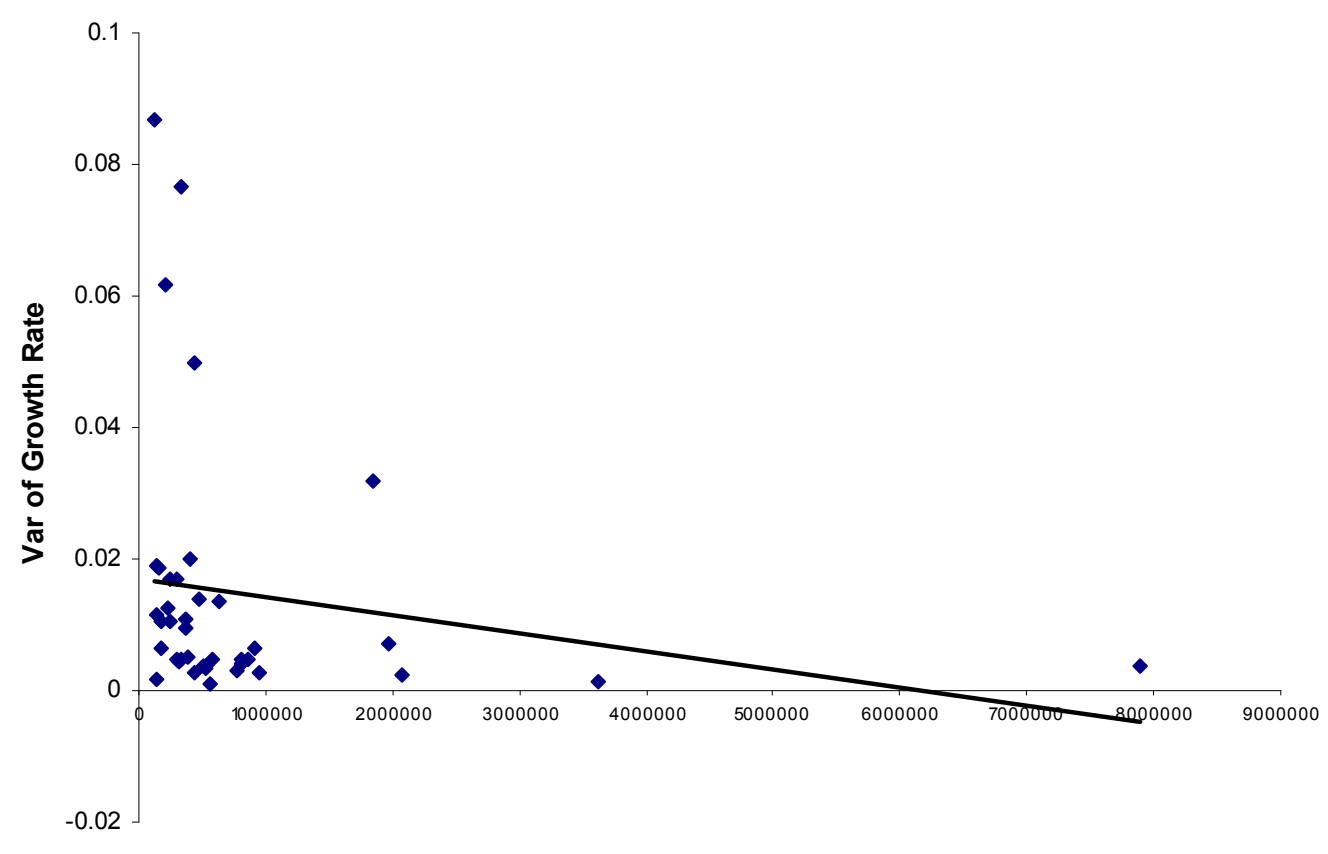

Size

B-1970-2000 All Cities

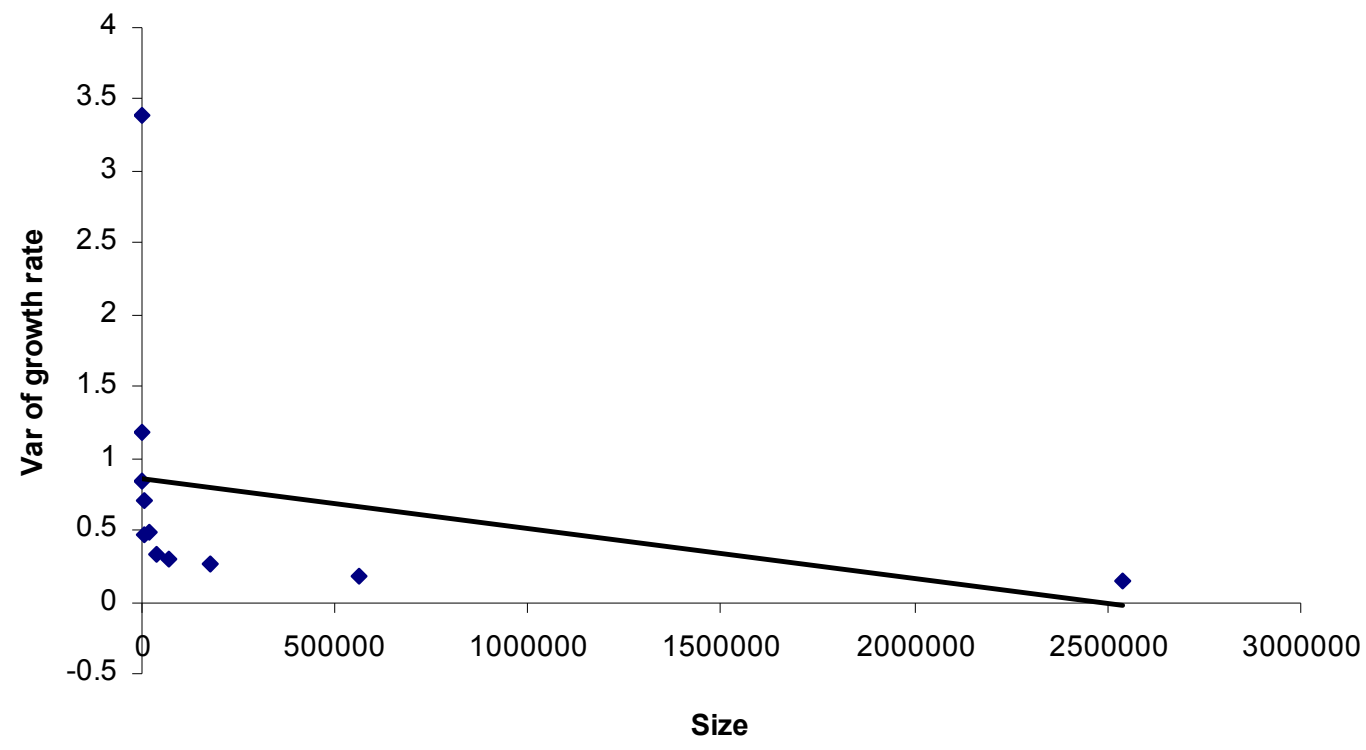


Figure II-7 - 1970-2000 Variance of Growth rate against size for 'Young' Cities A-1950-1990 Top 100 Cities

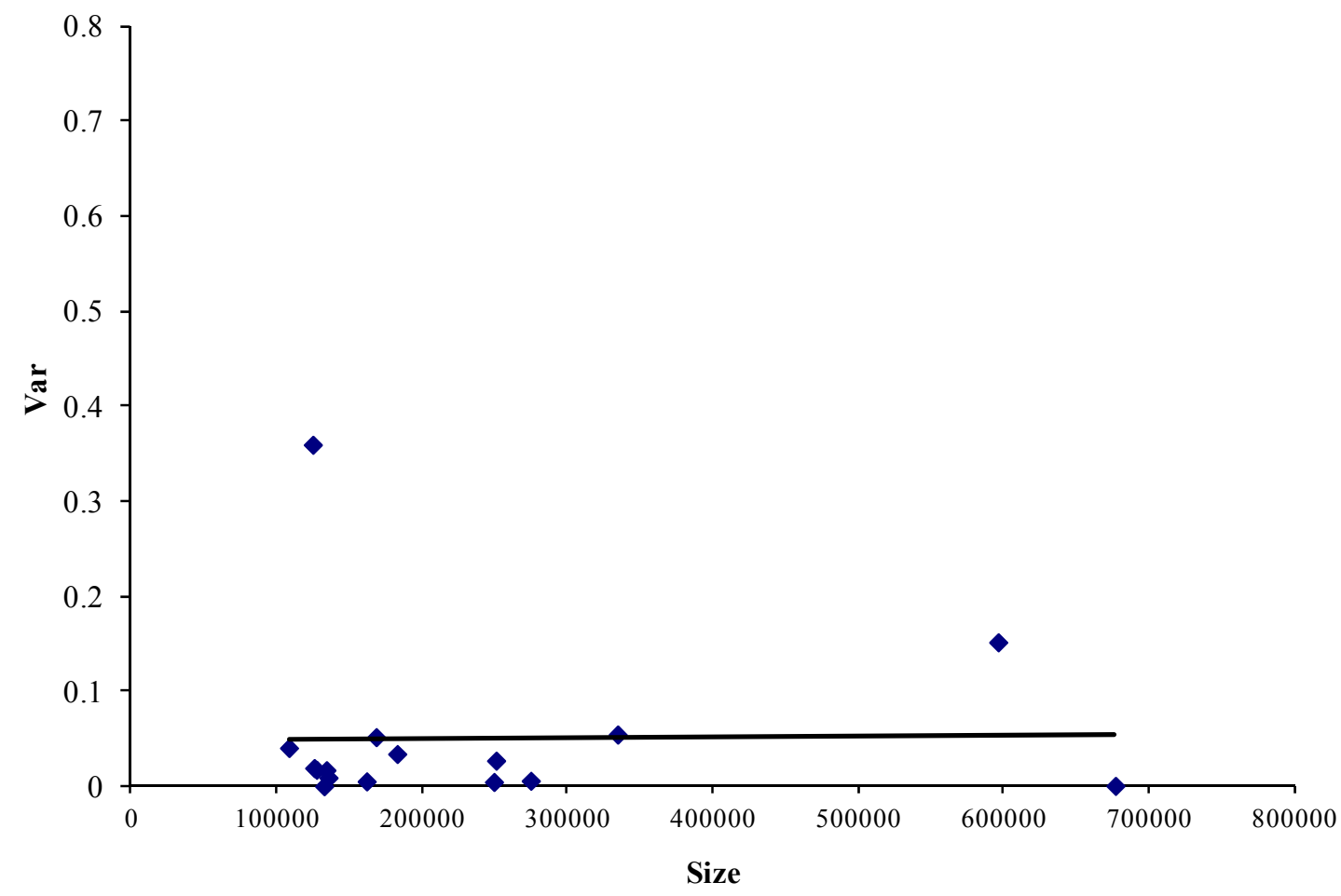

A-1970-2000 All Cities

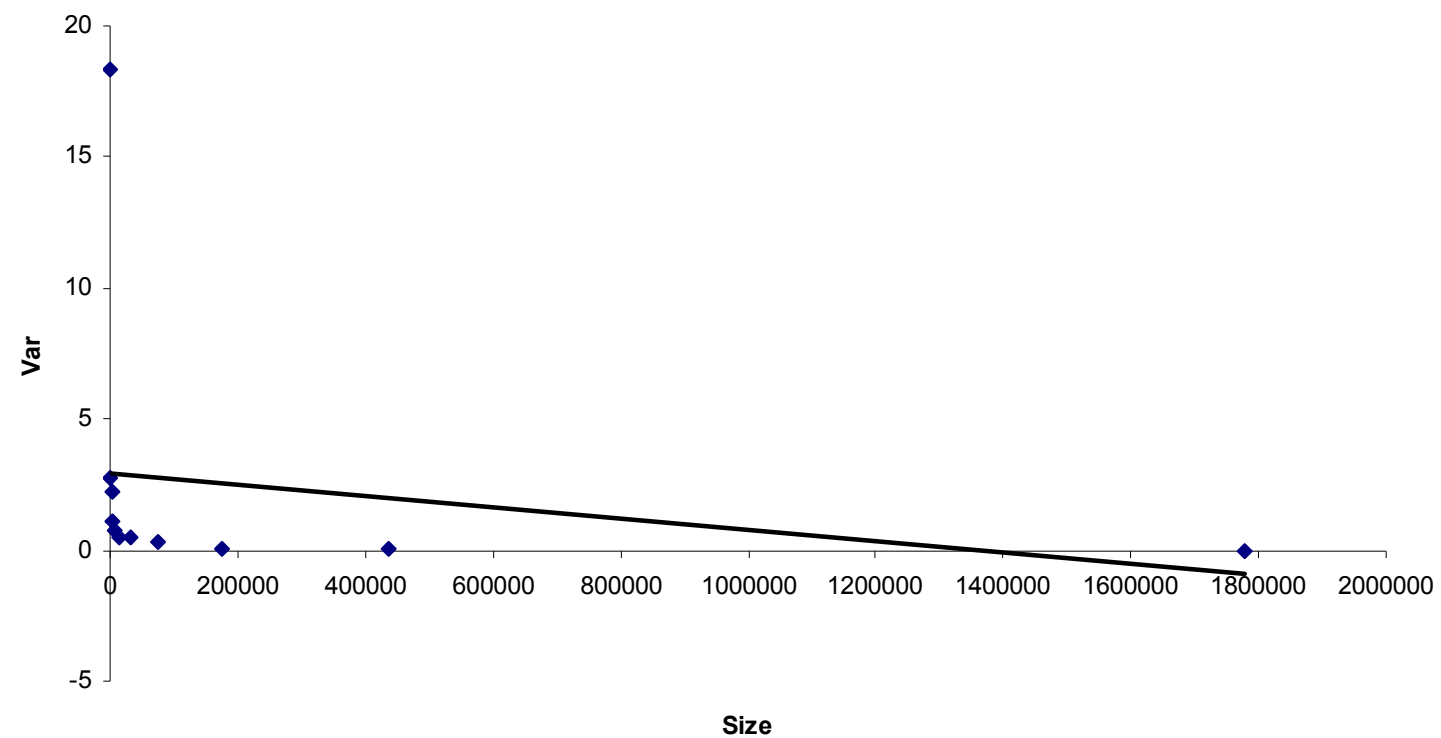


To analyze the second prediction of Result 11, mainly that variance of city growth is negatively correlated with age when controlling by size, I divided the large sample into eleven different size brackets. The predicted outcome fails to show up in two groups, the one that represents populations between $1,000-2,000$ and that of populations between 100,000 and 300,000 . The outcome in these two groups does not necessarily contradict Result 11 given that they represent a wide range of population size. Once I look at subdivisions of these groups I start to observe the expected pattern emerge. In Figures II8 and II-9 I present the situation when I divide the sample in two, where the cutting point is a population of 300,000 in 1950 for dataset A and 1970 for dataset B.

Figure II-8 - Variance of Growth rate by Year of Entry Cities Larger than 300,000 A- Top 100 Cities (Population in 1950 period 1950-1990)

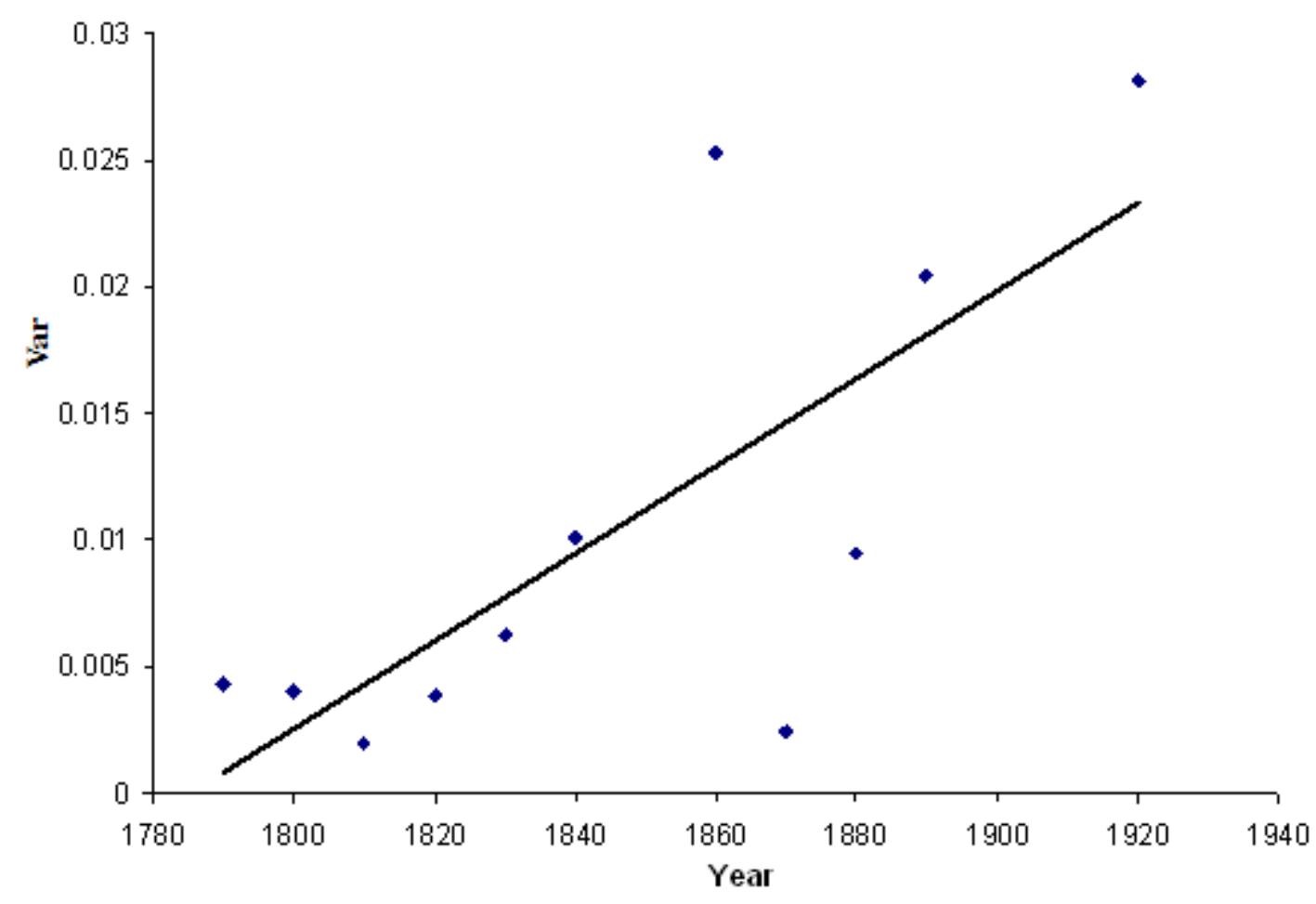


B- All Cities (Population in 1970 period 1970-2000)

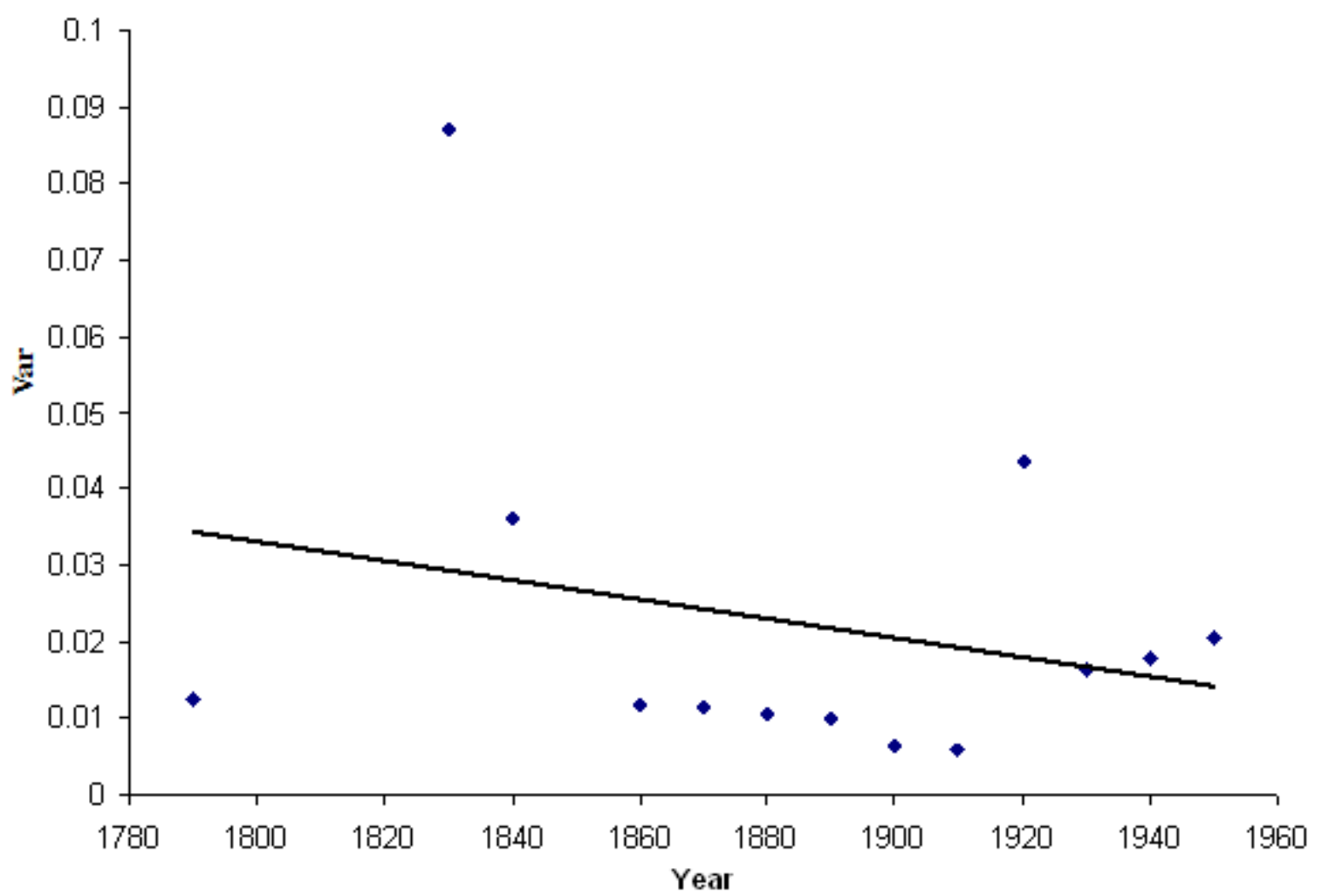

Figure II-9 - Variance of Growth rate by Year of Entry Cities Smaller than 300,000 Top 100 Cities (Population in 1950 period 1950-1990)

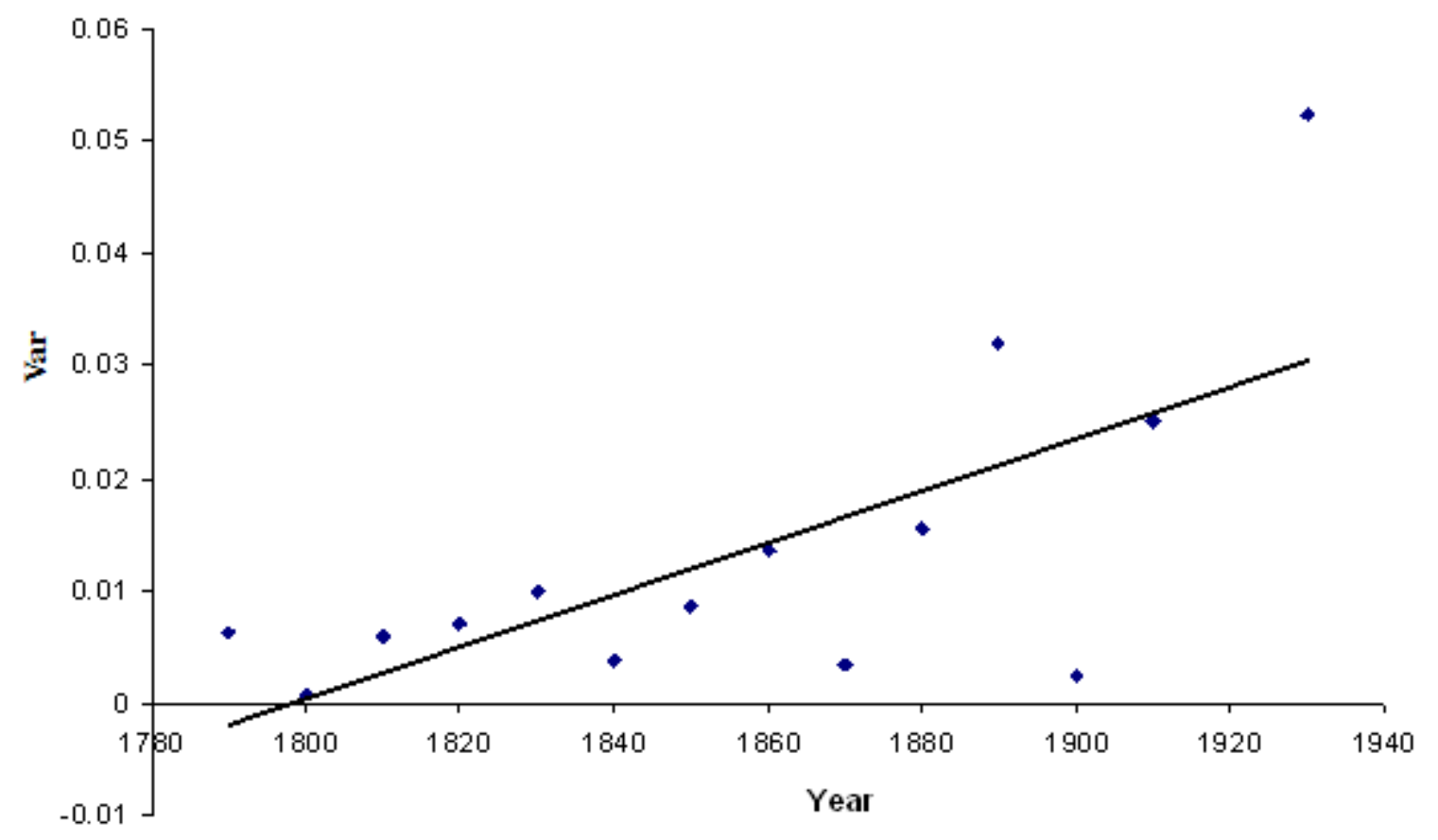


All Cities (Population in 1970 period 1970-2000)

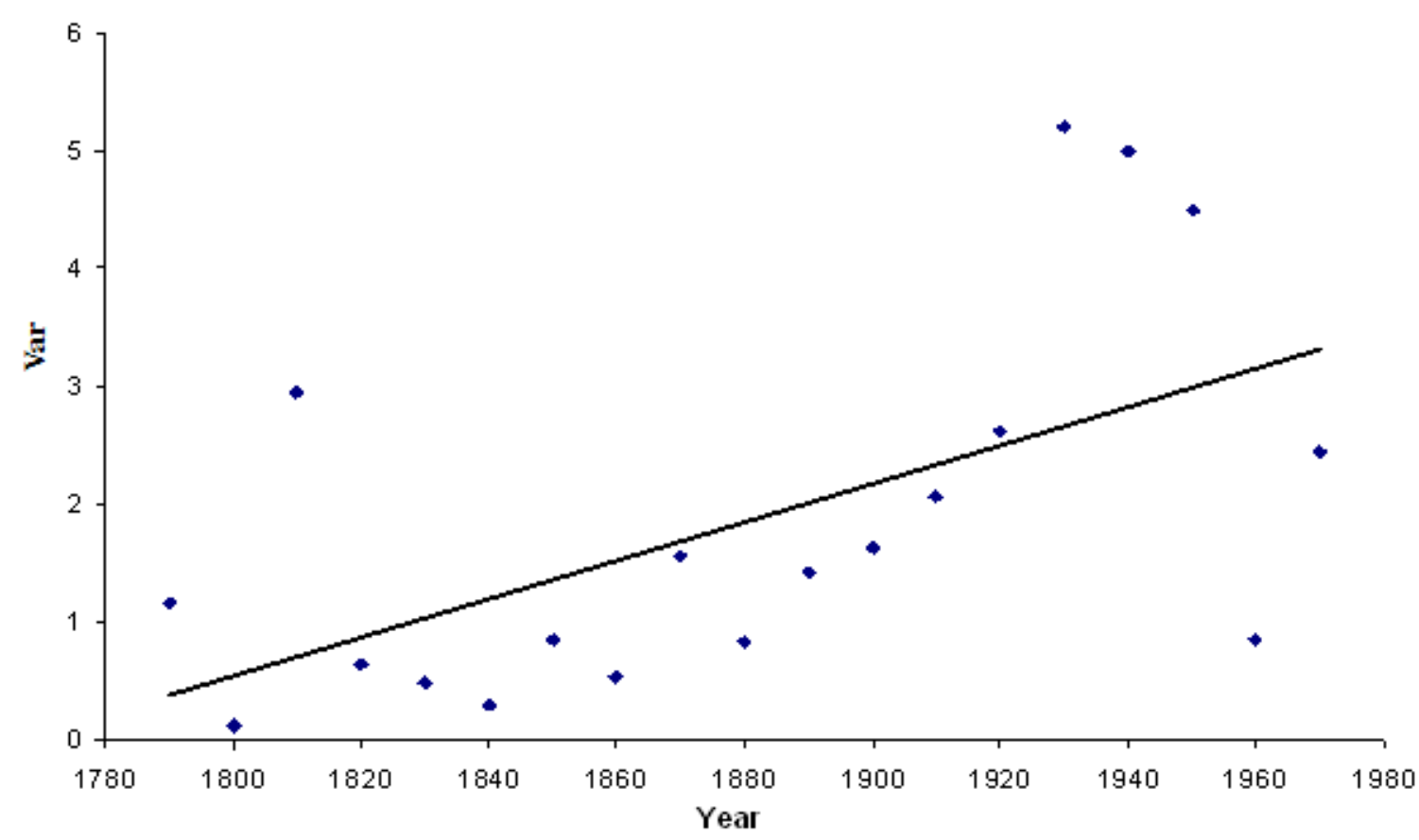

To further test the assertions of Result 11, I calculated the growth rate for 19701980, 1980-1990 and 1990-2000 of each of the cities in the large sample and on the basis of these growth rates calculated a value for the Variance of Growth rate. Using this last Variable as the independent variable and Size and Age as the dependent variables I calculated by means of Ordinary Least Squares (OLS) the coefficients of the equation: VarofGrowth 70-00=A0 + A1 * Size1970 + A2* Age1970 + e.

The results of this exercise are presented in Table II-3 below. 
Table II-3 - OLS Results of Regressing Variance of Growth Rates on Size and Age VarofGrowth $70-00=\mathrm{A} 0+\mathrm{A} 1 *$ Size $1970+\mathrm{A} 2 * \mathrm{Age} 1970+\mathrm{e}$ SUMMARY OUTPUT

\begin{tabular}{|c|c|c|c|c|c|c|}
\hline \multicolumn{2}{|c|}{ Regression Statistics } & & & & & \\
\hline Multiple R & 0.150064 & & & & & \\
\hline R Square & 0.022519 & & & & & \\
\hline Adjusted R Square & 0.021306 & & & & & \\
\hline Standard Error & 8.766535 & & & & & \\
\hline Observations & 1614 & & & & & \\
\hline \multicolumn{7}{|l|}{ ANOVA } \\
\hline & $d f$ & SS & $M S$ & $F$ & Significance $F$ & \\
\hline Regression & 2 & 2852.31034 & 1426.15517 & 18.55713 & $1.08 \mathrm{E}-08$ & \\
\hline Residual & 1611 & 123808.77870 & 76.85213 & & & \\
\hline \multirow[t]{2}{*}{ Total } & 1613 & 126661.08900 & & & & \\
\hline & Coefficients & Standard Error & $i$ Stat & P-value & Lower 95\% & Upper 95\% \\
\hline Intercept & 5.160482 & 0.531795 & 9.703902 & 0.000000 & 4.117400 & 6.203564 \\
\hline Size1970 & $-5.79 \mathrm{E}-08$ & $5.40 \mathrm{E}-07$ & -0.10711312 & 0.91471258 & $-1.12 \mathrm{E}-06$ & $1.00 \mathrm{E}-06$ \\
\hline Age 1970 & -0.041206 & 0.007056 & -5.839689 & 0.000000 & -0.055046 & -0.027365 \\
\hline
\end{tabular}

This last exercise lends support to the second part of Result 11, given that the Age coefficient is -0.0412 and statistically significant at the $99.99 \%$ confidence level. In other words, the older a city is, the less erratic its growth rate will be. The sign of the coefficient for Size is as expect on the basis of the first part of Result 11 although it is not statistically significant.

\section{Conclusions}

The model presented in this chapter assigns the motor of urban dynamics on a set of fortuite emergence of economic opportunities. In doing so, a number of observable and verifiable patterns emerge. These observable patterns which I have stated as results in section 3 are characteristics that, if observed, provide weight to the idea behind the model. 
It is encouraging that anecdotal evidence as well as my first approach empirical observations are consistent with these patterns. This calls for further research on this matter.

I have shown that for both the upper tail and the whole of the US urban system the distribution of city sizes is skewed; older groups of cities have a higher mean and variance, older cities are larger on average, and mean city growth as well as the variance of this growth is decreasing on city size. All of these results are consistent with the predictions of the model.

Despite the success of the predictions of the model for the United States urban system, there is a point to be made on the adaptability or how broad based is the application of the model presented in its current form.

The case observed here, the US urban system between 1790 and 2000 is particularly well suited to be viewed through this model's lens, given the overwhelming importance of migration in the growth of cities, where the growth of cities has been tied more to the economic opportunities they present than to the simple fact of natural population growth, thanks to a large immigration base, both from abroad and from the non urban areas of the country.

Modifications might be useful to explain the dynamics of an urban system that is not set in a period of urbanization; that is, whose urban share of population is stable at some level.

Another modification might be reasonable to study third world countries' urban systems where in effect the capital city often is able to capture a larger share of economic opportunities then what a random model would suggest. 


\section{CHAPTER III: \\ IN SEARCH OF A SPATIAL PATTERN FOR A REAL ESTATE BUBBLE: THE MIAMI-DADE 1999-2006 CASE}

\section{Introduction}

"The longer housing prices remain stagnant or fall, the greater the penalty to our future economic growth."

Henry Paulson, Treasury Secretary. October 16, 2007.

In December of 2007 the US economy entered into its longest recession since the 1930's. Real GDP declined by 4.1 percent $^{2}$ from peak to through, unemployment rose from 4.7 to 10.1 percent $^{3}$, 1.8 million construction jobs ${ }^{4}$ were lost, and the federal government was forced to act and intervene in the economy to a degree not seen in decades by opening the purse strings to shore up most major financial institutions, bailing out General Motors and Chrysler and overhauling the financial regulatory environment.

Two years earlier lack of housing affordability in the United States in general and coastal cities like Miami in particular was the most pressing issue in the minds of local governments and working class households alike, evidenced by the record number of households spending 30 percent or more of their incomes on housing ${ }^{5}$.

\footnotetext{
${ }^{2}$ Change in Quarterly real GDP between fourth quarter 2007 and second quarter 2009. Bureau of Economic Analysis - National Economic Accounts.

${ }^{3}$ Between October 2007 and October 2009. Bureau of Labor Statistics - Current Population Survey.

${ }^{4}$ Between October 2007 (7,575,000) and October 2009 (5,747,000) - Bureau of Labor Statistics - Current Employment Statistics Survey- Unadjusted.

${ }^{5}$ In 200749 percent of all renters and 37.6 percent of all mortgage holders in the US paid more than 30 percent of their income towards housing costs. In Miami-Dade the figures are 64 and 62 percent. U.S. Census Bureau - American Community Survey 2007.
} 
Both these undesirable situations were linked to the dynamics of the housing market during the period 1999-2009 and more visible in 2004-2009 in which housing prices experienced a never before seen explosive rise and fall ${ }^{6}$.

Understanding this period in the housing market is key in order to attempt to identify, avert and/or mitigate a possible repeat in the future. Understanding the situation in the housing market during the period in question can shed light not only on the future of the housing market but also on any number of other asset classes.

In the spirit of contributing to the study of this period and phenomenon I gathered real estate transaction data for Miami-Dade County and attempt to identify if the rapid increase in housing prices behaved in some identifiable pattern. I do this by analyzing the data from a descriptive perspective, applying a model of spatial dissemination and testing my results in novel ways.

I adopt a local housing bubble model on the basis of the interaction of two types of agents: home buyers and speculators, which classifies areas in terms of timing of the bubble, inelasticity of supply and speculative intensity. Further I formulate an innovative test of the results in terms of speculative intensity on the basis of proxies of investor activity available in my dataset. This latest test gives support to the result that the best or more expensive areas are also where the greatest speculative activity takes place and where the rapid increase in prices begins.

\footnotetext{
${ }^{6}$ Between January 2004 and June 2006 Home Prices increased by 36 percent then fell by 32.5 percent by April 2009. As measured by the 20 City composite S\&P Case Schiller Home Price Index.
} 
For the most part my results are in line with other real estate bubble periods (Roehner 1999, Rowendal 2007, Shimizu and Nishimura 2007) with a few notable exceptions.

The most significant departure from previous studies that emerges in my results is that during periods of rapid price appreciation in real estate, researchers find a wider gap between high-priced areas and low-priced areas in the peak year not observed in my study period. To analyze this situation I develop a measure of dispersion in value among areas and contrast the Miami-Dade and Paris episodes.

The rest of the Chapter is structured as follows:

In the second section I review the available literature on spatial aspects of real estate bubbles and related topics. Then I examine from a descriptive standpoint the data collected for the purpose of this study and discuss some methodological options concerning the aggregation of data. In the fourth section I take a first and multi-angled look at the data from a spatial perspective and seek to identify patterns that might stand out. In the fifth section I discuss and apply a model proposed by Rohener (1999) to the Miami-Dade County case, and analyze the findings and test them in new ways not available to the original model's author.

Section six concludes the chapter.

\section{Literature}

Much has been written about bubbles in the course of economic life, much has been written about the real estate markets, and even quite a few studies have looked at 
bubbles in the real estate markets, but the number of studies conducted into the spatial aspects of real estate market bubbles can be counted with one hand.

Probably the closest study in nature to mine, and the one I rely on in section V, is Roehner (1999). His aim was to study the housing bubble that took place in Paris between 1984 and 1991 to get insight into the spatial mechanisms of speculative bubbles. Roehner looked at the 20 districts of Paris's Intramuros and developed a model that stylized the behavior of the different kinds of agents in the market and categorized each district in terms of the relative strength of speculative vs. price supply inelasticity influence.

Roehner's main findings are 1) that prices in the best areas are seen to peak first and decrease in proportion to their former increase, 2) that speculation is a bigger factor in the best areas, while inelasticity of supply is more important in other areas; and, 3) that the price patterns in different areas was almost the same before and during the price bubble - but the price gap between the most expensive districts and the least expensive was substantially amplified by the bubble.

Another, more recent, study that looks at the spatial patterns of real estate bubbles is that of Rowendal \& Longhi's (2007). As Roehner tries to explain the bubble's spatial pattern in terms of speculation and price inelasticities, Rowendal \& Longhi (2007) try to explain the actual occurrence of the bubble by picking Consumer Confidence as their key explanatory variable.

Here the authors present a model in which they decompose the sales value of a house into pure price, a spatial and a quality component. Then they run the model once without the spatial component and next with the spatial component finding that the 
importance of variables appears higher when the spatial variables are not considered than when they are, suggesting that some of the effects are direct and others propagate through increases in prices in neighboring areas.

Here, too, the authors argue that bubbles seem to affect the level of house prices but not their spatial pattern, and to emphasize this they present side-by-side maps with price levels at two points in time that look similar. This finding is similar to Roehner's despite the difference in geographic scope of both studies: Roehner analyses the city of Paris while Rowendal \& Longhi look at the whole Netherlands.

Using a different approach and perhaps with less emphasis on the spatial question, Shimizu and Nishimura (2007) estimate a hedonic price model for Tokyo 1975-1999 and add dummy variables to take into consideration structural changes. Using Akaike Information Criteria (AIC) they divide the time line between pre-bubble, bubble and post-bubble and find structural differences between them.

In terms of spatial findings they argue that areas differ in the sense that coefficients for different characteristics (amenities, closeness to transportation, etc) are different, even in sign between them. And in terms of spatial dissemination they conclude that the bubble started in the Central Business District (CBD) and spread outwards.

Although not related to a "Bubble" period, another study of spatial aspects of price changes in real estate markets was conducted by Anglin (2007) who studied the different districts within Toronto and concluded that prices in different districts within a city grow at different rates, even over long time horizons.

He also finds that if a district is a neighbor of a high price growth district it will also see substantial price increase. 


\section{Data}

The data for the present study comes from the Miami-Dade County Property Appraiser's file, also referred to as PTX file. This file includes every property in the county identified by folio number and consists of more than 117 fields in its original form describing many aspects of the properties including their spatial location. For every property the last three transfers of ownership are reported including the transaction year and month and the sales price.

In the original file close to 850,000 properties are recorded, a number that includes all types of properties.

As mentioned above, each property contains information about its location, or in other words is geocoded in a way that can observed in a spatial plane using Geographical Information System (GIS) software packages.

Each property has a specific location in space, but in order to be able to visualize the spatial aspect of the bubble I must define areas and aggregate data.

For Miami-Dade County several options exist. In order of quantity there are political divisions such as Commission Districts that divide the county in 13, Municipalities of which there are 35, and then there are Zip codes that divide the county in 78. Other possible options are divisions created by the U.S. Census Bureau such as 346 Census Tracts, 1,222 Block Groups and 30,809 Blocks.

Aggregation of data also requires me to settle on segments of time, whether to look at monthly, quarterly or yearly intervals. 
In order to have enough observations for each space-time aggregated data point I will use the zip code divisions at a yearly interval. Zip Code areas have another advantage in my case since it is a variable homebuyers take into consideration when searching for a home.

The next methodological issue is in what way these space-time aggregated data points are to be constructed. The simplest way to come up with the aggregated data points is to use the mean or median for the transactions or in order to standardize somewhat the values I could look at this data by Square Feet.

Another option that incorporates more information is to use the hedonic approach where sales price is broken down into prices for the different characteristics. And yet another method is to use repeat sales where changes in price are computed exclusively from transactions in units that have been sold before.

\section{First Look at the Patterns}

As a first approach I look at the median price of sales for each year in each zip code area.

In order to standardize the data, I select transactions in which sales price are above 10,000 dollars and reported Lot size value above 2,500 Sq Ft so that I am including Single Family Homes and Town Homes and excluding Multifamily structure Apartments. Next I divide the sales price by the lot size to get a Price per Lot Sq Ft and group the transactions by Year-Zip Code intersection. Finally I take the median of the values of Price per Lot Sq Ft and assign it to each Year-Zip Code intersection, thus getting 74 
spatially assigned Values for each year I analyze. Starting with 1998 and ending in 2007 I have 10 years for a total of 740 data points I can use to analyze the spatial dissemination of the bubble in the county.

Given my selection rules for the sales transactions I have between 13,300 and 29,400 transactions for each year, and each of the Year-Zip Code intersection constructed data points come from the median value of a minimum of 20 observations.

From this point forward when I talk about prices I am referring to the Median Price per Lot Sq Ft in current dollars for the different areas.

At first glance there is no obvious pattern in the way the bubble behaves on the basis of the data points described above other than prices going up faster every year from 1999 to 2005 and then slowing down somewhat in 2006 and not much in the way of changes in the rank order of the different zip code areas.

In the following maps the Median prices per Lot Sq Ft are depicted for the prebubble year 1998 and for the peak-bubble year 2006. Several noteworthy aspects stand out from looking at them; the first can be appreciated by looking at the legends where I find that both the lowest and highest median price went up by a factor of three, from 7 to 22 on the low side and from 70 to 216 on the high side. This situation translates into a steady relationship between the lowest priced area and the highest, the latter being ten times the price of the former. Second, it is visible that most of the county in 1998 had median prices below $\$ 30$ Per Lot Sq Ft, while the opposite is true in 2006. Third, I find that the priciest areas in terms of dollars per Lot Sq Ft in 1998 continue to hold this status in 2006; these areas consisting of Key Biscayne, Aventura, South Beach, Coconut Grove, parts of Coral Gables, parts of Fountainblue and Doral. 
Finally these Map/Figures suggest that areas neighboring the 1998 higher priced areas became relatively more expensive than other areas during the bubble.
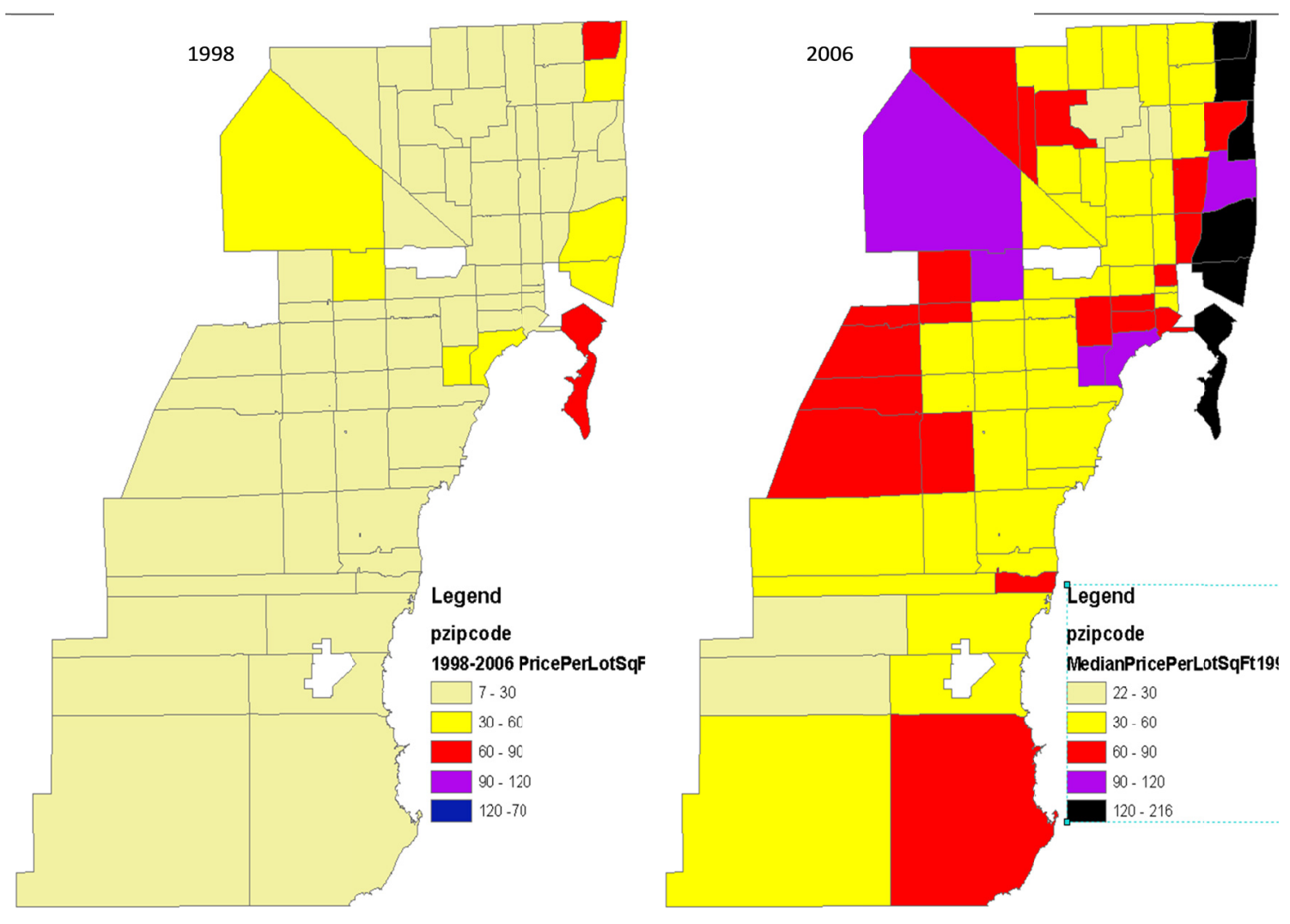

In the next set of Map-Figures I have the increase in price during the whole bubble period; here I compare the median sales price in 2006 to the same variable in 1998. On the left I have the change in absolute terms while on the right side map I have the percentage change.

In terms of absolute change I find an expected pattern in that initially high priced areas hold the top spots in terms of increase in absolute values. 
In terms of percentage increase, the maps seems to suggest two patterns, one is that the highest increases take place in initially really low-priced areas; and second, that the closest an area is to the coast, the higher the increase is.

The Percent Increase map legend also shows that the bubble impacted all areas, in that the area with the smallest increase more than doubled (117\% increase) in price in the eight-year period.

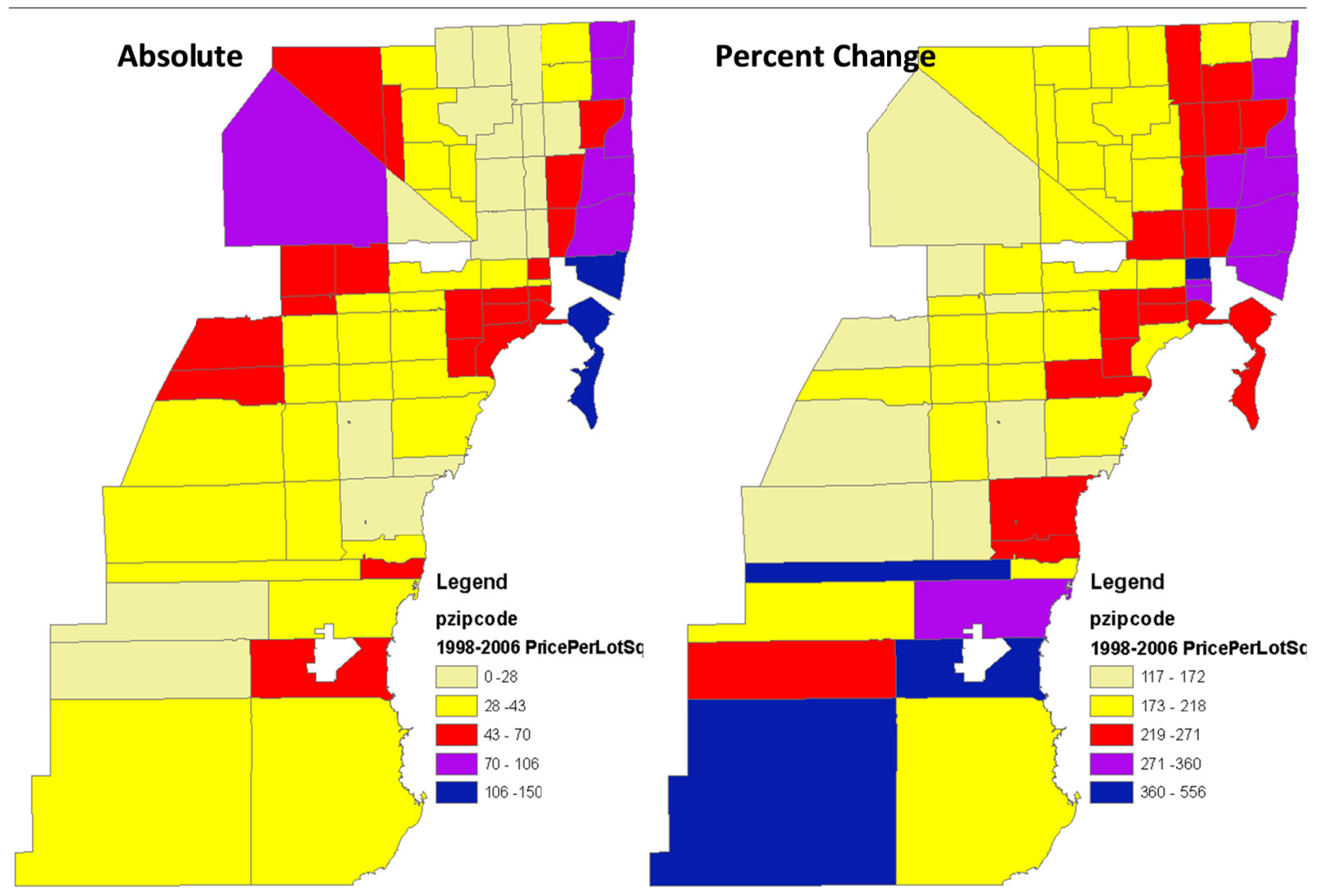


So far the maps presented show the before and after picture of the bubble process, the next set of visuals will introduce dynamics into the picture by looking at the changes that took place on a yearly basis.

First I have a set of 8 maps that represent the percent change in the Median Price per Lot SqFt for each of the years between 1999 and 2006, here the darker the color the higher the percent change for the year. With this in mind it is obvious that 2005 was the strongest year in terms of price hikes in the county.

By 1999 I find that several Zip code areas gained more than 20\% in price, yet around $40 \%$ of all areas actually saw price decreases. The number of areas that show decrease in their prices goes down every year, while price increases are ever sharper and more widespread. 
Figure III-3 - Annual Percent Change 1999 - 2006
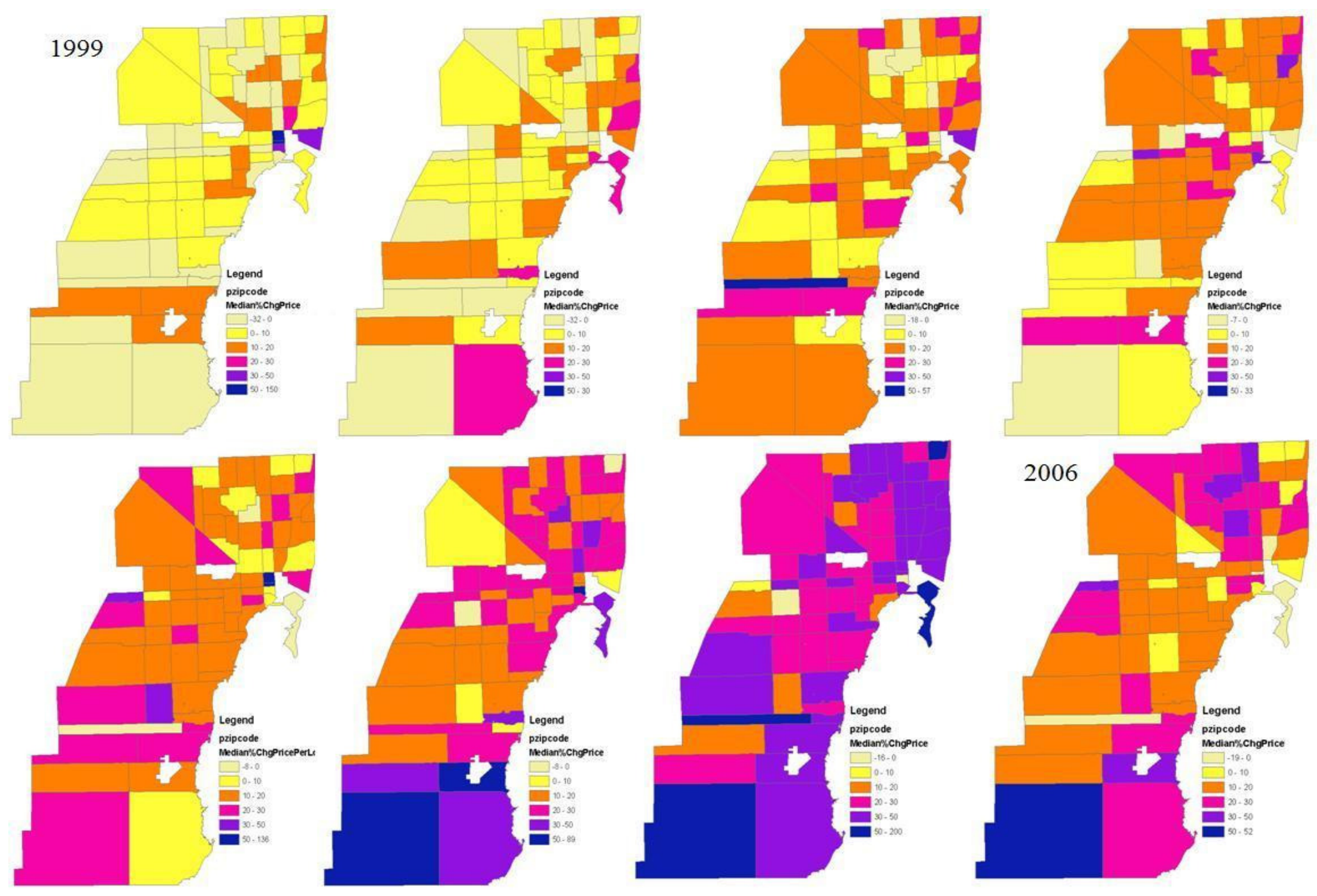
In order to visualize a pattern from these eight maps, I combine them into a single map that shows the year in which an area first reaches an increase of more than $20 \%$ and shade the earlier ones with darker shade of blue.

From this exercise I find that in a weak sense the sharp increases take place first in the area adjacent to the Central Business District (CBD) and spread outwards towards the inland.

Figure III-4 - Year Percent Change Reaches $20 \%$

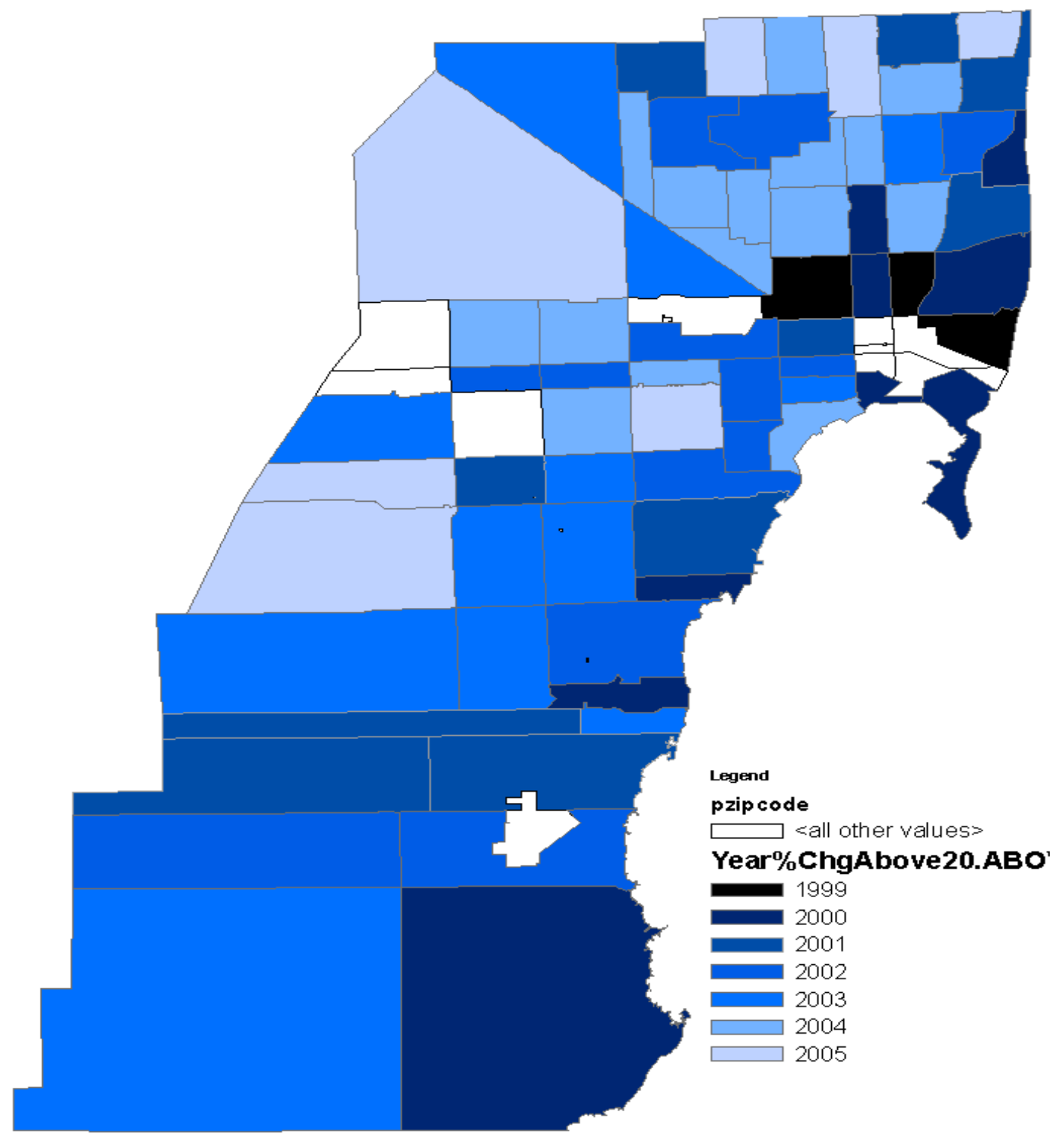


I qualify the last observation as weak given that the pattern is not clear cut when looking at the map. Another way of looking at this possibility is to measure the distance of each area from the CBD and graphing it against the year variable. By doing this the simple link between distance from CBD and High Growth year seems to be even weaker.

See following Figure.

Figure III-5 - Distance from CBD Against Year Percent Change Reaches 20\%

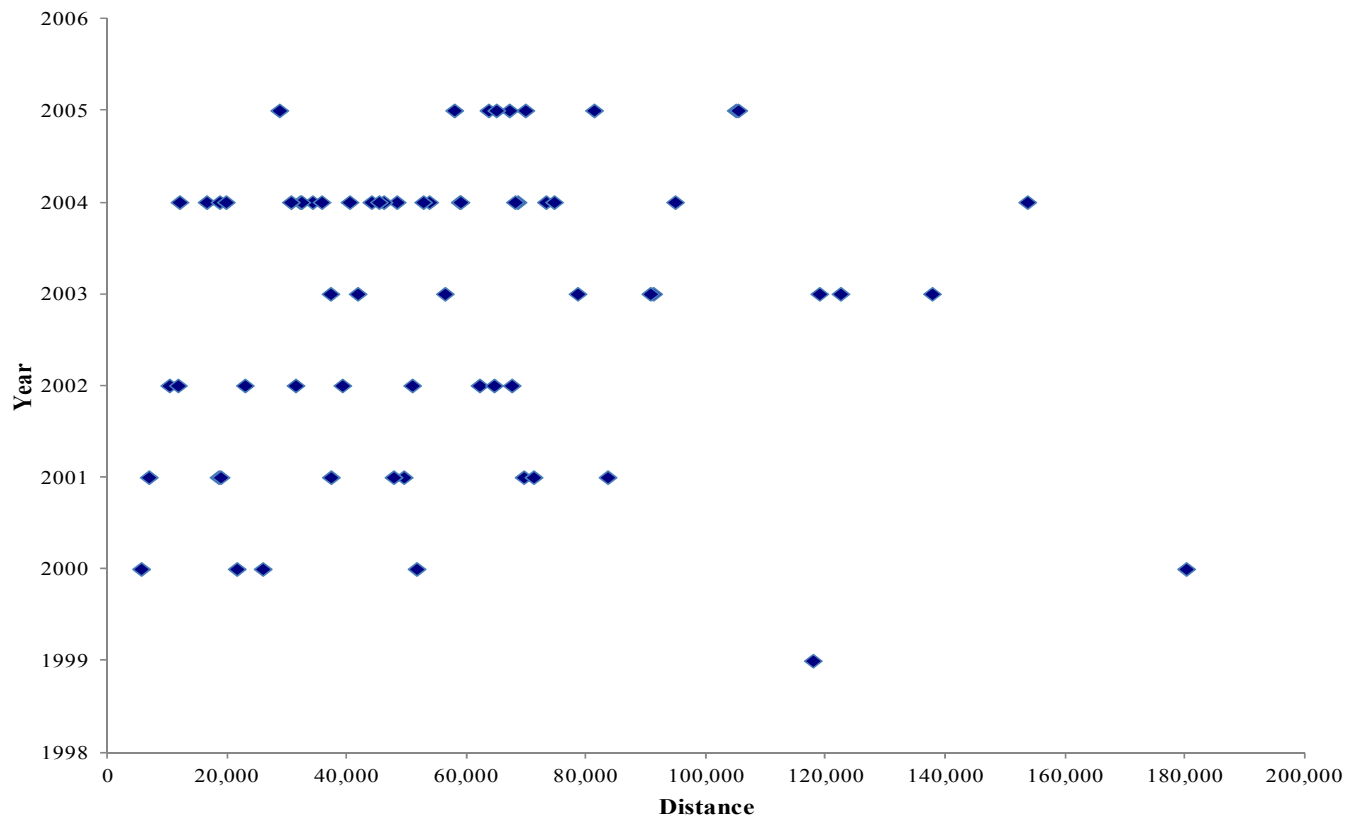

Another telling way to look at the changes over time is to fill in the blanks in between the two sides of the first map presented above. Here I present side-by-side maps depicting the price per lot sq $\mathrm{ft}$ by zip code from 1998 to 2007. From this perspective it appears that the high prices start on the upper laterals of the county and spread towards the middle and lower parts of the county.

This last set of maps may be the cleanest showing of some kind of pattern present in the behavior of the bubble. 
Figure III-6 - Price per Lot Sq Ft by Zip Code 1998 - 2007
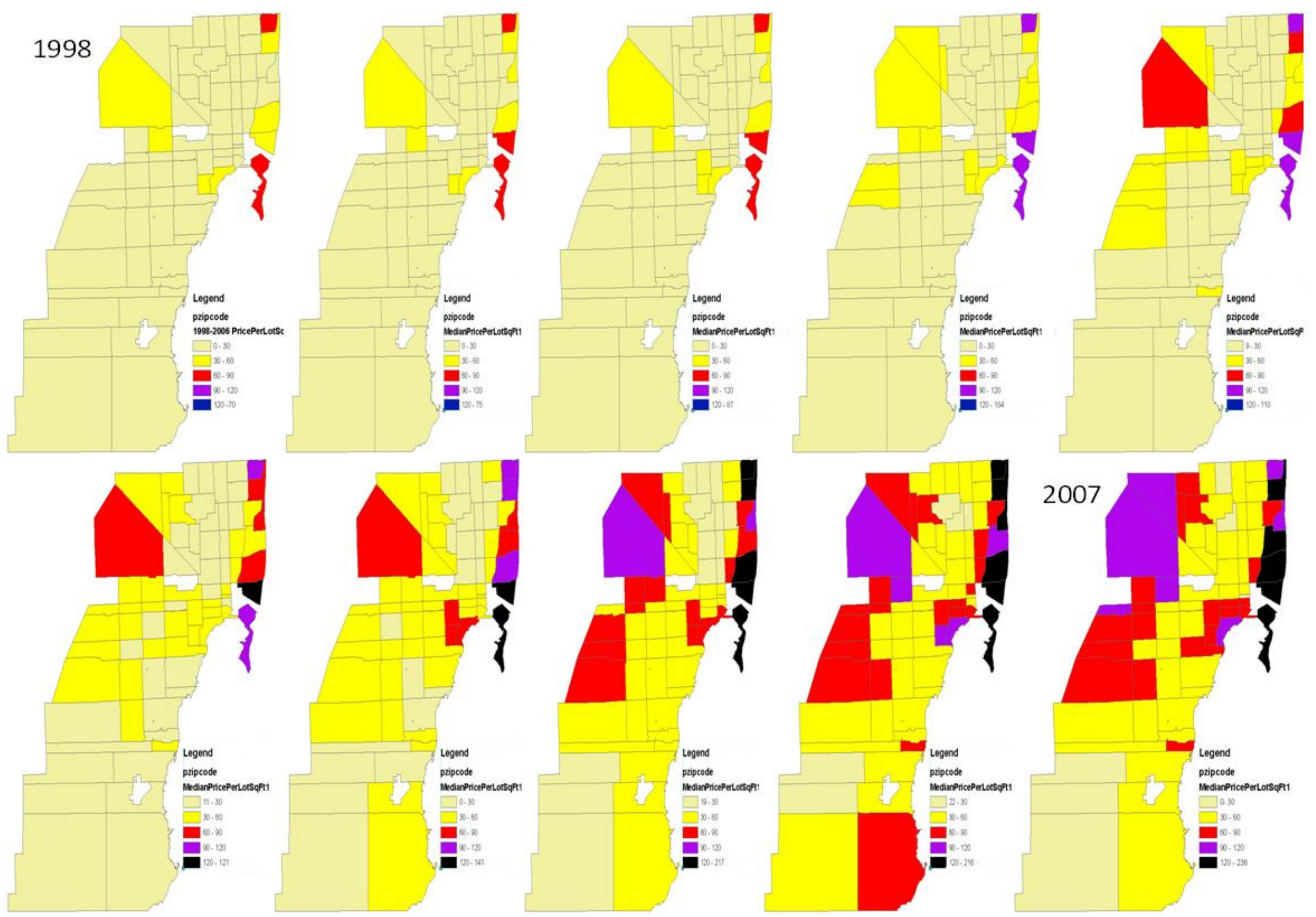
In this first look at the bubble data I have analyzed the situation from several perspectives; next I recount the findings that were made, adding in parenthesis a reference whether they support(+)or contradict(-) previous studies' findings; at the same time an asterisk is added to those observations that are not conclusive:

- Prices went up faster every year from 1999 to 2005 and then slowed down somewhat in 2006.

- No substantial changes in the rank order of the different zip code areas were observed. (+Rohener +Rowendal)

- Both the lowest and highest median price went up by a factor of three, from 7 to 22 on the low side and from 70 to 216 on the high side. (-Rohener)

- The median price in the most expensive area was ten times the median price in the cheapest area; this relation was present both at the beginning of the bubble and at its peak. (-Rohener)

- Most of the county in 1998 had median prices below $\$ 30$ Per Lot Sq Ft, while the opposite was true in 2006.

- The priciest areas in terms of dollars per Lot Sq Ft in 1998 continued to hold this status in 2006 .

- It appears that areas neighboring the 1998 higher priced areas became relatively more expensive than other areas during the bubble. (+Anglin)*

- Initially high priced areas held the top spots in terms of increase in absolute values during the whole bubble period. 
- In terms of percentage increase, the highest increases took place in initially really low priced areas.

- It appears that the closer an area is to the coast, the higher its percentage increase is. $(+$ Anglin)*

- The bubble impacted all areas; even the area with the smallest price increase more than doubled (117\% increase) in price in the eight-year period.

- The strongest year in terms of price increases was 2005, six years after the start of the bubble and two years before the burst.

- The number of areas that show decreases in their prices goes down every year, while price increases are more common and stronger as the bubble period transcribes.

- I find weak evidence of the bubble starting around the CBD and spreading outwards. (+Shimizu)*

- It appears more likely that the high prices start on the upper laterals of the county and spread towards the middle and lower parts of the county. *

Keeping in mind these findings I will take my analysis of the Miami-Dade county real estate bubble one step further in the next section by modeling the Bubble.

\section{Modeling the Bubble}

Rohener (1999) proposed an interesting economic model for analyzing spatial patterns of a real estate bubble. In his study he applied the model to the Paris bubble 
episode of 1984-1993. The proposed model provides as an output a classification of areas in the city in terms of Inelasticity of Supply/Demand, Speculative intensity and Delay in terms of the occurrence of the bubble.

The model is on the basis of a heterogeneous agent setting with two different groups of actors participating: residents who are out to sell their homes and/or buy houses to live in, and investors/speculators who buy and sell property to make money.

Residents exhibit a standard net supply function, on the basis of them selling and buying, moving, upsizing, downsizing etc.

$$
s_{t}^{(1)}=S_{t}^{(1)}-D_{t}^{(1)}=-c_{1}+\gamma_{1} p_{t}^{\prime}
$$

As for investors, the assumption is that they will withhold and buy additional properties as long as prices continue to increase. Once prices reach a plateau, their propensity to sell is assumed to be in direct relation to the level of the plateau.

$$
s_{t}^{(2)}=S_{t}^{(2)}-D_{t}^{(2)}=-c_{2}+\gamma_{2} p_{t}^{\prime}-g_{2}\left(p_{t-1}^{\prime}-p_{t-2}^{\prime}\right) \quad g, h>0
$$

Setting the proportion of speculators at $\mathrm{k}$, the equilibrium condition for which Rohener seeks a solution is

$$
s_{t}=(1-k) s_{t}^{(1)}+k s_{t}^{(2)}=0 \quad 0<k<1
$$

Combining the equations above, solving the resulting second order equation and taking into consideration the appropriate stability conditions Rohener shows that the solution takes the form: 
$p_{t}=c^{p_{t}^{\prime}}, \quad p_{t}^{\prime}=a(k)^{t / 2} \sin (\omega t-\varphi)+d(k), \quad \omega=\arccos (\sqrt{a(k)} / 2)$

This solution contains three parameters that Rohener estimates empirically for Paris 1984-1993 and I will estimate for Miami 1999-2007.

The three parameters are $c, a(k)$ and $\varphi$.

$c$ gives a sense of the elasticity of supply/demand in the area, more specifically $\ln (c)$ is inversely related to the elasticity of supply/demand of the residents.

$a(k)$ is related to the proportion of speculators, as $k$ goes from 0 to $1, a(k)$ goes from 0 to $a$.

$\varphi$ can be interpreted as a timing indicator, with smaller values indicating that the area considered began its rapid price appreciation earlier than larger $\varphi$ value areas.

By estimating these three parameters for the different areas of the city I can rank the areas by level of inelasticity of supply, proportion of speculators and timing of the start of the bubble.

What did Rohener find for the Paris 1984-1993 bubble period? 
For the empirical analysis section of his paper, Rohener relies on a dataset that is composed of semiannual/quarterly average transaction prices per square meter for apartments that have been sold at least once before for each of twenty districts within Paris intra-muros.

During Paris's real estate bubble, Rohener notes, the citywide average price increased in real terms from beginning to peak by roughly $100 \%$.

Rohener finds that the price patterns between the different districts were very similar before the bubble and during the peak, but finds that "the price gap between the most expensive districts and the cheapest districts was substantially amplified". For one pair example the price ratio increased from 1.68 to 2.33 .

Rohener finds that the speculative effect predominates in the best areas (with the highest priced real-estate), while the inelasticity effect is stronger in the lower priced areas of Paris.

Besides finding that the "best" districts are the most speculative, Rohener finds, on the basis of his results for the delay parameter $\varphi$, that the bubble started in the wealthy south-west districts and then spread north and eastward to the medium priced districts and finally reached the cheapest districts. He actually gets a strong negative correlation between delay and initial average price.

Rohener shows a subset of districts that suggest that individual districts also peaked first on the western side of Paris and followed in an easterly wave. While the peak prices were higher in the western districts than in the eastern ones.

Lastly Rohener gets an inverse relation between speculative intensity $(a(k))$ and inelasticity of demand (c). 
Results for the Miami Case:

Prior to presenting my empirical results I will go over some relevant geographic features of the Miami-Dade County area, mention a few points about the data employed and explain the methodology followed.

According to Rohener, in Paris the "best" or higher priced areas are located in the southwest, the medium areas are towards the center and the lower priced areas are located towards the northeast. This pattern should be noted as several of the results for the Paris bubble are related to this layout.

In Miami-Dade County, the higher priced areas are located in the east, near the ocean, in the inner central area and in the central west area. The lower priced areas are mainly the north central and the southwest portions of the County.

The data used here to run the model is the same set as the one used in the "First look at the Patterns" section above. The data differs from that used by Rohener in that I consider Single Family homes instead of apartments, I do not filter out homes that have never been sold before, the time interval is a year instead of quarters, the areas are zip code areas as opposed to districts and I use the Lot square feet instead of the buildings' square meters as the standardizing procedure.

From all the initial data points I ended up with a median sales price per lot sq feet for the years 1998 to 2008 for 66 eligible Zip code areas.

Then the three parameters of the model were estimated for each of the 66 zip code areas by the method of non-linear least squares (Generalized Reduced Gradiant (GRG2) nonlinear optimization method). 
I end up with a value of $c, a(k)$ and $\varphi$ for each of the 66 zip code areas.

Table III-1 in the appendix to this chapter presents the three main parameters of the model, $c, a(k)$ and $\varphi$ along with other key numbers: the initial (1998) price, the distance from the center of the downtown zip code area (33130), the highest price and the year it took place and the amplification factor between the initial price and the peak price. Standard errors for the parameters are shown in parenthesis.

According to the results shown in the table, the zip codes that experienced the bubble first were $33140,33139,33149$ and 33136 , and the areas that were last affected by the bubble were 33034,33184 and 33185 .

The most speculative areas are 33149, 33140, 33139 and 33167 while the least speculative areas are 33160, 33134, 33166 and 33135.

The areas where the inelasticity of supply is largest are 33141, 33160 and 33138 while the inelasticity effect is lowest in 33149, 33140 and 33039.

The amplification factor of the price between beginning and peak was greater in zip code areas 33170,33136 and 33140 while it was lowest in 33177,33196 and 33158 .

Countywide the increase in sales prices between 1998 and 2007 was in the order of $175 \%$ in nominal terms and $116 \%$ in real terms making it more pronounced than the Paris episode. 
Figure III-7 -Median Real Price

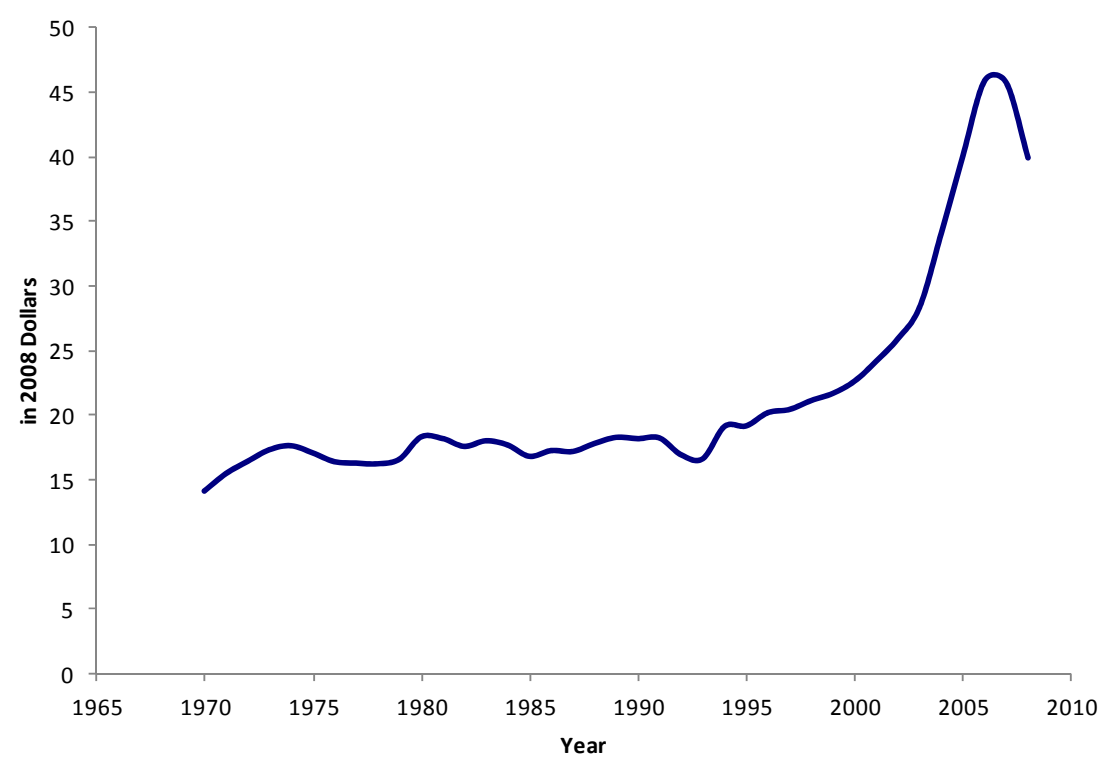

Consistent with Rohener's finding, the best areas are the most speculative. The data in the table for initial price is charted against the speculative parameter $a(k)$ to illustrate the point.

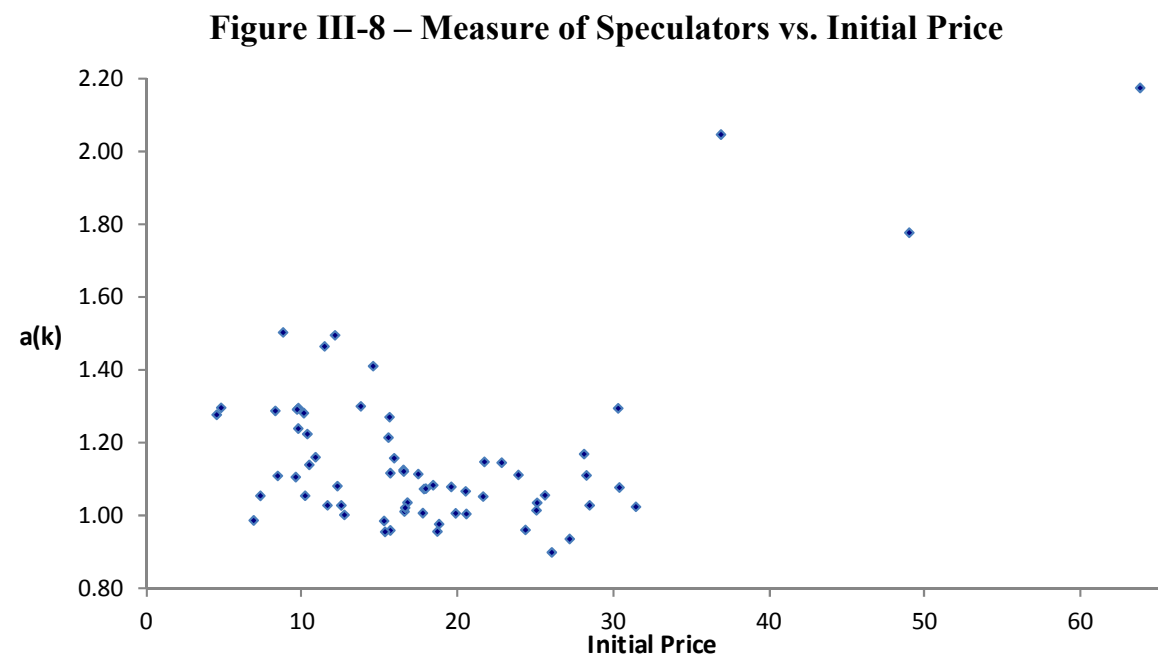

Charting initial Price against the Inelasticity parameter, I find that the Inelasticity effect predominates in the lower priced areas, also consistent with Rohener's findings. 
Figure III-9 - Measure of Elasticity vs. Initial Price

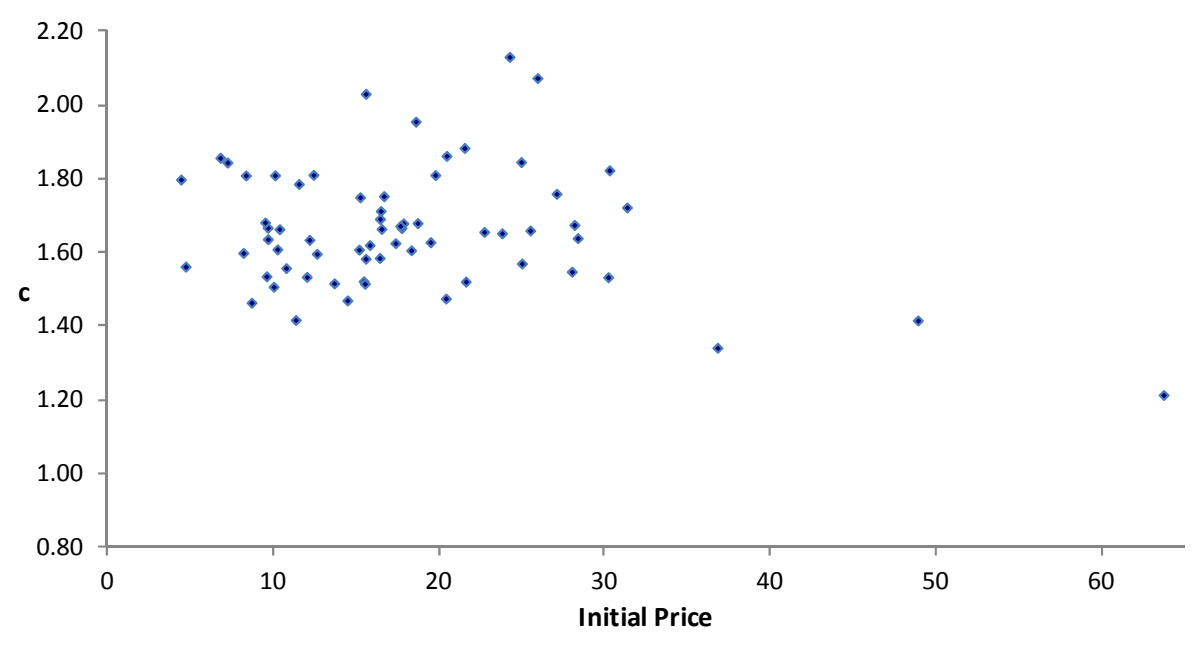

Another result in which I coincide with Rohener is in the relation between the Initial price and the start of the bubble measured through the delay parameter $\varphi$. As with the prior two relations I chart delay parameter $\varphi$ against the initial price showing a negative relation, a relationship that is similar to the analysis presented in the prior section where the year the price increase first hit $20 \%$ and the distance from the CBD is presented with an apparent positive relation.

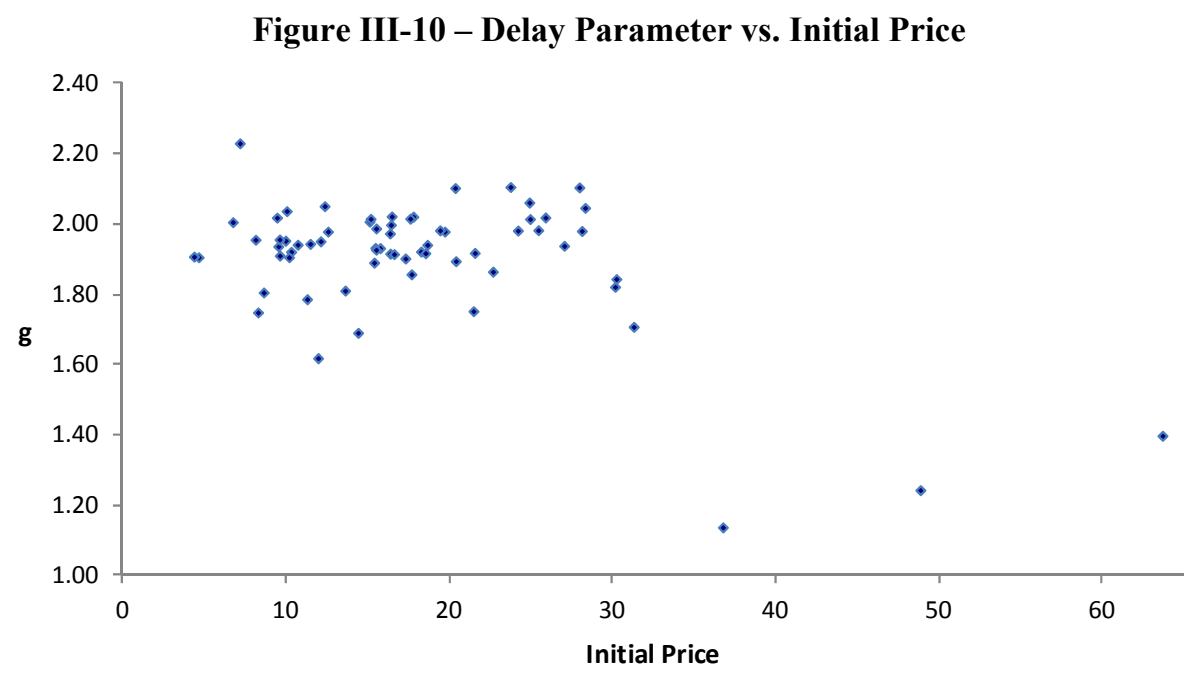


The year in which the area peaks does not show a strong correlation with the eastwest ordering of the areas. The figure below charts the peak year against the distance of the area to the Central Business District (CBD).

Figure III-11 - Peak Year vs. Distance to CBD

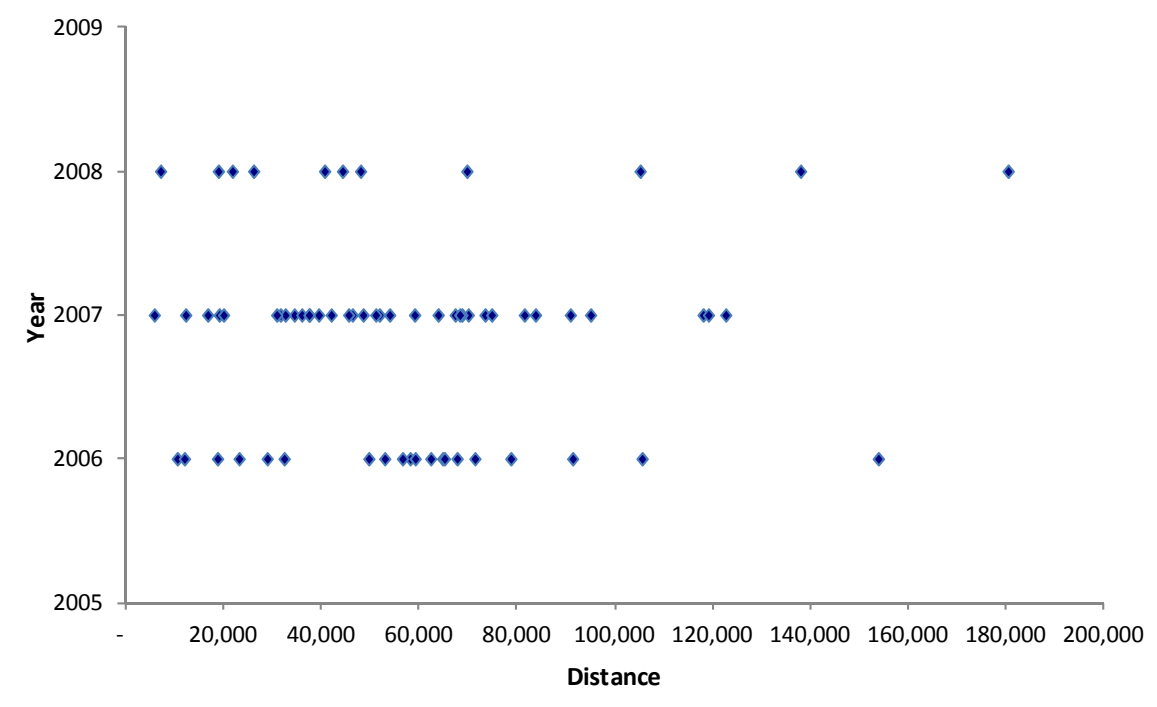

On the other hand, the peak price does present a negative correlation with the distance from the coast as well as the distance of the areas to the central business district. See Figure.

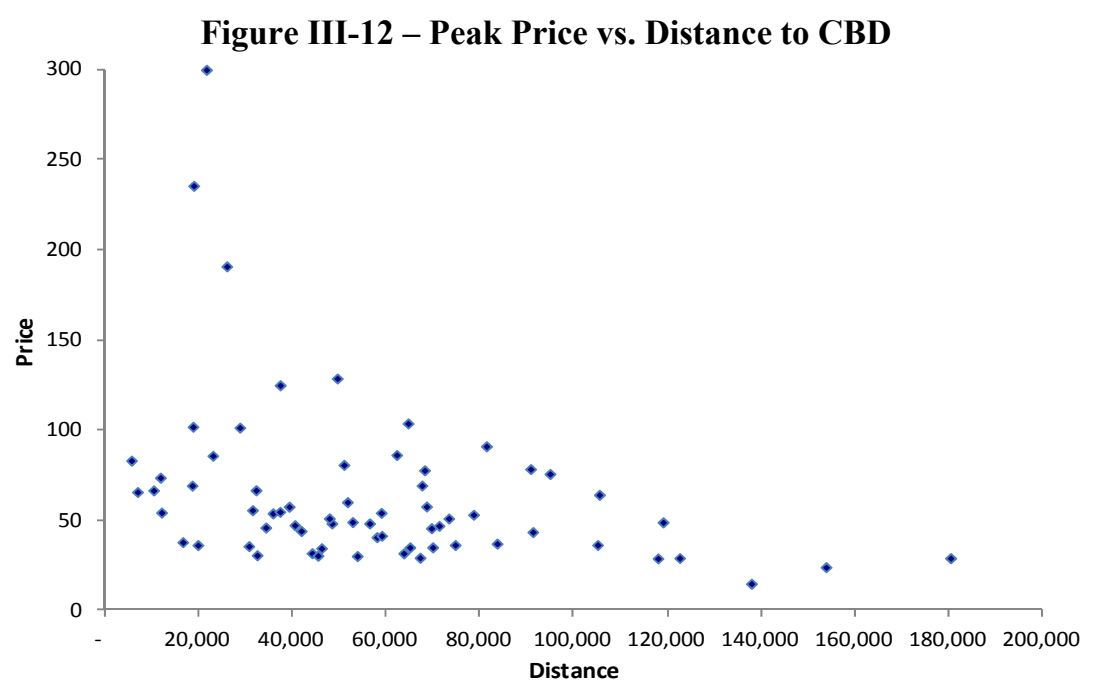


For the Miami case, the negative relationship between the inelasticity of demand and the speculative trading found by Rohener also holds.

Figure III-13 - Speculation Intensity vs. Inelasticity of Supply

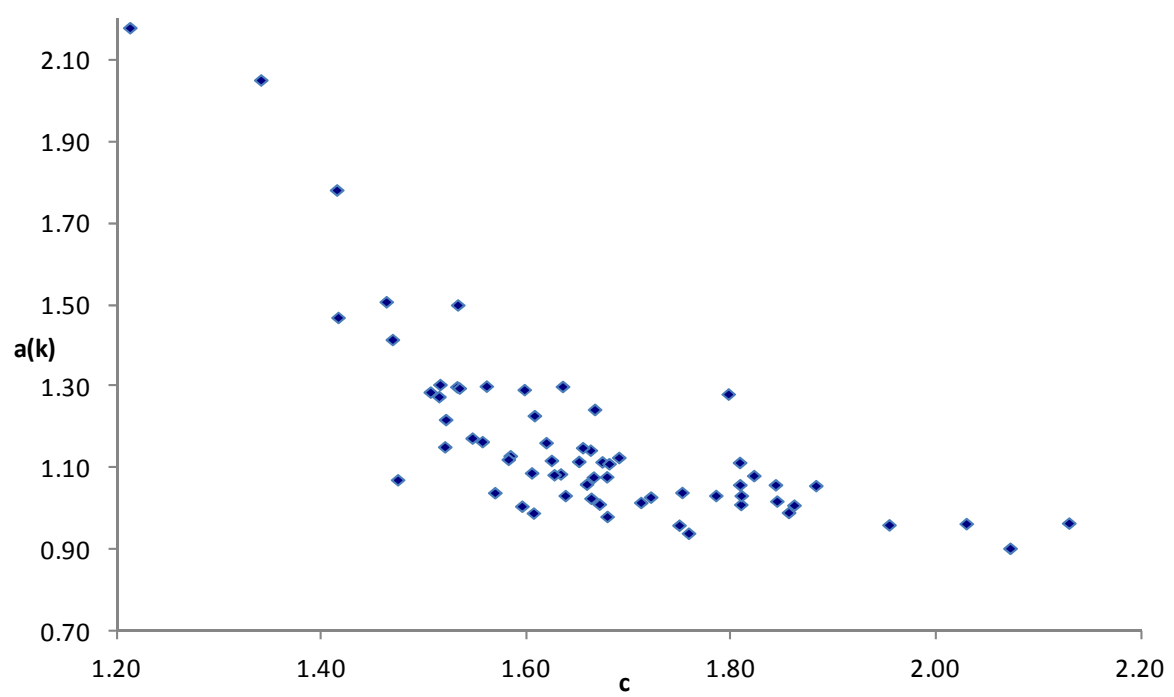

Examining the results of the model in novel ways:

So the results found in Paris by Rohener hold pretty well for the Miami-Dade case. In the following segment I will test the model further in ways in which Rohener did not or could not given the limitations of his dataset.

Given the nature of my dataset I can test the results of the model in terms of level of speculative intensity by area.

Within my database I have the capacity to know whether a property has changed hands multiple times in a given period of time or not, whether a property has homestead 
exemption or not and whether the mailing address for the owner is the same as for the property or not.

All of these measures seem like good proxies to the question of whether a buyer is a prospective homeowner or an investor. Of course a buyer can be a prospective homeowner who must resell quickly because of any number of circumstances. At the same time the fact that a home does not have a homestead exemption, nor a match between the owner's mailing address and the property's address, does not necessarily mean that the owner is an investor given that it could be someone's second home or that the owner has just not taken the time to apply for homestead exemption.

Nonetheless I presume that area wide there is a good correspondence between sales that end up in subsequent sales, sales of homes that end up non homesteaded, sales of homes for which the new owners mailing address differs from the property's address and the proportion of house buying done by investors.

To construct the measures used in this section I extract from the PTX file all the single-family properties that were sold between 2001 and 2007 and use this count as my base. From this initial base list I count the number of properties that did not have homestead exemption in 2007 and calculate the ratio of the two for each zip code area.

I repeat the same procedure with the count of properties from the base list that were sold more than once and with the count from the base list that by 2007 did not have a matching zip code between the owner's mailing address and the property's address.

\section{As illustrated next:}

A: Number of Single Family Properties sold between 2001 and 2007

B: Number of Single Family Properties sold between 2001 and 2007 with no homestead exemption in 2007 
C: Number of Single Family Properties sold more than once between 2001 and 2007

D: Number of Single Family Properties sold between 2001 and 2007 with different Owners mailing address and properties address.

Proportion of Non-Homesteaded properties $=\mathrm{B} / \mathrm{A}$

Proportion resold $=\mathrm{C} / \mathrm{A}$

Proportion of properties with different owners address $=\mathrm{D} / \mathrm{A}$

Results for all zip codes are presented in Table III-1.

The expected outcome here is to have the three values rank the zip code areas in a similar way and closely match the rank obtained when ordering them by $a(k)$. But as it turns out the expected relation does not seem to be there for all four variables.

The Proportion of non-homesteaded properties and the Proportion of properties with different owners address do hold a close relation, but the Proportion Resold does not coincide with the other two measures, nor the $a(k)$ values.

Figure III-14 - Relation between Proxies of Speculative Intensity

Portion Non Homesteaded in 2007

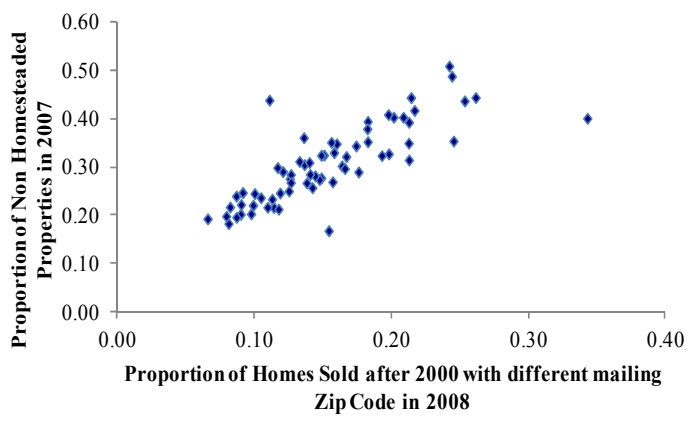

Portion Non Homesteaded in 2007

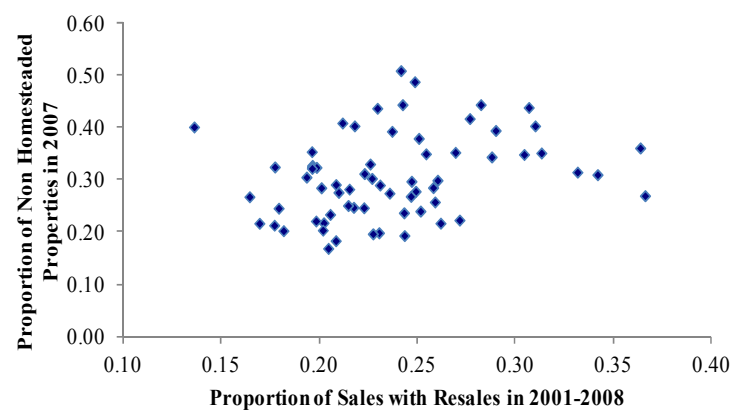

When I plot the $a(k)$ values against the Proportion of non-homesteaded properties and against the Proportion of properties with different owner address I do not get a strong 
relation but the overall correspondence is positive, suggesting that the greater the number of non homesteaded properties the higher the value of the speculative intensity parameter.

Figure III-15 - Speculative Intensity: Estimates vs. Proxies
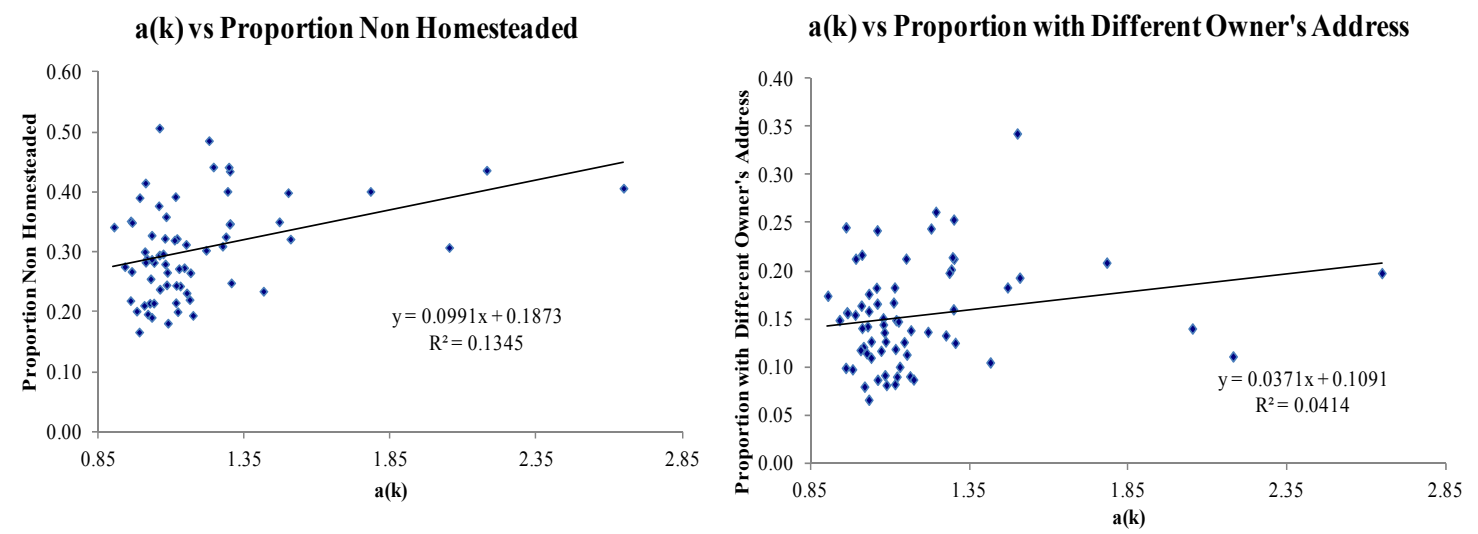

Next I concentrate on the gap between high priced and low priced areas during the bubble. Previous studies (Rohener, 1999, Shimizu and Watanabe, 2010) found that the gap increased between the beginning of the bubble and the peak. In my initial examination of the Miami-Dade episode I find the opposite. The ratio of the price in the highest area to the lowest area at the beginning of the period was 10.71 while at the peak it was 9.82 .

To corroborate the initial finding I develop a metric of home value differentials that takes more information into consideration and compute the results for all the years in the period for both Miami-Dade and Paris.

Following the literature on measures of statistical dispersion I compute a "Lorenz Curve" and "Gini Coefficient" for home price areas. I will refer to them here as Home Value by Area (HVA) Lorenz Curve and Gini Coefficient. 
The HVA Lorenz Curve provides a graphical representation of the inequality in home values across areas. To obtain this representation I first compute the Median Price for each area and order the areas from lowest to highest.

$$
P_{j}=P_{1}, P_{2}, P_{3}, \ldots P_{J}
$$

With the prices of all areas ordered from lowest to highest I construct the HVA Lorenz Curve. On the horizontal axis is the share of the cumulative value of $j$ while the vertical axis shows the cumulative share of sum of median values. On this chart the $45^{\circ}$ line represents perfect equality: all areas have the same median value. And the further separated it is from this line the more unequal are the median values of the areas within the city.

The following figure shows the Home Value by Area Lorenz Curve for MiamiDade County in 1999.

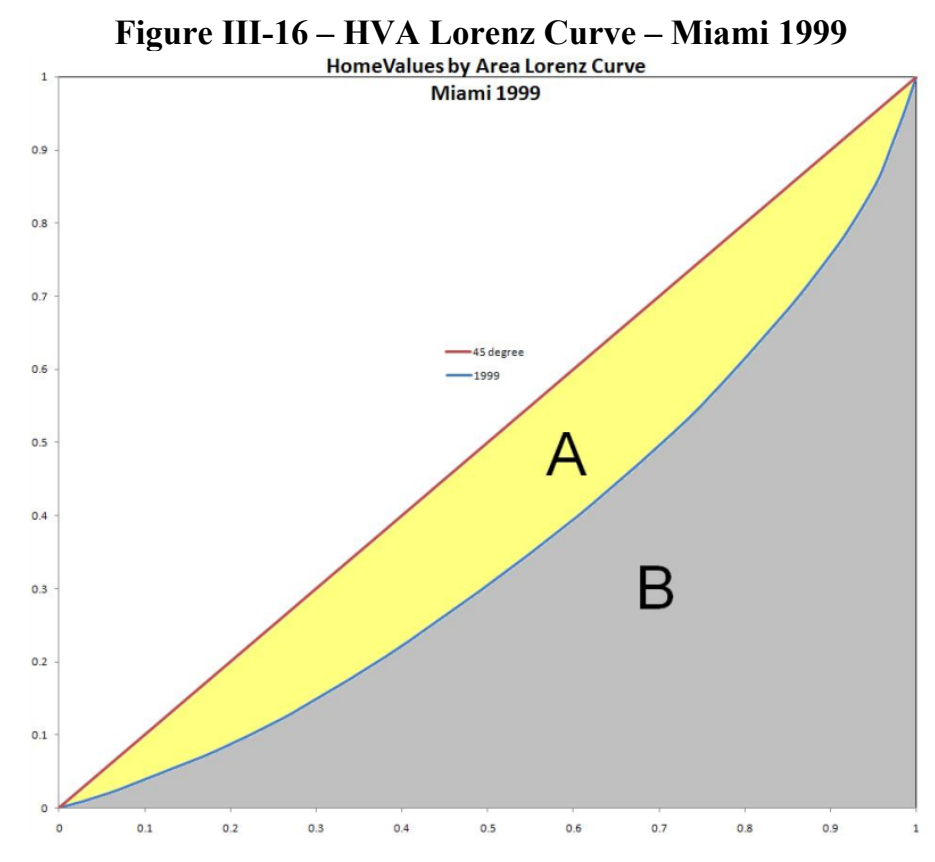


The HVA Gini coefficient represents the ratio of the area between the $45^{\circ}$ line and the HVA Lorenz Curve (A in the Figure) and the area between the $45^{\circ}$ line and the axis's ( $\mathrm{A}+\mathrm{B}$ in the Figure). Possible values range from 0 for perfect equality to 1 for most unequal.

I compute this Gini Coefficient $G$ :

$$
G=1-\frac{\sum_{i=1}^{N} S_{i}}{(J+1) / 2}
$$

Where $\mathrm{J}$ is the number of areas and,

$$
S_{i}=\frac{\sum_{j=0}^{i} P_{j}}{\sum_{j=0}^{J} P_{j}}
$$

Where $P_{j}$ is the Median Price for area $j$ ordered from lowest to highest by $j$. The Coefficient associated with the Miami-Dade 1999 case depicted above comes out to 0.289

The following figure shows the Lorenz Curve for Miami and Paris at the beginning of the period, at the height of inequality and at the peak of the bubble.

Figure III-17 - HVA Lorenz Curve - Paris 1984-1991 and Miami 1999-2006
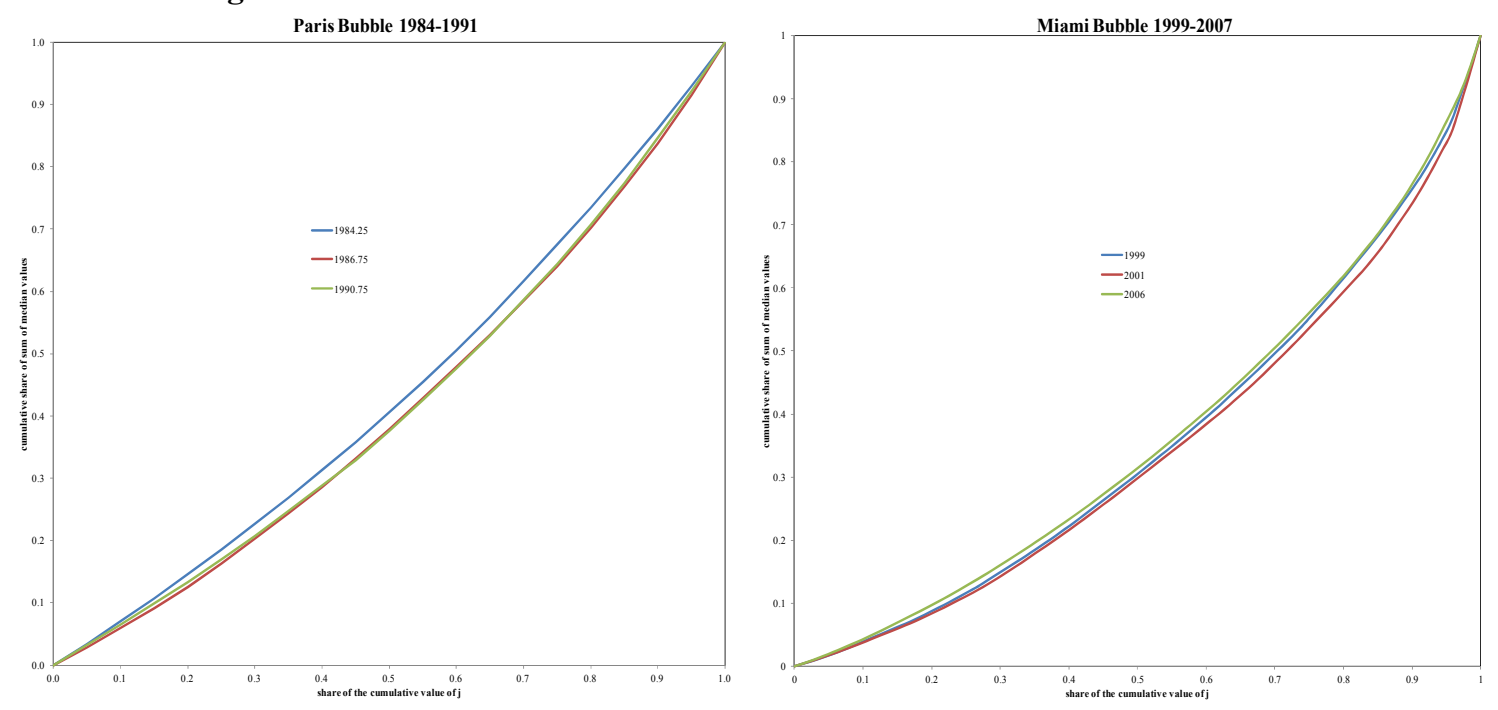
The first result to point out from the Curves above is that in the case of Paris the Peak year (1990) displayed a higher degree of inequality than the initial year (1984), while for Miami the Peak year (2006) displayed a lower degree of inequality than the initial year (1999). This finding corroborates the initial observation made on the basis of the ratio of highest to lowest value area. And in this sense the outcome of both episodes are opposites.

After computing the HVA Gini coefficient for all years in both cases I also find a few similarities:

In both cases inequality starts low, goes up for 2 years and then goes down. It goes down much more in the case of Miami than in the case of Paris. The evolution of the HVA Gini Coefficient for both areas can be appreciated in the following figure.

\section{Figure III-18 - HVA Gini Coefficient - Paris 1984-1991 and Miami 1998-2006}
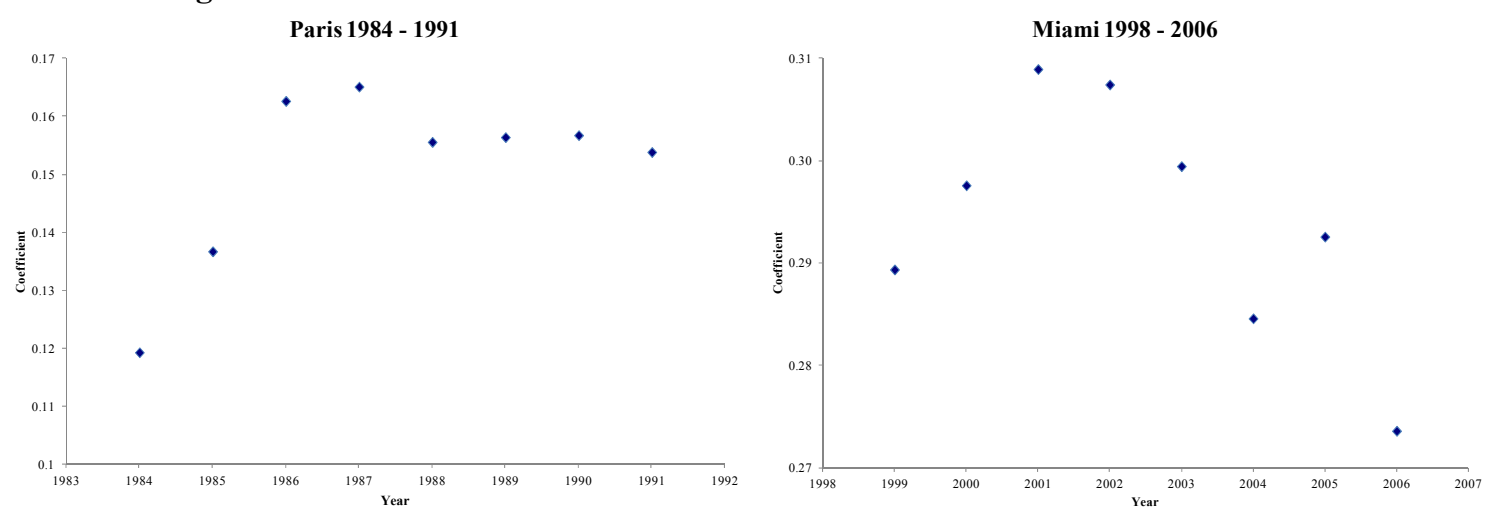

The fact that at the beginning of the period of rapid price appreciation the HVA Gini Coefficient increases indicates that the price appreciation is initially tilted towards the higher priced areas. 


\section{Conclusions}

Despite the lack of previous studies done on the subject tackled in this chapter and the complications this entails I was able to extract and present a few interesting notions related to the spatial aspects of the real estate bubble I set out to explore. In doing so I viewed the data from several angles and presented it in multiple forms, and I applied the only pertinent economic model I could find and tested it in novel ways.

As is usually the case, I did not find an overarching and clear-cut pattern to the bubble in question, but I was able to identify specific aspects that are worthwhile recapping in this section.

The magnitude of the Miami-Dade County 1999-2006 Real-estate bubble was considerable, reaching all areas of the county and increasing home sales prices by 163 percent countywide and by between 117 and 216 percent within the individual zip code areas. Now in 2012 I can report that the bubble did not simply deflate but instead popped bringing with it a slew of unsavory consequences. Just to give an example of said outcomes, the Miami-Dade County Clerk of Courts in 2008 received 56,656 foreclosure fillings, more than the combined total for 2002 through 2006. The number later increased to 63,882 for 2009 .

I found the rate of increase in sales prices to speed up as the bubble progressed, and the areas with year over year price declines to shrink in numbers year after year although never disappearing. The strongest year in terms of price increases was 2005, six

years after the start of the bubble and two years before the burst. The price differential between the lowest priced area and the highest was ten times at the beginning of the bubble and stayed this way during the peak year. 
The order of the areas in terms of sales price did not change in any significant way because of the bubble.

From my initial observations, it appears more likely that the high prices started on the upper laterals of the county and spread towards the middle and lower parts of the county.

I found many similarities between the Miami-Dade 99-06 and Paris 84-93 bubbles when looked through the lens of Bertrand Rohener's 1999 model. In both cases the price of real estate more than doubled, and the best areas turned out to be the most speculative while an Inelasticity Effect predominated in the lower priced areas.

The two episodes also coincide in that, on the basis of the output of the model and the results of the Home Value Area Gini Coefficients, the bubble began in the higher priced areas and spread to the other areas in a descending price order.

Another similarity is that the level of speculative intensity and inelasticity effect are negatively correlated in both cases.

A key difference between what was found in the Paris case and the Miami-Dade case was a wider gap between high-priced areas and low-priced areas in the peak year.

In the last section I compared the output of the model in terms of speculative intensity with proxy measures for proportion of investors and found some support for the outcome of the model.

It seems clear that the behavior of real estate bubbles in terms of spatial diffusion is not random, but much work remains to be done in order to fully understand the workings of such occurrences. The bubble episode that is described in this study was repeated in countless other areas around the country and throughout the world, situation 
that provides a natural experiment wealth of information that can be taken advantage in

order to further study and understand this line of research.

\section{Appendix}

Table III-1 - Regression Results and Relevant Characteristics of Each Zip Code

\begin{tabular}{|c|c|c|c|c|c|c|c|c|c|c|c|}
\hline $\begin{array}{l}\text { ZIP } \\
\text { Code }\end{array}$ & $\begin{array}{l}P \text { in } \\
1998\end{array}$ & $\begin{array}{c}\text { Distance } \\
\text { From } \\
33130\end{array}$ & c & $a(k)$ & g & $\begin{array}{l}\text { Peak } \\
\text { Price }\end{array}$ & $\begin{array}{l}\text { Peak } \\
\text { Year }\end{array}$ & $\begin{array}{l}\text { Am- } \\
\text { plific } \\
\text { ation }\end{array}$ & $\begin{array}{l}\text { Prop } \\
\text { diff } \\
\text { Zip }\end{array}$ & $\begin{array}{c}\text { Resaled } \\
\text { Prop }\end{array}$ & $\begin{array}{c}\text { Portion } \\
\text { Non } \\
\text { Homeste } \\
\text { aded in07 }\end{array}$ \\
\hline 33010 & 15 & 34,261 & $1.52(0.01)$ & $1.22(0.07)$ & $1.89(0.13)$ & 46 & 2007 & 3.0 & 0.14 & 0.19 & 0.30 \\
\hline 3012 & 16 & 48,347 & $1.58(0.01)$ & $.13(0.09)$ & $1.97(0.16)$ & 49 & 2007 & 3.0 & 0.10 & 0.18 & 0.24 \\
\hline 3013 & 16 & 40,460 & $.51(0.01)$ & $27(0.07)$ & $.93(0.13)$ & 48 & 2008 & 3.1 & 0.13 & 0.22 & 0.31 \\
\hline 3014 & 18 & 58,877 & $.61(0.02)$ & $.09(0.15)$ & $1.92(0.27)$ & 54 & 2007 & 3.0 & 0.08 & 0.21 & 0.18 \\
\hline 3015 & 16 & 73,293 & 1) & $16(0.08)$ & $1.93(0.14)$ & 51 & 2007 & 3.2 & 0.09 & 0.27 & 0.22 \\
\hline 33016 & 25 & 62,187 & $.85(0.01)$ & $.02(0.05)$ & $2.06(0.09)$ & 87 & 2006 & 3.5 & 0.08 & 0.23 & 0.20 \\
\hline 33018 & 28 & 81,331 & $1.67(0.01)$ & $1.11(0.08)$ & $1.98(0.15)$ & 91 & 2007 & 3.2 & 0.08 & 0.20 & 0.22 \\
\hline 33030 & 7 & 153,760 & $.86(0.06)$ & $.99(0.15)$ & $2.01(0.26)$ & 24 & 2006 & 3.6 & 0.21 & 0.24 & 0.39 \\
\hline 33031 & 5 & 137,839 & $1.56(0.02)$ & $1.30(0.10)$ & $1.91(0.17)$ & 15 & 2008 & 3.2 & 0.21 & 0.25 & 0.35 \\
\hline 33032 & 11 & 105,030 & 01) & $.47(0.08)$ & 1.79 & 37 & 2008 & 3.2 & 0.18 & 0.27 & 0.35 \\
\hline 33033 & 8 & 122,532 & $1.81(0.09)$ & $1.11(0.29)$ & $1.75(0.44)$ & 29 & 2007 & 3.5 & 0.18 & 0.29 & 0.39 \\
\hline 33034 & 7 & 180,319 & 1.84 & 1.06( & 2.23 & 29 & 2008 & 4.1 & 0.24 & 0.24 & 0.51 \\
\hline 33054 & 8 & 53,768 & $1.60(0.03)$ & $1.29(0.11)$ & $1.96(0.20)$ & 30 & 2007 & 3.7 & 0.20 & 0.22 & 0.40 \\
\hline 33055 & 10 & 69,851 & 4) & 16) & 28) & 35 & 2007 & 3.4 & 0.13 & 0.21 & 0.27 \\
\hline 33056 & 10 & 67,162 & 01) & $.29(0.09)$ & $1.95(0.16)$ & 30 & 2007 & 3.0 & 0.2 & 0.20 & 0.33 \\
\hline 33125 & 18 & 12,032 & & & & 55 & 07 & 3.1 & & 20 & 0.32 \\
\hline 33126 & 17 & 31,427 & 1.621 & $12(0.09)$ & $1.90(0.15)$ & 56 & 2007 & 3.2 & 0. & 0.18 & 0.32 \\
\hline 33127 & 10 & 16,561 & & 12) & 21) & 38 & 2007 & 4.0 & & 0.23 & 0.44 \\
\hline 33129 & 22 & 5,619 & 05) & $.06(0.19)$ & 1.75 & 83 & 2007 & 3.9 & 0. & 0.25 & 0.38 \\
\hline 33133 & 30 & 18,735 & & .07) & 1.82 & 102 & 2008 & 3.4 & 0 . & 0.30 & 0.35 \\
\hline 33134 & 27 & 22,964 & & 08) & 1.94 & 86 & 2006 & 3.2 & 0 . & 0.25 & 0.28 \\
\hline 3135 & 19 & 10,334 & & 15) & 4) & 67 & 2006 & 3.6 & & 20 & 0.35 \\
\hline 33136 & 12 & 6,901 & 3) & $.50(0.27)$ & 1.62( & 66 & 2008 & 5.5 & 0.34 & 0.14 & 0.40 \\
\hline 33137 & 20 & 18,562 & 02) & $.01(0.09)$ & $1.98(0.16)$ & 70 & 2006 & 3.5 & & 0.28 & 0.42 \\
\hline 33138 & 16 & 32,189 & 04) & $.96(0.11)$ & $1.99(0.20)$ & 67 & 2006 & 4.3 & 0.16 & 0.37 & 0.27 \\
\hline 33139 & 49 & 18,897 & & 29) & 1.24 & 236 & 2007 & 4.8 & & 0.31 & 0.40 \\
\hline 33140 & 37 & 25,943 & 3) & 2.05 & 4) & 191 & 2008 & 5.2 & 4 & 0.34 & 0.31 \\
\hline 33141 & 24 & 37,343 & & .961 & $1.98(0.74)$ & 125 & 2007 & 5.2 & & 0.31 & 0.35 \\
\hline 33142 & 10 & 19,792 & $1.61(0.03)$ & $1.23(0.16)$ & $1.91(0.27)$ & 37 & 2007 & 3.6 & 0.24 & 0.25 & 0.49 \\
\hline 33143 & 16 & 39,250 & & $1.13(0.08)$ & $1.92(0.14)$ & 58 & 2007 & 3.5 & & 0.24 & 0.27 \\
\hline 33144 & 18 & 35,791 & 01) & $.08(0.06)$ & $2.02(0.11)$ & 54 & 2007 & 3.0 & 0. & 0.22 & 0.28 \\
\hline 33145 & 20 & 11,774 & 4) & 14) & 3) & 74 & 2006 & 3.6 & 0 . & 0.23 & 0.30 \\
\hline 33146 & 31 & 28,725 & 3) & 21) & 32) & 102 & 2006 & 3.2 & 0.14 & 0.26 & 0.26 \\
\hline 33147 & 10 & 32,413 & $1.53(0.02)$ & $1.30(0.10)$ & $1.94(0.17)$ & 31 & 2007 & 3.2 & 0.21 & 0.24 & 0.44 \\
\hline 33149 & 64 & 21,608 & & T & 26) & 300 & 2008 & 4.7 & & 0.31 & 0.44 \\
\hline 33150 & 10 & 30,654 & $1.67(0.02)$ & $1.24(0.09)$ & $1.96(0.15)$ & 36 & 2007 & 3.7 & 0.26 & 0.28 & 0.44 \\
\hline 33154 & 30 & 49,513 & 3) & .16) & 1.84( & 129 & 2006 & 4.3 & 0.14 & 0.36 & 0.36 \\
\hline 33155 & 17 & 37,274 & $1.75(0.02)$ & $1.04(0.11)$ & $1.91(0.19)$ & 55 & 2007 & 3.3 & 0.13 & 0.20 & 0.28 \\
\hline 33156 & 14 & 47,813 & 01) & 12) & $1.69(0.20)$ & 51 & 2008 & 3.6 & 0. & 0.24 & 0.24 \\
\hline 33157 & 12 & 74,651 & $1.63(0.02)$ & $1.09(0.09)$ & $1.95(0.17)$ & 37 & 2007 & 3.0 & 0.13 & 0.25 & 0.27 \\
\hline 33158 & 15 & 57,957 & $1.61(0.01)$ & $0.99(0.07)$ & $2.01(0.13)$ & 41 & 2006 & 2.7 & 0.15 & 0.20 & 0.17 \\
\hline 33160 & 26 & 64,610 & $2.07(0.01)$ & $0.90(0.44)$ & $2.02(0.64)$ & 104 & 2006 & 4.0 & 0.17 & 0.29 & 0.34 \\
\hline
\end{tabular}


Table III- 1 (Continued)

\begin{tabular}{|c|c|c|c|c|c|c|c|c|c|c|c|}
\hline $\begin{array}{l}\text { ZIP } \\
\text { Code }\end{array}$ & $\begin{array}{l}\mathrm{P} \text { in } \\
1998\end{array}$ & $\begin{array}{c}\text { Distance } \\
\text { From } \\
33130\end{array}$ & C & $a(k)$ & $\mathrm{g}$ & $\begin{array}{l}\text { Peak } \\
\text { Price }\end{array}$ & $\begin{array}{l}\text { Peak } \\
\text { Year }\end{array}$ & $\begin{array}{l}\text { Am- } \\
\text { plific } \\
\text { ation }\end{array}$ & $\begin{array}{l}\text { Prop } \\
\text { diff } \\
\text { Zip }\end{array}$ & $\begin{array}{c}\text { Resaled } \\
\text { Prop }\end{array}$ & $\begin{array}{c}\text { Portion } \\
\text { Non } \\
\text { Homeste } \\
\text { aded in07 }\end{array}$ \\
\hline code & & & $c$ & $a(1)$ & 5 & & & & & & \\
\hline 3161 & 10 & 46,151 & $1.81(0.03)$ & $1.06(0.09)$ & $2.04(0.17)$ & 35 & 2007 & 3.5 & 0.17 & 0.25 & 0.30 \\
\hline 3162 & 12 & 58,994 & $1.81(0.02)$ & $1.03(0.08)$ & $2.05(0.14)$ & 42 & 2006 & 3.4 & 0.16 & 0.23 & 0.33 \\
\hline 33165 & 16 & 52,768 & $1.71(0.01)$ & $1.02(0.07)$ & $2.00(0.12)$ & 49 & 2006 & 3.0 & 0.12 & 0.21 & 0.29 \\
\hline 33166 & 15 & 41,813 & $1.75(0.01)$ & $0.96(0.05)$ & $2.01(0.09)$ & 44 & 2007 & 2.9 & 0.10 & 0.20 & 0.22 \\
\hline 33167 & 9 & 44,122 & $1.46(0.01)$ & $1.51(0.08)$ & $1.80(0.14)$ & 32 & 2008 & 3.7 & 0.19 & 0.20 & 0.32 \\
\hline 33168 & 9 & 45,379 & $1.68(0.03)$ & $1.11(0.13)$ & $2.02(0.23)$ & 31 & 2007 & 3.2 & 0.17 & 0.20 & 0.32 \\
\hline 33169 & 11 & 63,691 & $1.56(0.02)$ & $1.16(0.14)$ & $1.94(0.25)$ & 32 & 2007 & 3.0 & 0.14 & 0.16 & 0.27 \\
\hline 33170 & 4 & 117,914 & $1.80(0.14)$ & 1.28 (1.09) & $1.91(1.42)$ & 29 & 2007 & 6.6 & 0.20 & 0.21 & 0.41 \\
\hline 33173 & 17 & 56,397 & $1.66(0.01)$ & $1.03(0.07)$ & $2.02(0.12)$ & 49 & 2006 & 2.9 & 0.11 & 0.17 & 0.22 \\
\hline 33174 & 22 & 51,671 & $1.52(0.01)$ & $1.15(0.09)$ & 17) & 0 & 007 & 2.8 & & 0.21 & 0.23 \\
\hline 33175 & 19 & 68,547 & $1.63(0.02)$ & $1.08(0.10)$ & $1.98(0.17)$ & 58 & 2007 & 3.0 & 0.09 & 0.22 & 0.25 \\
\hline 33176 & 13 & 64,990 & $1.60(0.01)$ & $1.01(0.07)$ & $1.98(0.13)$ & 35 & 2006 & 2.8 & 0.12 & 0.18 & 0.21 \\
\hline 33177 & 20 & 91,218 & $1.47(0.01)$ & $1.07(0.06)$ & $2.10(0.12)$ & 44 & 2006 & 2.1 & 0.12 & 0.26 & 0.30 \\
\hline 33179 & 14 & 69,576 & $1.52(0.02)$ & $1.30(0.12)$ & $1.81(0.20)$ & 46 & 2008 & 3.4 & 0.12 & 0.21 & 0.25 \\
\hline 33181 & 23 & 50,927 & $1.66(0.01)$ & $1.15(0.06)$ & $1.86(0.11)$ & 81 & 2007 & 3.6 & 0.21 & 0.33 & 0.31 \\
\hline 33182 & 28 & 68,119 & $1.64(0.01)$ & $1.03(0.09)$ & $2.05(0.16)$ & 78 & 2007 & 2.8 & 0.07 & 0.24 & 0.19 \\
\hline 33183 & 16 & 71,218 & $1.58(0.01)$ & $1.12(0.08)$ & $1.93(0.15)$ & 47 & 2006 & 3.0 & 0.09 & 0.18 & 0.20 \\
\hline 33184 & 24 & 67,576 & $1.65(0.01)$ & $1.12(0.06)$ & $2.11(0.11)$ & 70 & 2006 & 2.9 & 0.12 & 0.22 & 0.25 \\
\hline 33185 & 28 & 90,744 & $1.55(0.01)$ & $1.17(0.08)$ & $2.10(0.16)$ & 79 & 2007 & 2.8 & 0.09 & 0.23 & 0.20 \\
\hline 33186 & 19 & 78,571 & $1.68(0.02)$ & $0.98(0.10)$ & $1.94(0.18)$ & 53 & 2006 & 2.9 & 0.10 & 0.20 & 0.20 \\
\hline 33187 & 18 & 118,993 & $1.67(0.03)$ & $1.01(0.14)$ & $2.02(0.25)$ & 49 & 2007 & 2.8 & 0.14 & 0.26 & 0.28 \\
\hline 33189 & 12 & 83,597 & $1.79(0.04)$ & $1.03(0.16)$ & $1.94(0.27)$ & 37 & 2007 & 3.2 & 0.18 & 0.23 & 0.29 \\
\hline 33193 & 25 & 94,883 & $1.66(0.02)$ & $1.06(0.12)$ & $1.98(0.21)$ & 76 & 2007 & 3.0 & 0.09 & 0.25 & 0.24 \\
\hline 33196 & 25 & 105,423 & $1.57(0.01)$ & $1.04(0.07)$ & $2.01(0.13)$ & 64 & 2006 & 2.6 & 0.11 & 0.26 & 0.22 \\
\hline
\end{tabular}




\section{CHAPTER IV: PROPERTY TAX EQUITY IMPLICATIONS OF SAVE OUR HOMES}

\section{Introduction}

In 1992 Florida voters passed Amendment 10, known as the "Save Our Homes" (SOH) constitutional amendment that went into effect in 1995. The main feature of the measure was a cap in the yearly increase of assessed value for homesteaded properties of the lesser of 3 percent and the national rate of inflation, regardless of what happens to market values (Thomas, 2006). This structure has implications on the fairness or equity of the tax. Several studies have looked at these implications in the past, and concluded that the $\mathrm{SOH}$ provision increases considerably the inequities in the tax system (Allen (2009), Shone (2009) and Moore (2008)). The conclusions of these studies are most likely exaggerated because they only look at periods of rising home values. Shone (2009) and Moore (2008) look at the inequities between homesteaded and non-homesteaded properties, in which case $\mathrm{SOH}$ can only make the system less equitable, but the degree of this effect goes up in raising markets and goes down in down markets. However, and of more interest to me here, is Shone (2009) who is the only one that studies the equity implications of $\mathrm{SOH}$ within the subset of homesteaded properties. In the case of this last study the argument of $\mathrm{SOH}$ making the system less progressive is also most likely exaggerated since it only looks at a period of price appreciation and does not consider a baseline scenario to which compare the SOH outcome. Shone (2009) argues that SOH makes the system less progressive thanks to a combination of home ownership transfer 
pattern and differential price appreciations during his study period. Here I present an alternative approach that teases out the actual effects of the $\mathrm{SOH}$ amendment by computing the level of progressivity with and without $\mathrm{SOH}$ and with and without differential growth rates. In doing so I find that the home value appreciation and differentials in appreciation rates make the system less progressive independently of the implementation of $\mathrm{SOH}$. And more importantly, that $\mathrm{SOH}$ may reduce the degree in which the system becomes less progressive.

I will address briefly what happens to the tax equity in terms of homesteaded vs. non-homesteaded properties in a period of both rapid price appreciation and rapid price depreciation followed by an analysis of the inequities within the sub group of homesteaded properties.

The first analysis will rely on the observed empirical data, while the second will consist of two approaches; an empirical analysis of the observed data coupled with the application of different scenarios followed by a theoretical discussion.

In the second section of this paper I provide some background on Florida's Property Tax structure, in the third section I go over previous literature on property taxes, save our homes and inequity; next I discuss the data and methodology used to assess inequality; Followed by the analysis of the inequalities in taxation caused by the $\mathrm{SOH}$ amendments in terms of homesteaded vs. non-homesteaded properties and within the subset of homesteaded properties. Section six concludes. 


\section{Background on Florida's Property Tax and Homestead Exemption}

Property taxes pre-date the now more popular income taxes and sales taxes. In the United States property taxes have been in place since at least 1787 as reflected in the Northwest Ordinance of that year (Stark, 1992). Now day's most local governments collect the lion's share of their revenue from this source. By 1999 all fifty states had in place a property tax and close to seventy-three percent of all local revenues were generated by this form of taxation (Melink, 2009).

In the 1930's propelled by the Great Depression many states implemented property tax relief measures in the form of exemptions. In 1933 Florida State Representative Dwight Rogers of Fort Lauderdale proposed and passed legislation to place a \$5,000 Homestead Exemption Amendment on a state ballot. The amendment was approved by Florida voters in 1934 (Article X, Section 7). This Homestead Exemption was intended to ease the burden on homeowners by exempting property taxes on the first $\$ 5,000$ of the homeowner's residence. The value of the exemption has been adjusted three times since. The Florida legislature increased by statute the exemption to $\$ 10,000$ in the 1960 's, and voters approved an increase to $\$ 25,000$ in 1980 and to $\$ 50,000$ (leaving the exemption at $\$ 25,000$ for the school portion of taxes) on January 29th 2008 .

Thinking about all the newly created exemptions of the 1930's as a first taxpayer's revolt, one can refer to the last three decades of the 21 st century as a period in which a second taxpayer's revolt took place. In 1973, California Gov. Ronald Regan introduced Proposition 1, a comprehensive Tax and Expenditure Limitation (TEL), that was voted down in the polls that same year (Paulson et al., 2005). Five years later, in 
1978 voters approved Proposition 13, the first TEL of its kind. In section 1 it states that "The maximum amount of any ad valorem tax on real property shall not exceed One percent $(1 \%)$ of the full cash value of such property". Another feature of Proposition 13 is that the value used to calculate property taxes, called assessed value, cannot be increased by more than 2 percent a year until or unless there is a change in ownership (O'Sullivan et all., 1995).

The passage of Proposition 13 inspired others to follow suit resulting in the passage of similar TELs in at least 28 other states. The most comprehensive of them is Colorado’s Taxpayer's Bill of Rights (TABOR) amendment (Poulson, 2005).

In 1992 Florida voters passed Amendment 10, known as the Save Our Homes constitutional amendment with similar provisions to California's Proposition 13. The Save our Homes provisions went into effect in 1995 and included a cap in the yearly increase of assessed value for homesteaded properties of the lesser of 3 percent and the national rate of inflation (Thomas, 2006).

The reference of Amendment 10 as Save Our Homes amendment was because of to the idea that it would reduce the likelihood of homeowners seeing their tax bill increase to a point that they would be forced to sell their properties and move.

After years of unusually high home price appreciation across the state, the value of the protection of "SOH" for many residents was significant; to the point that changes were proposed and approved that include portability of the savings when a beneficiary changed residences.

Since the period of high price appreciation gave way to a period of sharp price depreciation many homeowners learned of a previously overlooked provision of $\mathrm{SOH}$ 
called the "Catch Up Provision" in which the assessed value of a homesteaded property should increase by the lesser of 3 percent and the rate of inflation as long as the assessed value is below market value even if the latter is declining.

One peculiarity that enables me to conduct this study is that the law in Florida requires the property appraiser to estimate the market value of every property every year regardless of the status of the property in terms of exemptions.

\section{Literature}

The subject of concern to earlier researchers in the field of property tax equity has been the accuracy with which properties are appraised for taxing purposes. A pioneer is Paglin and Forgarty (1972) who asserted that the best approach to analyze vertical equity was to study the value/selling price relationship. This earlier study inspired a chain of further research on the topic that tended to adjust the methodology and variables to be used. Cheng (1974) proposed a similar model but with log-linear form. Bell (1984) incorporates a quadratic equation to the model. Kochin and Parks (1982) reverse Paglin and Fogarty's (1972) equation arguing that assessed value is a better predictor of value than sales price. Sunderman et al. (1990) presented a spline regression model for testing vertical inequity in the Chicago area. Clapp (1990) introduced a simultaneous equation model with an instrumental variable.

A widely cited review of this line of literature is included in Sirmans, Diskin and Friday (1995) who present a useful comparison table and argue that Clapp's model is the superior approach. 
More recently, Smith (2000) estimated market value for Bloomington, Indiana single-Family homes and tested for tax inequity, using all the models developed earlier and presented in Sirmans et al. (1995), finding that the structure was progressive in five of the models, and inconclusive in one. Birch, Sundermand and Smith (2004) utilize the same data as Smith (2000) but take into account smaller geographical areas to uncover sources of inequity that did not show up under the previous methods used by Smith (2000).

Although the models became technically more complex with each additional study a consensus as to the best approach has not been reached. A more recent review of the literature can be found in Sirmans, Gatzlaff and Macpherson (2008).

I find that the estimates of these models are affected by the nominal value of the home values and sales prices, this is they are not Homogeneous of degree zero. I find it to be desirable to have a measurement of equity that is homogeneous of degree zero and thus present an alternative measurement in this chapter.

My concern in this study is not with the accuracy of the property appraiser's estimate of property values, since I take the market value estimate as given, but the effect on vertical equity of the divergence between taxable value and estimated market value brought about by the implementation of the $\mathrm{SOH}$ amendment that introduces a further distortion into the property tax equity picture.

Thanks to the implementation of property value assessment caps coupled with the real estate boom of the early 2000's research has emerged that focuses on the relation of market value and assessed value as computed by the property appraiser as opposed to the accuracy of the property appraisers' valuations. 
One article in the Journal of Real Estate Research (Allen, 2009) and two recent dissertations (Shone, 2009 and Moore, 2008) examine the equity implications of "Save Our Homes" amendment, type measures. Shone examines the case of Maryland while Allen and Moore study the case of Florida.

Shone looks at equity in tax burden between residential and non-residential property owners. Moore studies both horizontal and vertical equity, where the vertical equity is among quintiles of homes by value. Allen studies vertical equity for a continuum of homesteaded homes by value.

Allen uses countywide data for all counties in Maryland for the period 1999 2006. Both Allen and Moore use a dataset of individual properties for the state of Florida for the period 1995-2004 with the difference that Allen only selects properties that maintain Homestead Exemption status throughout the 10 years.

Shone's dissertation is comprised by two essays. Essay number two studies targeted property tax relief and the burden of taxes by property classification in Maryland. Shone explains that in Maryland in 1992 each county was allowed the right to set the annual assessment increase cap at anything between 0 and 10 percent. This arrangement gave him a natural experiment to study the effects of different cap levels on tax burden. Shone divides property owners in two: residential and non residential. Shone uses 1999 to 2006 data to regress the level and share of non-residential property taxes on "assessment cap" and eleven other explanatory variables using a 2 Stage Least Squares approach. The results that Shone finds suggest that the caps are negatively and significantly related to both level and share of non-residential property taxes. 
Moore uses 1995 to 2004 State of Florida parcel level data to determine the impact of "save our homes" on vertical and horizontal equity. Specifically Moore asks "to what extent do measures of equity differ among groups of Florida single-family homes when specific tax administration preferential treatments are withheld or applied during the study period of 1995 to 2004?". Moore does not include in his data set post2004 years nor the South Florida counties of Miami-Dade, Broward and Palm Beach as to exclude the bubble and what he calls international beach oceanfront resort destination markets. The methodology employed by Moore was a simulated experimental design with random selection and assignment of subject homes as well as manipulation of the independent variable (net assessed value). Moore views his population study to be all properties in the United States, his observed population as being all the properties in the State of Florida and his sample as a randomly selected subset of Florida homes.

Moore uses the Net Assessed Value instead of Market value used in previous studies given the impact of $\mathrm{SOH}$ on the actual value taxes are collected on. The source of inequity in previous studies, Moore argues, stemmed from assessor's market value estimates. Moore develops a Vertical Equity Index as an alternative to the Price Related Differential (PRD) and uses Analysis of Variance (ANOVA) to measure inequities.

Moore finds statistically significant $(\mathrm{p}<.001)$ evidence that both horizontal equity and vertical equity deteriorated in Florida between 1995 and 2004.

According to Moore only two previous scholarly articles specifically address Florida's constitutional SOH amendment. ${ }^{7}$

\footnotetext{
${ }^{7}$ (1): "To date, the only scholarly research located that specifically addressed Florida's constitutional amendment were papers by Hawkins (2006) and Stumm and Mann (2001)."
} 
Allen (2009) state that there is little doubt that SOHA has shifted a significant portion of the property tax burden onto non-homestead property owners. The purpose of their study is to consider whether the SOHA has impacted the vertical equity or fairness in Florida property tax system within the class of properties it was intended to protect (homestead properties). This study uses data from the state of Florida for the years 1999 to 2004. Only selects individual property records that were homesteaded at the start of the study period and maintained that status throughout the study period, sample that consists of 17 million records. To determine the change in vertical equity they propose a regression where the dependent variable is the share of market value shielded from taxation and the independent variables are the changes in market value over the six-year period. A positive coefficient estimate indicates that the benefits of $\mathrm{SOH}$ occur in a greater magnitude to higher valued real estate. Which is what the authors find in a statistically significant way.

Their explanation:

"Combining the effects of differential appreciation and ownership transfers across market value ranges, the overall impact of the SOHA has been a reduction in the degree of progressivity in the state's property tax system during the study period."

\section{Data and Methodology}

The data for this study is mined from the Miami-Dade County Property Appraiser's file, also referred to as the PTX file. The relevant information I extract from this file are the type of property and Homestead exemption status as well as the market, assessed and taxable values for each property in the county. 
In this instance, market value is the value as computed by the Miami-Dade Property Appraiser department. The assessed value is the current value derived from the rules imposed by the "Save Our Homes" amendment over time. And the Taxable Value is the Assessed value adjusted by exemptions, such as Homestead, Senior, Widow and Veterans exemptions.

I analyze the equity implications of SOH from two perspectives. First I look at the share of property taxes shouldered by homesteaded properties vs. non homesteaded properties over time. Second I focus on the subset of homesteaded properties, more specifically single family homes that had homestead exemption at the beginning of the period and maintained that status till the end. This subset includes 107,731 homes, roughly a third of the 310,660 single family homes located in the county in 1998 .

For the first subject of analysis I compute the share of property value sheltered by both homesteaded and non-homesteaded properties for every year and analyze its progression.

For the second subject of analysis I filter the records to work exclusively with those properties that were homesteaded since the beginning of the period and kept that status until the end. Next I regress the effective tax rate on the market value under different scenarios to figure out the impact of $\mathrm{SOH}$ on taxation equity.

\section{Measuring the level of Inequity - Results}

The percent of market value protected by $\mathrm{SOH}$ for the subset of Homesteaded homes was 6.6 percent in 1998, grew to 64 percent in 2007 and came down to 34 percent by 2010 . 
Figure IV-1 - Percent of Homesteaded Home's Market Value Sheltered from Taxation by SOH 1998 $-2010$

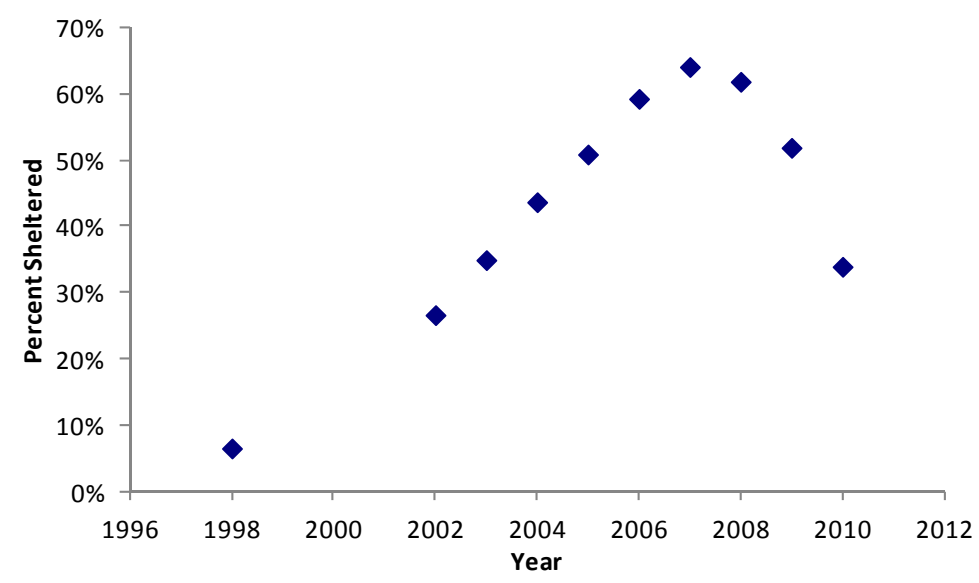

When I incorporate the homestead exemption to get the real sheltered value from taxation I have that in 199828.2 percent of the market value was exempt, it grew to 70.5 percent in 2007 and declined to 45.2 percent in 2010.

Figure IV-2-Percent of Homesteaded Home's Market Value Sheltered from Taxation by SOH and Homestead Exemption 1998 - 2010

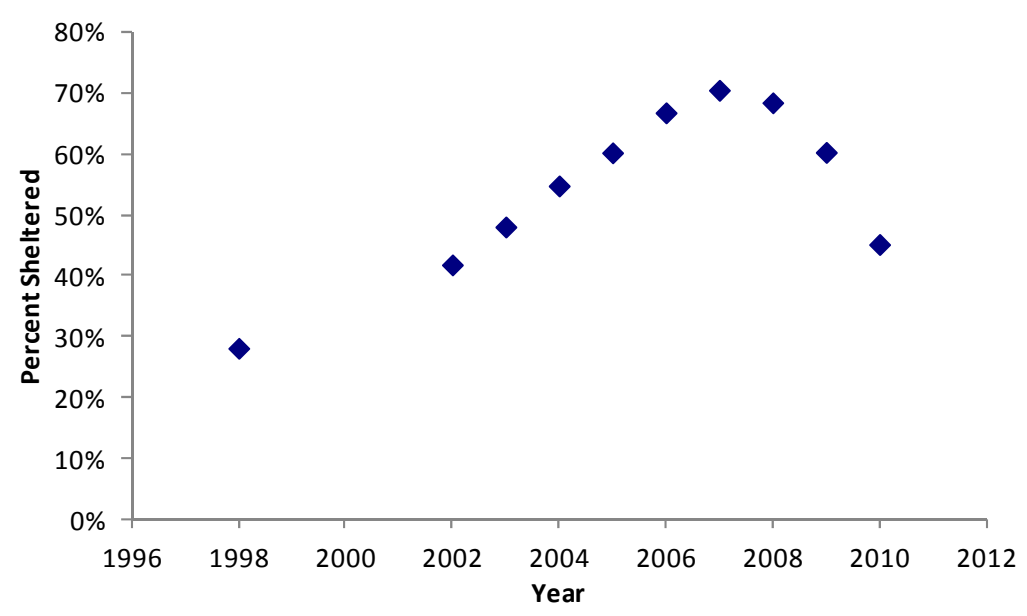

The percent sheltered for the non-homesteaded properties is zero, so in terms of homesteaded vs. non-homesteaded properties, inequality rose between 1998 and 2007 and declined thereafter, in accordance with the housing cycle, more so, it is clear that $\mathrm{SOH}$ makes the homesteaded vs. non-homesteaded relation more inequitable, given that 
the percent sheltered for homesteaded properties would be considerably lower without $\mathrm{SOH}$, and would go down as market values increased.

$\mathrm{SOH}$ increased the inequity in terms of homesteaded vs. non-homesteaded properties, and that inequity grew during the period of rapid price appreciation, as other authors have found, but fell as the process of price appreciation reverted to price depreciation.

Less straightforward and what interests me next is the situation that takes place within the subset of homesteaded properties.

Recapping the state of the current literature on this subject:

One previous study, Allen (2009), looked at this issue and concluded that:

The results suggest that the amendment has reduced the degree of progressivity in the state's property tax system such that the owners of lower value home properties are shouldering an increasing proportion of the property tax burden relative to the owners of higher valued homesteaded properties.

The study that arrived to the above conclusion looked at the proportion sheltered from taxation as the years went by. But did not examine what would have been the case if the $\mathrm{SOH}$ amendment were not in place. Here I contend that under certain reasonable conditions $\mathrm{SOH}$ amendment actually made the system more progressive than would have otherwise been the case. In other words, the system did become less progressive with the $\mathrm{SOH}$ amendment in place, but it did despite the amendment and not because of it.

\section{Empirically:}

I look at the case of homesteaded properties in Miami-Dade County who never lost this status between 1998 and 2010. Using the yearly valuations for these homes I 
construct four scenarios beginning with the premise that in 1998 all properties are taxed on the basis of their full assessed value and:

$1^{\text {st: }}$ NoSOH: There is no $\mathrm{SOH}$ and properties are taxed on the basis of the system that was in place prior to $\mathrm{SOH}$, meaning on the full assessed value minus a standard deduction of $\$ 25,000$.

$2^{\text {nd }}$.SimulatedSOH: There is $\mathrm{SOH}$ such that the taxable value increase is capped at 3 percent year after year.

$3^{\text {rd }}$. SameGrowthNoSOH: To tease out the effects of differential appreciation rates I look at the case of having all properties appreciate (depreciate) at the same countywide appreciation (depreciation) rate. And compute the progressivity measure in the absence of $\mathrm{SOH}$.

$4^{\text {th }}$. SameGrowthSimulatedSOH: The same as the $3^{\text {rd }}$ but with the $\mathrm{SOH}$ mechanism in place.

To compare the four scenarios I calculate the level of progressivity in every year for each scenario using the following regression ${ }^{8}$ :

$$
\frac{e_{i}}{\operatorname{Avg}(e)}=b_{0}+b_{1} \frac{M_{i}}{\operatorname{Avg}(M)}+\varepsilon
$$

Here $e_{i}$ is the effective tax rate faced by homeowner $i$ defined as:

$$
e_{i}=t \frac{T_{i}}{M_{i}}, \text { where } \quad T_{i}=A V_{i}-E
$$

$M_{i}$ is the Market Value of home $i$ as computed by the property appraiser.

$T_{i}$ is the taxable value of home $i$ computed as Assessed Value $\left(A V_{i}\right)$ of home $i$ minus the standard exemption $(E)$.

If $b_{1}<0$ the tax structure is Regressive $b_{1}=0$ the tax structure is neutral $b_{1}>0$ the tax structure is progressive and the greater $b_{1}$, the more progressive the system is.

\footnotetext{
${ }^{8}$ Using Median Values instead of Averages in the denominators does not change the outcomes of the model.
} 
The following figure depicts the estimated coefficient $b_{1}$ for each year and scenario.

Figure IV-3 - Level of Progressivity under Different Scenarios 1998 -2010

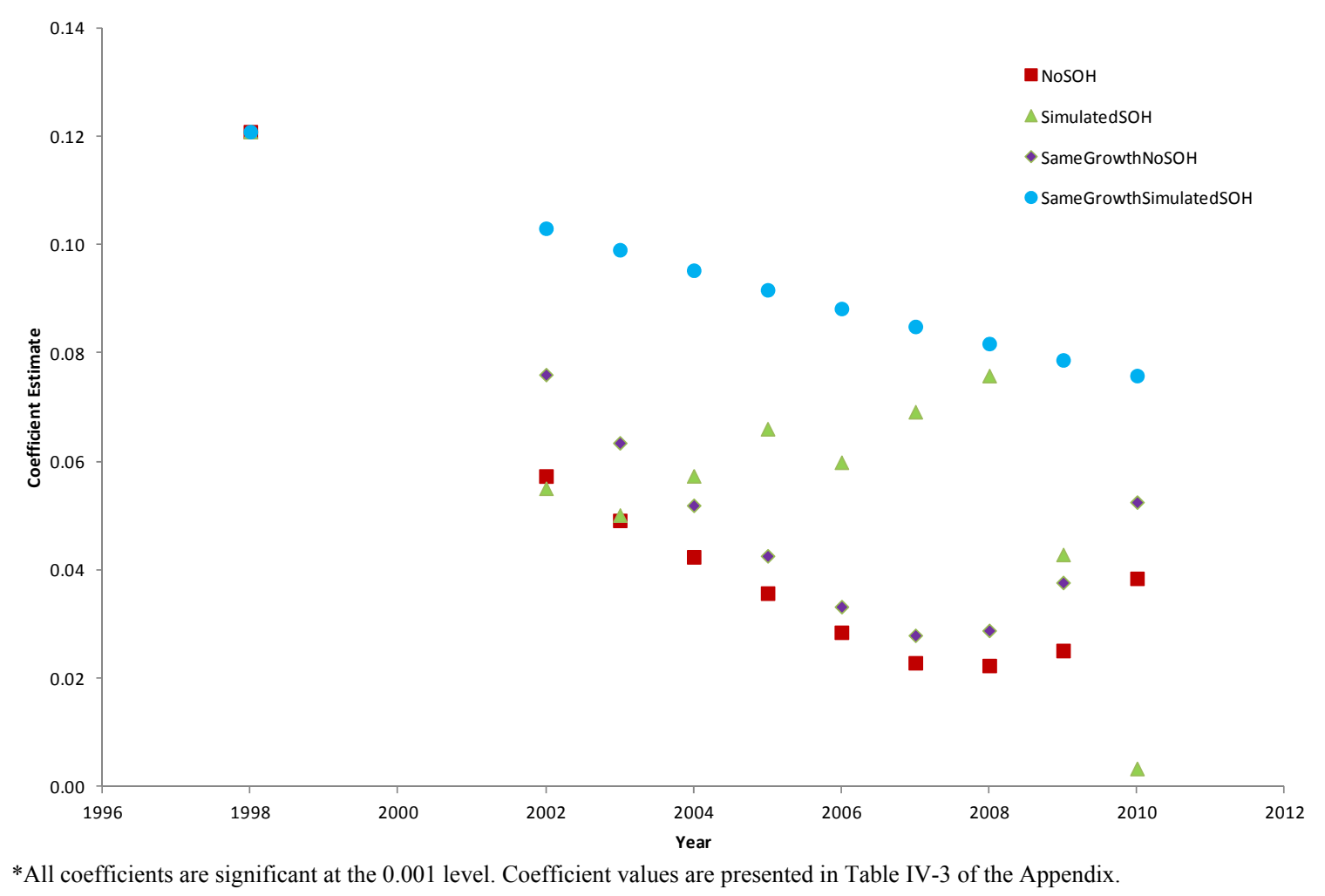

As can be seen above, if there were no differential in growth rates the $\mathrm{SOH}$ would have consistently kept the system more progressive than without. Once I factor in the differentials in growth rates SOH made the system slightly less progressive by 2002 and then more progressive thereafter until 2010 when it made it considerably less progressive.

It must be noted that this is a measure of progressivity and not of taxation. Without the $\mathrm{SOH}$ amendment all households that are represented in this study would pay a considerably higher tax in the years following $1998 .^{9}$

\footnotetext{
${ }^{9}$ For a discussion on the topic mentioned in this paragraph see Dye and McMillen (2007)
} 
To better understand the difference between the four taxing options and their impact on progressivity let's look at each of the scenarios case by case:

\section{No Homestead Exemption and No Save Our Homes.}

In this case there is no impact on tax equity. The initial system would be Neutral (b1=0), and stay this way no matter what happens to home values. This neutrality would not be affected by a depreciating nor appreciating housing market, nor by significant or un-existing differential growth rates among different house value segments.

\section{Homestead Exemption with No Save Our Homes}

The Homestead Exemption is the key factor in making the tax system progressive given that it is a set amount that is deducted from assessed value to obtain taxable value. This is the system that was in place in Florida from 1934 to 1995 . Under this system the level of progressivity varies depending on both the direction of the housing market and the differential in appreciation rates. Absent of differential growth rates the system will become less progressive in an increasing price environment and more progressive in a declining price environment. This comes about because the effect of the changes in value affects more the lower value homes than the higher.

If the changes in value are more pronounced at the higher end of the market the impact on progressivity will be less than under a no differential change scenario. Conversely, if the changes in value are more pronounced at the lower end of the market the impact on progressivity will be greater than under a no differential change scenario. 


\section{$\underline{\text { Save Our Homes with No Homestead Exemption }}$}

This is a hypothetical structure that has never existed in Florida. Without the presence of the Homestead Exemption the source of change in tax equity comes from differential growth rates. In the absence of differential growth rates I get a neutral tax system $(\mathrm{b} 1=0)$ that is unchanged during periods of home values appreciation or depreciation.

Under this system, as opposed to the "No Homestead Exemption and No SOH" system, differential appreciation/depreciation rates have a strong influence on tax equity. In a period of rising (falling) home values, if the appreciation (depreciation) rates are greater in the more expensive homes, the system becomes more regressive (progressive) and vice versa.

\section{$\underline{\text { Homestead Exemption with Save Our Homes }}$}

This is the structure that is currently in place in Florida. This is also the more complicated structure to analyze in terms of tax equity implications and the one that has received most attention in the literature lately.

Under this structure, the interaction between the Save Our Homes cap, time elapsed since implementation, Homestead Exemption, direction of the real estate market and the differential in growth rates among property segments determines the changes that occur to tax equity over the years.

The following discussion will assume a starting point that coincides with the implementation of the system. 
Under a no differential growth rate scenario, the system will become less progressive during a period of home price appreciation and will behave like the "Homestead Exemption with No Save Our Homes" system during a period of home price depreciation (more progressive).

Lifting the assumption of no differential growth rates does not alter the outcome mentioned above under a period of home price depreciation.

During a period of home price appreciation, the effect of a higher rate of growth in the high end homes is to make the system even less progressive. If the higher rate of growth occurs in the lower valued homes the pull is towards more progressivity. This last effect can outweigh the regressive effect of the generalized home value appreciation.

Under a scenario similar to the one presented in the figure above where there are no growth rate differentials and a initial period of home price appreciation followed by a period of home price depreciation, the system is going to become less progressive until the difference between assessed value and market value brought about by the cap during the appreciation years disappears at which point the system will become more progressive.

The following table summarizes the effects of the different market conditions under the various property tax structures discussed in this section. 
Table IV-1 - Tax Equity by Tax Structure and Market Evolution

\begin{tabular}{|c|c|c|c|c|c|c|}
\hline & & & & & Progressi & ity Under \\
\hline $\begin{array}{l}\text { Homestead } \\
\text { exemption }\end{array}$ & $\mathrm{SOH}$ & \begin{tabular}{|c} 
Growth Rate \\
Differentials \\
\end{tabular} & $\begin{array}{c}\text { Tilted } \\
\text { Towards }\end{array}$ & Initial System & $\begin{array}{c}\text { Appreciating } \\
\text { Market }\end{array}$ & $\begin{array}{c}\text { Depreciating } \\
\text { Market }\end{array}$ \\
\hline \multirow{6}{*}{ NO } & \multirow{3}{*}{ NO } & \multicolumn{2}{|l|}{ NO } & Neutral $(b 1=0)$ & $\begin{array}{l}\text { Unchanged } \\
\text { (1) }\end{array}$ & $\begin{array}{l}\text { Unchanged } \\
\text { (2) }\end{array}$ \\
\hline & & \multirow[t]{2}{*}{ YES } & High end & Neutral (b1=0) & $\begin{array}{c}\text { Unchanged } \\
\text { (3) }\end{array}$ & $\begin{array}{l}\text { Unchanged } \\
\text { (4) }\end{array}$ \\
\hline & & & Low end & Neutral $(b 1=0)$ & $\begin{array}{c}\text { Unchanged } \\
\text { (5) }\end{array}$ & $\begin{array}{l}\text { Unchanged } \\
\text { (6) }\end{array}$ \\
\hline & \multirow{3}{*}{ YES } & \multicolumn{2}{|l|}{ NO } & Neutral (b1=0) & $\begin{array}{c}\text { Unchanged } \\
\text { (7) }\end{array}$ & $\begin{array}{c}\text { Unchanged } \\
\text { (8) }\end{array}$ \\
\hline & & \multirow[t]{2}{*}{ YES } & High end & Neutral (b1=0) & $\begin{array}{l}\text { Less } \\
\text { (9) }\end{array}$ & $\begin{array}{c}\text { Unchanged } \\
\text { (10) }\end{array}$ \\
\hline & & & Low end & Neutral (b1=0) & $\begin{array}{c}\text { More } \\
(11)\end{array}$ & $\begin{array}{c}\text { Unchanged } \\
\text { (12) }\end{array}$ \\
\hline \multirow{6}{*}{ YES } & \multirow{3}{*}{ NO } & \multicolumn{2}{|l|}{ NO } & Progressive (b1>0) & $\begin{array}{l}\text { Less } \\
\text { (13) }\end{array}$ & $\begin{array}{l}\text { More } \\
(14)\end{array}$ \\
\hline & & \multirow[t]{2}{*}{ YES } & High end & Progressive (b1>0) & $\begin{array}{c}\text { Less - to More } \\
\text { (15) }\end{array}$ & $\begin{array}{c}\text { More - to Less } \\
\text { (16) }\end{array}$ \\
\hline & & & Low end & Progressive (b1>0) & $\begin{array}{c}\text { Less + } \\
(17) \\
\end{array}$ & $\begin{array}{c}\text { More + } \\
(18) \\
\end{array}$ \\
\hline & \multirow{3}{*}{ YES } & \multicolumn{2}{|l|}{ NO } & Progressive (b1>0) & $\begin{array}{l}\text { Less } \\
(19)\end{array}$ & $\begin{array}{c}\text { More } \\
(20)\end{array}$ \\
\hline & & \multirow[t]{2}{*}{ YES } & High end & Progressive $(b 1>0)$ & $\begin{array}{c}\text { Less+ } \\
(21) \\
\end{array}$ & $\begin{array}{c}\text { More - to Less } \\
\text { (22) }\end{array}$ \\
\hline & & & Low end & Progressive (b1>0) & $\begin{array}{l}\text { Less - to More } \\
\text { (23) }\end{array}$ & $\begin{array}{c}\text { More + } \\
\text { (24) }\end{array}$ \\
\hline
\end{tabular}

A plus or minus sign indicates the effect is greater than the comparable direction without the sign within the comparable scenario. See appendixfor proofs and Simulations explanation. 
By looking at the table presented above I can determine that in the absence of the homestead exemption, the implementation of $\mathrm{SOH}$ will make the system less progressive only if the housing market is appreciating and the rate of appreciation is tilted towards the higher priced properties.

Implementing $\mathrm{SOH}$ in a downward market will have no effect in tax system equity relative to the system with Homestead Exemption alone.

What can't be determined by looking at the table is the effect of implementing $\mathrm{SOH}$ when the Homestead Exemption is in place and the market is appreciating. All that can be said is that with and without $\mathrm{SOH}$ the system becomes less progressive. To determine if adding $\mathrm{SOH}$ to the Homestead Exemption makes the system more or less progressive I will compare the two alternatives during a period of rapid appreciation with no growth rate differentials from a theoretical perspective.

\section{Save Our Homes impact on tax equity during a rapidly appreciating real estate market.}

For the Case of No differential growth rates and No SOH I have that the effective tax rate is

$$
e=\frac{t(M-E)}{M}
$$

Where

$t=$ nominal tax rate

$M=$ market value

$E=$ Exemption

Taking the first and second derivative of e with respect to $M$

$$
e^{\prime}=\frac{d e}{d M}=t \frac{E}{M^{2}}>0, \quad e^{\prime \prime}=\frac{d^{2} e}{d M^{2}}=-2 t \frac{E}{M^{3}}<0
$$


From the results above I have that as $M$ increases $e$ increases, but increases more for lower values of $M$ than for higher values of $M$, making the system less progressive.

On top of the simple first and second derivatives I must calculate the following relative changes in order to compare the changes in progressivity of the system with and without $\mathrm{SOH}$.

The relative change of $e$ with respect to $M$ is

$$
\delta=\frac{e^{\prime}}{|e|}=\frac{\frac{d e}{d M}}{|e|}=\frac{E}{M(M-E)}>0
$$

And the relative change of $\delta$ with respect to $M$ is

$$
\varphi=\frac{\delta^{\prime}}{|\delta|}=\frac{\frac{d \delta}{d M}}{|\delta|}=-\frac{2 M^{2}-3 E M+E^{2}}{M^{3}-2 E M^{2}+E^{2} M}<0
$$

The results I got with the first and second derivatives hold in relative terms as well.

For the case of No differential in growth rates with SOH I have that the effective tax rate is

$$
e^{S O H}=\frac{t(A V-E)}{M}
$$

Where once again:

$A V=$ Assessed Value

And the first and second derivatives are:

$$
e^{S O H^{\prime}}=\frac{d e^{S O H}}{d M}=t \frac{E}{M^{2}}-t \frac{A V}{M^{2}}+\frac{t}{M} \frac{d A V}{d M} \leq 0
$$




$$
e^{S O H^{\prime \prime}}=\frac{d^{2} e^{S O H}}{d M^{2}}=-2 t \frac{E}{M^{3}}+2 t \frac{A V}{M^{3}}-2 \frac{t}{M^{2}} \frac{d A V}{d M}+\frac{t}{M} \frac{d^{2} A V}{d M^{2}} \geq 0
$$

These expressions will hold in a fast growing period since for changes in $M$ above $3 \%$ any additional change in $M$ will result in a zero change in $A V$, and the exemption value for properties whose assessed value is bellow $E$ is $A V$.

With $\mathrm{SOH}$ in place, during a period of rapid price appreciation, the system will become less progressive. But in this case as Market Value increases, effective tax rate will go down, but will go down less for lower valued properties than for higher valued properties.

The relative change of $e$ with respect to $M$ in a rapid price appreciation environment is

$$
\delta^{S O H}=\frac{e^{S O H^{\prime}}}{\left|e^{S O H}\right|}=\frac{d e^{S O H}}{\left|e^{S O H}\right|}=-\frac{1}{M}<0
$$

And the relative change of $\delta$ with respect to $\mathrm{M}$ is

$$
\varphi^{S O H}=\frac{\delta^{S O H}{ }^{\prime}}{\left|\delta^{S O H}\right|}=\frac{\frac{d \delta^{S O H}}{d M}}{\left|\delta^{S O H}\right|}=\frac{1}{M}>0
$$

In a rapid price appreciation environment, $\mathrm{SOH}$ will make the system relatively more progressive if the rate at which the decrease in the effective tax rate falls increases by a smaller magnitude than the rate at which the increase in the effective tax rate decreases under the no $\mathrm{SOH}$ scenario. That is, the following condition holds:

$$
|\varphi|>\left|\varphi^{S O H}\right|
$$


For this condition to be met the only requirement is that $M>A V$. Since $M$ is always greater or equal to $A V$ I have that during periods of rapid price appreciation and no differentials in growth rates, implementing $\mathrm{SOH}$ will increase the level of progressivity relative to the status quo.

In reality a scenario in which there is no differentials in growth rates among different property value segments is unlikely, but in order for $\mathrm{SOH}$ to decrease the level of progressivity during periods of high price appreciation it is needed the appreciation rates of higher valued properties to be higher than that of lower valued properties up to a point that the differential growth rate effect outweighs the overall price appreciation effect presented here.

\section{Conclusion}

Prior to this study the conclusion to be had by looking at the literature on Save our Homes and tax equity was that $\mathrm{SOH}$ makes the property tax system more unequal among different types of property owners and less progressive among homesteaded homeowners. And that these effects grow over time.

By looking at the system in a period of both increasing and decreasing property values and analyzing in a more methodical way the structure of the Property Tax system I find that the effects of $\mathrm{SOH}$ do not move in one direction alone, and that it does not necessarily decrease progressivity among homesteaded homeowners.

In terms of the relation of Homesteaded vs. Non Homesteaded properties, the effects of $\mathrm{SOH}$ grow as properties appreciate faster than inflation, but this divergence can 
be reduced fairly quickly during a period of property value correction as the "catch up" provision kicks in. During periods of zero to moderate property appreciation the effects of SOH are modest and unlikely to attract the kind of attention that it did following its implementation in the 1990s.

A different story would emerge following a period of high price inflation in which real estate prices increase substantially and in line with the overall rate of inflation leaving the real value of real estate unchanged and the nominal prices substantially above their previous level. In this scenario, because of to the alternative cap set by $\mathrm{SOH}$ of $3 \%$, the protection to homesteaded properties could increase substantially and become permanent.

No straightforward answer can be given as to what is the effect of SOH on tax equity among homesteaded property owners. It will depend on the interaction between the Save Our Homes cap, time elapsed since implementation, Homestead Exemption, direction of the real estate market and the differential in growth rates among property segments.

Under current Florida law the system is structured to be inherently progressive. During an appreciating market the system becomes less progressive, unless the appreciation is heavily tilted towards the low end of the market. Conversely, under a declining market the system becomes more progressive, and this effect is stronger when the declines are tilted towards the lower end of the market.

This study provides a lens through which to look at the impact on equity of the Save Our Homes structure under any market condition. It can also serve as a framework to study other property tax systems, existing or proposed. 


\section{Appendix}

Table IV-2 - Share of Value Sheltered by the Save Our Homes Amendment - Homesteaded Properties from 1998 to 2010 -Miami-Dade County, FL

\begin{tabular}{|c|c|c|c|}
\hline & $\begin{array}{l}\text { Total } \\
\text { Value }\end{array}$ & $\begin{array}{c}\text { Assessed } \\
\text { Value }\end{array}$ & $\begin{array}{l}\text { Percent } \\
\text { Sheltered }\end{array}$ \\
\hline 1998 & $12,493,428,949$ & $11,663,766,251$ & $6.6 \%$ \\
\hline 2002 & $17,778,797,253$ & $13,032,999,546$ & $26.7 \%$ \\
\hline 2003 & $20,570,286,124$ & $13,378,013,888$ & $35.0 \%$ \\
\hline 2004 & $24,308,218,925$ & $13,686,554,432$ & $43.7 \%$ \\
\hline 2005 & $28,812,366,041$ & $14,158,007,250$ & $50.9 \%$ \\
\hline 2006 & $35,867,578,190$ & $14,616,676,905$ & $59.2 \%$ \\
\hline 2007 & $41,943,870,074$ & $15,085,028,878$ & $64.0 \%$ \\
\hline 2008 & $40,751,945,813$ & $15,567,190,040$ & $61.8 \%$ \\
\hline 2009 & $32,078,734,593$ & $15,437,688,214$ & $51.9 \%$ \\
\hline 2010 & $24,079,950,180$ & $15,896,755,016$ & $34.0 \%$ \\
\hline & $\begin{array}{l}\text { Total } \\
\text { Value }\end{array}$ & $\begin{array}{c}\text { Taxable } \\
\text { Value }\end{array}$ & $\begin{array}{l}\text { Percent } \\
\text { Sheltered }\end{array}$ \\
\hline 1998 & $12,493,428,949$ & $8,975,720,074$ & $28.2 \%$ \\
\hline 2002 & $17,778,797,253$ & $10,342,920,616$ & $41.8 \%$ \\
\hline 2003 & $20,570,286,124$ & $10,687,584,762$ & $48.0 \%$ \\
\hline 2004 & $24,308,218,925$ & $10,995,867,235$ & $54.8 \%$ \\
\hline 2005 & $28,812,366,041$ & $11,466,956,536$ & $60.2 \%$ \\
\hline 2006 & $35,867,578,190$ & $11,925,393,553$ & $66.8 \%$ \\
\hline 2007 & $41,943,870,074$ & $12,393,395,973$ & $70.5 \%$ \\
\hline 2008 & $40,751,945,813$ & $12,875,317,436$ & $68.4 \%$ \\
\hline 2009 & $32,078,734,593$ & $12,745,813,575$ & $60.3 \%$ \\
\hline 2010 & $24,079,950,180$ & $13,204,677,689$ & $45.2 \%$ \\
\hline
\end{tabular}


Table IV-3 - Regression Results: Progressivity by Year and Scenario

\begin{tabular}{|c|c|c|c|c|c|}
\hline Year & $b_{1}$ & Std. Err. & Year & $b_{1}$ & Std. Err. \\
\hline \multicolumn{3}{|c|}{$\mathrm{NoSOH}$} & \multicolumn{3}{|c|}{ SameGrowthNoSOH } \\
\hline 1998 & 0.1208 & $(0.0006)$ & 1998 & 0.1208 & $(0.0006)$ \\
\hline 2002 & 0.0573 & $(0.0003)$ & 2002 & 0.0760 & $(0.0004)$ \\
\hline 2003 & 0.0491 & $(0.0003)$ & 2003 & 0.0635 & $(0.0003)$ \\
\hline 2004 & 0.0424 & $(0.0002)$ & 2004 & 0.0519 & $(0.0003)$ \\
\hline 2005 & 0.0357 & $(0.0002)$ & 2005 & 0.0426 & $(0.0002)$ \\
\hline 2006 & 0.0285 & $(0.0001)$ & 2006 & 0.0332 & $(0.0002)$ \\
\hline 2007 & 0.0229 & $(0.0001)$ & 2007 & 0.0280 & $(0.0001)$ \\
\hline 2008 & 0.0224 & $(0.0001)$ & 2008 & 0.0289 & $(0.0001)$ \\
\hline 2009 & 0.0252 & $(0.0001)$ & 2009 & 0.0377 & $(0.0002)$ \\
\hline 2010 & 0.0385 & $(0.0002)$ & 2010 & 0.0525 & $(0.0003)$ \\
\hline \multicolumn{3}{|c|}{ SimulatedSOH } & \multicolumn{3}{|c|}{ SameGrowthSimulatedSOH } \\
\hline 1998 & 0.1208 & $(0.0006)$ & 1998 & 0.1208 & $(0.0006)$ \\
\hline 2002 & 0.0551 & $(0.0006)$ & 2002 & 0.1030 & $(0.0005)$ \\
\hline 2003 & 0.0501 & $(0.0006)$ & 2003 & 0.0991 & $(0.0005)$ \\
\hline 2004 & 0.0573 & $(0.0007)$ & 2004 & 0.0953 & $(0.0005)$ \\
\hline 2005 & 0.0660 & $(0.0007)$ & 2005 & 0.0917 & $(0.0005)$ \\
\hline 2006 & 0.0599 & $(0.0008)$ & 2006 & 0.0882 & $(0.0005)$ \\
\hline 2007 & 0.0692 & $(0.0008)$ & 2007 & 0.0849 & (0.0004) \\
\hline 2008 & 0.0758 & $(0.0008)$ & 2008 & 0.0818 & (0.0004) \\
\hline 2009 & 0.0428 & $(0.0008)$ & 2009 & 0.0787 & (0.0004) \\
\hline 2010 & 0.0034 & $(0.0006)$ & 2010 & 0.0759 & $(0.0004)$ \\
\hline
\end{tabular}

*All Coefficients presented here are significant at the 0.001 level.

In all cases the sample size is 107,731 .

Obtaining Table IV-1

(1) Through (6)

With no Homestead Exemption and no SOH: $M_{i t}=A V_{i t}=T_{i t} \forall i$ and $t$, thus:

$$
e_{i t}=\tau \frac{T_{i t}}{M_{i t}}=\tau
$$


The effective tax rate $\left(e_{i t}\right)$ is equal to the nominal tax rate $(\tau)$ for all properties, making the system neutral. Regardless of the evolution of market value the relation above will hold for all properties leaving the effective tax rate and progressivity unchanged.

(7) Through (12)

With no Homestead Exemption: $M_{i 0}=A V_{i 0}=T_{i 0} \quad \forall i$

$$
e_{i 0}=\tau \frac{T_{i 0}}{M_{i 0}}=\tau
$$

The initial system is neutral.

Going forward because of no Homestead Exemption: $A V_{i t}=T_{i t} \forall i$

$$
e_{i t}=\tau \frac{T_{i t}}{M_{i t}}=\tau \frac{A V_{i t}}{M_{i t}}
$$

In a depreciating market (8), (10) and (12) SOH has no effect, leaving $M_{i t}=A V_{i t}=$ $T_{i t} \forall i$ and $t$

$$
e_{i t}=\tau \frac{T_{i t}}{M_{i t}}=\tau
$$

In an appreciating market (7) SOH may kick in but with no differentials in growth rate the relation $\frac{A V_{i t}}{M_{i t}}$ is equal for all $i^{\prime} s$ in every $t$. The effective tax rate is different in every year but equal among all properties thus leaving progressivity unchanged.

For (9) and (11) I take a look at a two property case. Where there is a High Value (h) and Low Value (1) property and in order for there to be a change in effective tax rate at least the fastest appreciating property appreciates at a rate that exceeds the $\mathrm{SOH}$ cap: $i=h, l$ 


$$
e_{h t}=\tau \frac{T_{h t}}{M_{h t}}=\tau H_{t} \quad, \quad e_{l t}=\tau \frac{T_{l t}}{M_{l t}}=\tau L_{t}
$$

Where

$$
H_{t}=\frac{T_{h t}}{M_{h t}} \quad, \quad L_{t}=\frac{T_{l t}}{M_{l t}}
$$

If prices appreciate more in the high end of the market (9)

$\% \Delta M_{h t}>\% \Delta M_{l t}$ and there are two possibilities:

- $\quad$ The low end appreciates less than the SOH cap: $\% \Delta M_{h t}>\% \Delta T_{h t}$ and $\% \Delta M_{l t}=\% \Delta T_{l t}$

Then $H_{t}<L_{t}=1 \rightarrow e_{h t}<e_{l t}$

- $\quad$ The low end appreciates more than the SOH cap: $\% \Delta M_{h t}>\% \Delta M_{l t}$ and $\% \Delta T_{h t}=$ $\% \Delta T_{l t}$

Then $H_{t}<L_{t} \rightarrow e_{h t}<e_{l t}$

In both cases the system becomes less progressive.

Conversely (11) the system becomes more progressive.

For (13) and (14)

With Homestead Exemption and no SOH $T_{i t}=A V_{i t}-E=M_{i t}-E \forall i$ and $t$

$$
e_{i t}=\tau \frac{T_{i t}}{M_{i t}}=\tau \frac{M_{i t}-E}{M_{i t}}=\tau\left(1-\frac{E}{M_{i t}}\right)
$$

Calculating the first derivative

$$
e^{\prime}=\frac{d e}{d M}=\tau \frac{E}{M^{2}}>0
$$

I have that the higher $\mathrm{M}$, the higher $e$ will be. Thus the initial system is progressive.

After a period where property values change by a factor $\delta$ : 


$$
e_{i t}=\tau \frac{T_{i t}}{M_{i t}}=\tau \frac{\delta_{i} M_{i 0}-E}{\delta_{i} M_{i 0}}=\tau\left(1-\frac{E}{\delta_{i} M_{i 0}}\right)
$$

Where $\delta_{i}$ is the factor by which property i's value changed between periods 0 and $\mathrm{t}$.

$$
e_{i \delta_{i}}{ }^{\prime}=\frac{d e_{i}}{d \delta_{i}}=\tau \frac{E}{\delta_{i}{ }^{2} M_{i 0}}>0
$$

Going back to the two property case with no differential in growth rates, since $M_{h 0}>$ $M_{l 0}$ and $\delta_{h}=\delta_{l} \quad-->\left|e_{l \delta_{l}}{ }^{\prime}\right|>\left|e_{h \delta_{h}}{ }^{\prime}\right|$. In an Appreciating Market both effective tax rates go up and $\frac{e_{h t}}{e_{l t}}<\frac{e_{h 0}}{e_{l 0}}$, meaning the system becomes less progressive. Conversely, in a depreciating market both effective tax rates drop, but it drops more for property 1 than for property h making the system more progressive.

(15) to (18) result from SIMULATIONS that are discussed at the end of this section.

For (19) to (24) the initial system analysis holds from (13) and (14) given that in period 0: $A V_{i 0}=M_{i 0}$.

In a depreciating market following the Initial period SOH plays no roll, thus (20), (22) and (24) are analogous to (14), (16) and (18).

In an appreciating market with price appreciations bellow the $\mathrm{SOH}$ cap, $\mathrm{SOH}$ plays no roll, in which case (19), (21) and (23) would be analogous to (13), (15) and (17).

In the more relevant case, depicted in the table, with appreciation rates above the $\mathrm{SOH}$ cap:

For (19) see proof in the discussion in page 98.

(21) and (23) result from SUMULATIONS.

About SIMULATIONS: simulations were done on the 2 property case, with values for the Low and High end properties set at (100k, 200k), (100k, 1,000k) and (190k, 200k). A 
nominal tax rate of 10 per mill, and growth rates of $-50 \%,-25 \%,-10 \%,-5 \%$, $5 \%, 10 \%, 25 \%, 50 \%$ and a break even rate in the cases where there were opposing forces (15), (16), (22) and (23). 


\section{REFERENCES}

\section{Chapter II}

Auerbach, F. (1913) "Das Gesetz der Bevölkerungskonzentration". Petermanns Geographische Mitteilungen 59: 73 - 6

Black, Duncan and Henderson, Vernon (1998) "Urban evolution in the USA", Working Paper No. 98-121, Brown University.

Boswell, M. T. and Patil, G. P. (1970). "Chance mechanisms generating negative binomial Distributions”. In Random Counts in Scientific Work, Vol. 1, G. P. Patil, ed., Pennsylvania State University Press.

Córdoba, J.C. (2003), "On the distribution of city sizes”, working paper, Rice University.

Denise, Pumain and François Moriconi-Ebrard (1997) "City size distributions and metropolisation", GeoJournal.

Dobkins, L. H., and Y. M. Ioannides (2001), "Spatial interactions among U.S. cities", Regional Science and Urban Economics.

Duranton, Gilles and Puga Diego (2000) "Diversity and Specialization in Cities: Why, Where and When Does it Matter?" Urban Studies

Duranton, Gilles (2002), "City Size Distributions as a Consequence of the Growth Process”, CEPR Discussion Papers 35777.

Eeckhout, Jan (2004) “Gibrat's Law for (all) Cities”, American Economic Review.

Gabaix, X. (1999), “Zipf’s Law and the growth of cities”, American Economic Review, Papers and Proceedings.

Gabaix, X. (1999b), “Zipf's Law for cities: an explanation”, Quarterly Journal of Economics.

Henderson, J. V. (1974) “The sizes and types of cities”, American Economic Review.

Klepper, Steven and Thompson, Peter (2006) "Submarkets and the Evolution of Market Structure", RAND Journal of Economics.

Krugman, P. (1996), "Confronting the mystery of urban hierarchy", Journal of the Japanese and the International Economies. 
Nitsch, Volker (2005) “Zipf Zipped”, Journal of Urban Economics.

Reed, W. (2002) "On the rank-size distribution for human settlements", Journal of Regional Science.

Simon, H. (1955) “On a class of skew distributions". Biometrika.

Steindl, J. "Random Processes and the Growth of Firms". Hafner, New York.

Sutton, John, (1998) “Technology and Market Structure”. Cambridge, MA, MIT Press.

Zipf, G. K. (1949), "Human Behavior and the Principle of Least Effort". AddisonWesley, Cambridge, MA.

\section{Chapter III}

Anglin, Paul (2007), "An Empirical Study of Local Dynamics and Contagion in Real Estate Markets”. Preliminary Draft.

Bureau of Economic Analysis - National Economic Accounts 2007-2009.

Bureau of Labor Statistics - Current Population Survey 2007-2009.

Bureau of Labor Statistics - Current Employment Statistics Survey 2007-2009.

Roehner, Bertrand (1999), "Spatial Analysis of Real Estate Bubbles: Paris, 1984 - 1993", Regional Science and Urban Economics - Elsevier.

Rowendal, J \& Longhi, S. (2007), "The Effect of Consumers' expectations on a Booming Housing Market: Space Time Patterns in the Netherlands, 1999-2000", Tinbergen Institute Discussion Paper No. TI 07-078/3.

Shimizu and Nishimura (2007) "Pricing Structure in Tokyo Metropolitan Land Markets and its Structural Changes: Pre-bubble, Bubble, and Post-bubble Periods" The Journal of Real Estate Finance and Economics.

Shimizu and Watanabe (2010) "Housing Bubble in Japan and the United States" Research Center for Price Dynamics, Institute of Economic Research, Hitotdubashi University. Working Paper Series; No. 50.

S\&P Case Schiller Home Price Index. 1998-2009.

U.S. Census Bureau - American Community Survey 2007. 


\section{Chapter IV}

Allen, Marcus. Dare, William. (2009) "Changes in Property Tax Progressivity for Florida Homeowners after the "Save Our Homes Amendment"'. Journal of Real Estate Research.

Bell, E.J. (1984). "Administrative Inequity and Property Assessment: The Case for the Traditional Approach”. Property Tax Journal.

Birch J.W, Sunderman M.A. and Smith B.C (2004). "Vertical Inequity in Property Taxation: A Neighborhood Based Analysis". Journal of Real Estate Finance and Economics.

Cheng, P.L. (1974) "Property Taxation, Assessment Performance and Its Measurement", Public Finance.

Clapp, J.M. (1990) “A New Test for Equitable Real Estate Tax Assessment”, Journal of Real Estate Finance and Economics.

Dye, Richard and McMillen, Daniel P. (2007) "SURPRISE! And Unintended Consequence", Land Lines -Lincoln Institute of Land Policy.

O'Sullivan, A. Sexton, T. A. \& Sheffrin, S. M. (1995). "Property taxes and tax revolts: The legacy of proposition 13". UK: Cambridge University Press.

Kochin, L. and Parks, R.W. (1982) "Vertical Equity in Real Estate Assessment: A Fair Appraisal", Economic Inquiry.

Melink, Steven. Cendella, David (2009). "Real Property Taxation and Assessment Processes: A Case for a Better Model". Legislation and Public Policy [Vol. 12:259].

Moore, Jennings W. (2008) "Evaluating Property Tax Equity Implications of Capping Assessment Increases: Evidence from Florida". Dissertation - Northcentral University.

Paglin, M and Fogarty, M. (1972) Equity and The Property Tax: A New Conceptual Performance Focus" National Tax Journal.

Poulson, Barry. Holcombe, Randall (2005). "Empowering Florida's Taxpayers". Madison Institute Backgrounder.

Shone, Bryan. (2009) "Essays on Property Tax Limitation Mechanisms". Dissertation University of Tennessee.

Sirmans, S.G., Diskin B.A. and Friday, H.S. (1995) "Vertical Inequity in the Taxation of Real Property" National Tax Journal. 
Sirmans S.G., Gatzlaff D.H. and Macpherson D.A. (2008) "Horizontal and Vertical Inequity in Real Property Taxation”. Journal of Real Estate Literature.

Smith B.C. (2000) "Applying Models for Vertical Inequity in the Property Tax to a NonMarket Value State”. Journal of Real Estate Research.

Stark, Jo.O. (1992). "A History of the Property Tax and Property Tax Relief in Wisconsin”. Madison,WI: State of Wisconsin Legislative Reference Bureau.

Sunderman, M.A., Birch, J.W., Cannaday, R.A. and Hamilton, T.W (1990) "Testing for Vertical Inequity in Property Tax Systems". Journal of Real Estate Research .

Thomas, Josephine (2006). "Increasing the Homestead Tax Exemption: "Tax Relief" or Burden on Florida Homeowners and Local Governments?”. Stetson Law Review. 


\section{VITA}

\section{JOHN PAUL LUCAS}

Born, Caracas, Venezuela

2001

B.S. Economics

Universidad Católica Andrés Bello

Caracas, Venezuela

2002-2003

Research Assistant

Economic Research Services

Tallahassee, Florida, USA

2005

M.A., Economics

Florida International University

Miami, Florida, USA

2004-2006

Teacher Assistant

Florida International University

Miami, Florida, USA

2006-2007

Adjunct Professors

Miami-Dade Collage

Miami, Florida, USA

2006-Present

Senior Planner (Economics)

Planning and Zoning, Miami-Dade County

Miami, Florida, USA 